\title{
Human Response to Helicopter Noise: A Test of A-Weighting
}

by

Paul D. Schomer

Brian D. Hoover

Lee R. Wagner

\begin{abstract}
Department of Defense and U.S. Army policy has long been to adjust measured helicopter noise levels upwards to account for the special character of helicopter noise in terms of human and community annoyance. In the United States, the A-weighted Day/Night Average Sound Level (DNL) descriptor is used most often for this purpose, but research has shown that it is not completely adequate. Also, many questions remain about human perception of, and response to helicopter noise and the rattles and vibrations it causes. Since sound exposure level (SEL) is the fundamental building block to DNL, SEL has been used as the unit of study in this research.

This study is an extension of earlier research in which an Army UH-1H (Huey) helicopter was flown over a test site that included a farmhouse, a tent, and a new mobile home. This report documents a follow-up test done with six different helicopters at a California Marine Corps air station to replicate and expand on the findings from the earlier study.

Overall, the data indicate that the A-weighted DNL is inadequate for assessment of helicopter noise. The $\mathrm{C}$-weighted scale was also tried and found inadequate. Helicopter noise measurement by either scale must be corrected to assess the noise in a way that correctly corresponds to human perceptions. For indoor situations, use of $A$ weighting to assess helicopter noise requires an offset that varies with helicopter A-weighted sound exposure level (ASEL). This offset changes based on the type of helicopter (e.g., number of blades). For two-bladed helicopters, a correction factor of approximately $10 \mathrm{~dB}$ should be added to the measured ASEL of the helicopter sound. An $8 \mathrm{~dB}$ correction factor should be added to the measured ASEL of a multibladed helicopter.
\end{abstract}

Approved for public release; distribution is unlimited.

\section{For Reference}

\author{
Not to be taken from this room
}


The contents of this report are not to be used for advertising, publication, or promotional purposes. Citation of trade names does not constitute an official indorsement or approval of the use of such commercial products. The findings of this report are not to be construed as an official Department of the Army position, unless so designated by other authorized documents. 


\begin{tabular}{|c|c|c|c|}
\hline \multicolumn{3}{|c|}{ REPORT DOCUMENTATION PAGE } & $\begin{array}{l}\text { Form Approved } \\
\text { OMB No. 0704-0188 }\end{array}$ \\
\hline \multicolumn{4}{|c|}{ 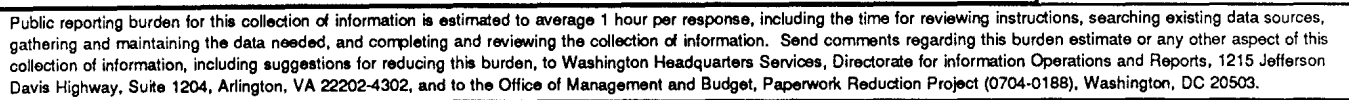 } \\
\hline 1. AGENCY USE ONLY (Leave Blank) & $\begin{array}{l}\text { 2. REPORT DATE } \\
\text { November } 1991\end{array}$ & \multicolumn{2}{|c|}{$\begin{array}{l}\text { 3. REPOAT TYPE AND DATES COVERED } \\
\text { Final }\end{array}$} \\
\hline \multicolumn{3}{|l|}{ 4. TITLE AND SUBTITLE } & 5. FUNDING NUMBERS \\
\hline \multicolumn{3}{|c|}{ Human Response to Helicopter Noise: A Test of A-Weighting } & PE 62720 \\
\hline \multicolumn{3}{|c|}{$\begin{array}{l}\text { 6. AUTHOR(S) } \\
\text { Paul D. Schomer, Brian D. Hoover, and Lee R. Wagner }\end{array}$} & TA NN TGO \\
\hline \multicolumn{3}{|c|}{$\begin{array}{l}\text { 7. PERFORMING ORGANIZATION NAME(S) AND ADDRESS(ES) } \\
\text { U.S. Army Construction Engineering Research Laboratory (USACERL) } \\
\text { P. O. Box } 9005 \\
\text { Champaign, IL } 61826-9005\end{array}$} & $\begin{array}{l}\text { 8. PERFORMING ORGANIZATION } \\
\text { REPORT NUMBER } \\
\text { TR N-91/13 }\end{array}$ \\
\hline \multicolumn{3}{|c|}{ 9. SPONSORING/MONITORING AGENCY NAME(S) AND ADDAESS(ES) } & $\begin{array}{l}\text { 10. SPONSORING/MONITORING } \\
\text { AGENCY REPORT NUMBER }\end{array}$ \\
\hline \multicolumn{4}{|l|}{ 11. SUPPLEMENTARY NOTES } \\
\hline \multicolumn{3}{|c|}{$\begin{array}{l}\text { 12a. DISTRIBUTION/AVALABILITY STATEMENT } \\
\text { Approved for public release; distribution is unlimited. }\end{array}$} & 12b. DISTRIBUTION CODE \\
\hline \multicolumn{4}{|c|}{$\begin{array}{l}\text { Department of Defense and U.S. Army policy has long been to adjust measured helicopter noise levels upwards to } \\
\text { account for the special character of helicopter noise in terms of human and community annoyance. In the United } \\
\text { States, the A-wcighted Day/Night Average Sound Level (DNL) descriptor is used most often for this purpose, but } \\
\text { rescarch has shown that it is not completely adequate. Also, many questions remain about human perception of, and } \\
\text { response to, helicopter noise. }\end{array}$} \\
\hline \multirow{2}{*}{\multicolumn{4}{|c|}{$\begin{array}{l}\text { This study is an extension of earlier research that tested human response to the noise of an Army UH-1H (Huey) } \\
\text { helicopter flown over various indoor environments. This report documents a follow-up test using six different heli- } \\
\text { copters to replicate and expand on the earlier study. } \\
\text { The data generally indicate that the A-weighted DNL is inadequate for assessing helicopter noise. The C-weighted } \\
\text { scale was also tried and found inadequate. Helicopter noise measurement by either scale must be corrected to } \\
\text { accurately correspond to human perceptions. Measuring indoors, the use of A-weighting to assess helicopter noise } \\
\text { requires an offset that varies with helicopter A-weighted sound exposure level (ASEL), and this offset varies for } \\
\text { different helicopters. }\end{array}$}} \\
\hline & & & \\
\hline \multirow{2}{*}{\multicolumn{3}{|c|}{$\begin{array}{l}\text { 14. SUBJECT TERMS } \\
\text { helicopters } \\
\text { Marine Corps Air Station, Tustin, CA }\end{array}$}} & $\begin{array}{l}\text { 15. NUMBER OF PAGES } \\
90\end{array}$ \\
\hline & & & 16. PRICE CODE \\
\hline $\begin{array}{l}\text { 17. SECURITY CLASSIFICATION } \\
\text { OF REPORT } \\
\text { Unclassified }\end{array}$ & $\begin{array}{l}\text { 18. SECURITY CLASSIFICATION } \\
\text { OF THIS PAGE } \\
\text { Unclassified }\end{array}$ & $\begin{array}{l}\text { 19. SECURITY CLASSIFICATION } \\
\text { OF ABSTRACT } \\
\text { Unclassified }\end{array}$ & $\begin{array}{l}\text { 20. LIMITATION OF ABSTRACT } \\
\text { SAR }\end{array}$ \\
\hline NSN 7540-01-28 & & & $\begin{array}{l}\text { Standard Form } 298 \text { (Rev. 2-89) } \\
\text { Proscribod by ANSI Std 239-18 } \\
298-102\end{array}$ \\
\hline
\end{tabular}




\section{FOREWORD}

This study was conducted for the Army Environmental Office, Office of the Chief of Engineers (OCE), U.S. Army Corps of Engineers (USACE), under Project 62720A896, "Environmental Quality Technology"; Work Unit NN-TGO, "Department of Defense (DOD) Noise Source Human Response Characterization." Cosponsors of this research were the U.S. Marine Corps and the U.S. Navy under FAD90-080002 and FAD90-080062. The OCE technical monitor was LTC Hans Graven, ENVR-E.

This research was performed by the Environmental Division (EN) of the U.S. Army Construction Engineering Research Laboratory (USACERL). Dr. Edward W. Novak is acting Chief of EN. The USACERL technical editor was Gordon L. Cohen, Information Management Office.

COL Everett R. Thomas is Commander and Director of USACERL, and Dr. L.R. Shaffer is Technical Director. 


\section{CONTENTS}

SF298

FOREWORD

LIST OF FIGURES AND TABLES

1 INTRODUCTION

Background

Purpose

Approach

Mode of Technology Transfer

2 STUDY CONCEPTS

3 DATA COLLECTION

The General Area

The Test Site

The Subjects

Data Measurement Equipment

Control Noise

The Test

4 DATA ANALYSIS

Data Reduction

Frequency-Weighted Results

Effect of Distance on Subjects' Response

5 CONCLUSIONS AND RECOMMENDATIONS $\ldots \ldots \ldots \ldots \ldots \ldots \ldots \ldots \ldots \ldots \ldots$

METRIC CONVERSION TABLE

REFERENCES

APPENDIX A: Plots of MCAS Tustin Indoor Test Data Arranged by Helicopter in Ascending Order of Control SEL

APPENDIX B: Plots of MCAS Tustin Indoor Test Data Converted to Z-Scores Arranged by Helicopter in Ascending Order of Control SEL

APPENDIX C: Plots of MCAS Tustin Outdoor Test Data

DISTRIBUTION 


\section{LIST OF FIGURES AND TABLES}

Figures $\quad$ Page

1 Two Views of MCAS Tustin Test House

$2 \quad$ Layout of MCAS Tustin Test Site 9

3 Two Examples of "Haystack" Distribution 9

$4 \quad$ Typical Curve Expected for a Single White-Noise Level 10

$5 \quad$ Overall View of Test Area 12

$6 \quad$ Data Measurement Equipment Setup 14

$7 \quad$ Consent Form 16

$8 \quad$ Annoyance Factor Form 17

$9 \quad$ Follow-up Form $\quad 18$

10 Data Plots for Percentage 20

11 Example of Discarded Data 22

12 Offset as a Function of Control ASEL for CH-53E 26

13 Offset as a Function of Control ASEL for Helicopters Grouped by Number of Blades 27

14 Subject Response to Different Sideline Distances 29

Tables

$1 \quad$ Breakdown of Test Subjects by Age and Sex 13

2 Correlation Coefficients for Data $\quad 23$

3 Offset Data for Indoor Test Locations (by Helicopter) 25

$4 \quad$ Offset Data Grouped by Number of Blades and Test Environment 28 
HUMAN RESPONSE TO HELICOPTER NOISE:

A TEST OF A-WEIGHTING

\section{INTRODUCTION}

\section{Background}

How a community responds to helicopter noise is only a partially answered question. Many researchers have tried to find a simple measurement of human annoyance caused by helicopter noise but, so far, no measure is considered completely adequate. ${ }^{1}$ An "A-weighted" scale ${ }^{2}$, a sound measure that attempts to emulate how humans respond to impulsive noise, is the most common method in use today. In the U.S., the A-weighted Day/Night Average Sound Level (DNL) descriptor is most commonly used to estimate the percentage of a community that is highly annoyed by noise. However, many questions remain about human perception of helicopter noise and the role of rattles and vibrations in the human and community response to it. For many years it has been the policy of the Department of Defense (DOD) and the U.S. Army to add a constant penalty (adjustment) to measured helicopter noise levels to account for its special character. ${ }^{3}$ The U.S. Army Construction Engineering Research Laboratory (USACERL), with support from the Federal Aviation Administration (FAA), initiated a major research program to examine descriptors for helicopter noise and study the role of helicopter noise-induced vibration and rattle. The first phase of this program showed that if the helicopter noise induced high levels of window rattling, then A-weighting was inadequate and a large adjustment to the measurement (10 to $20 \mathrm{db}$ ) had to be made. $^{4}$

In the first phase of this program, performed near USACERL in Savoy, IL, an Army UH-1H (Huey) helicopter was flown over a test site that included a farmhouse, a tent, and a new mobile home. Subjects were asked to compare the noise of the helicopter flying by to a control noise, and indicate which was more annoying. For each helicopter flyby, a research assistant was asked to rate the amount of rattle present on a three-point scale: "none," "some," or "a lot." The data were analyzed by test location and level of rattle, and curves were developed that established equivalency between the helicopter noise and the control noise. It was found that the human response curve depended on the level of rattle caused by the helicopter, and that the A-weighted curve was not sufficient to fully assess the noise of the UH-1H. ${ }^{5}$

' J.B. Ollerhead, Laboratory Studies of Scales for Measuring Helicopter Noise, National Aeronautics and Space Administration (NASA) Contractor Report 3610 (NASA, November 1982); John A. Molino, Should Helicopter Noise Be Measured Differently From Other Aircraft Noise? - A Review of Psychoacoust ic Literature, NASA Contractor Report 3609 (NASA, November 1982 ). ${ }^{2}$ American National Standards Institute (ANSI) 512.9-1988, Quantities and Procedures for Description and Measurement of Environmental Sound, Part l (New York, 1988).

${ }^{3}$ DOD Instruction 4165.57, Air Installations Compatible Use Zones (AICUZ) (DOD, 8 November 1977); Army Regulation 200-1, Environmental Protection and Enhancement, Chapter 7, Environmental Noise Abatement Program (Headquarters, Department of the Army [HQDA], Washington, D.C., June 15, 1982).

${ }^{4}$ Paul D. Schomer and Robert D. Neathammer, "The Role of Helicopter Noise-Induced Vibration and Rattle in Human Responsc," J. Acoust. Soc. Am., Vol 81, No. 4 (April 1987), pp 966-976.

5 Paul D. Schomer and Robert D. Neathammer, The Role of Vibration and Rattle in Human Response to Helicopter Noise, Technical Report (TR) N-85/14/ADA162486 (USACERL, September 1985). 
The U.S. Navy and U.S. Marine Corps, also interested in properly assessing helicopter noise, proposed tests that would expand on the Savoy findings. These tests were conducted at the Marine Corps Air Station at Tustin, CA (MCAS Tustin).

\section{Purpose}

The purpose of the follow-up study at MCAS Tustin, the subject of this report, was to replicate and expand on the findings from the Savoy test. The data would be used to expand the research on an accurate measure to describe human and community response to helicopter noise, and the role played by noise-induced rattle. This test would add to the data available on the effects of different types of helicopters and housing constructions on the human response to helicopter noise.

\section{Approach}

The approach to this test was the same as for the Savoy test; this was required since one objective was to replicate the Savoy study. Juries of test subjects were asked to compare the noise from a helicopter flying over to a control white noise. By varying the type of helicopter and the slant distance of the helicopter from the houses containing the juries, a variety of sound exposure levels (SELs) was produced. From these data, statistical equivalencies could be established between various helicopter noises and control noises judged to be equivalently annoying. The other objective-expansion of the Savoy results -was accomplished by performing the test in a new location with different test house construction and different types of helicopters. However, for purposes of comparison with the previous test, the Tustin test included an Army UH-1H helicopter.

\section{Mode of Technology Transfer}

The Army will use these data as input to revisions of Army Regulation (AR) 200-1, Environmental Protection and Enhancement, Chapter 7: Environmental Noise Abatement Program. It is also expected that the Navy, Marine Corps, U.S. Air Force, and the FAA will use these data as input for developing recommendations on heliports. 


\section{STUDY CONCEPTS}

This study was performed using juries of test participants, some in the living rooms of adjacent test houses (duplexes) and others at an outdoor location in line with these houses. The duplex houses used were enlisted quarters at MCAS Tustin (Figure 1). The general layout of the four test residences (in three structures), the outdoor group (tent site), and the instrumentation truck are shown in Figure 2. Six different types of helicopters were used to create the noise stimuli: $\mathrm{CH}-53 \mathrm{~A} / \mathrm{B}, \mathrm{CH}-53 \mathrm{E}, \mathrm{CH}-46 \mathrm{E}, \mathrm{UH}-1 \mathrm{H}$, $\mathrm{UH}-1 \mathrm{~N}$, and AH-1W. These helicopters flew by the test houses at a variety of slant distances to create a wide assortment of single-event SELs.

The test was designed as a paired comparison test in which the subjects were presented with pairs of differing noise stimuli. One noise was generated by the helicopter flying by and the other was white noise played through a loudspeaker. The participants were asked to decide which noise was more annoying. As previously noted, the purposes of this test were to replicate and expand on the Savoy study, so the Savoy test protocol was used. ${ }^{6}$ As in Savoy, the amplitude of the white noise was modulated in a "haystack" pattern. The shape of this modulating pattern was chosen to approximate the $10 \mathrm{~dB}$ down time of the passing helicopter. (The $10 \mathrm{~dB}$ down time is defined as the time that the helicopter's sound takes to rise from $10 \mathrm{~dB}$ below its maximum level to the maximum, and then fall back to $10 \mathrm{~dB}$ below the maximum.) Two examples of the haystack distribution are shown in Figure 3.

It is important to note that in this test protocol everything except for the control stimuli is real; real helicopters were used instead of recordings and loudspeakers. This was done to produce the very lowfrequency sounds, the rattles, and the vibrations characteristic of helicopter noise. These conditions would be too hard to simulate realistically in a laboratory, so the data had to be taken in this field setting.

Figure 4 shows a typical curve expected from the experiment for a single white-noise control level. Many curves of this type were generated. Each yiclds a pair of numbers: a helicopter SEL and corresponding control A-weighted SEL (ASEL). This pair of numbers describes a point on the curve where 50 percent of the subjects perceived the helicopter noise to be more annoying than the control white noise and 50 percent perceived it to be less annoying. This point, as marked on Figure 4, was taken as the equivalency point-the point at which the control noise causes the same annoyance as the helicopter noise. The number of decibels that the helicopter noise differs from the equivalently annoying control noise is the "offset," or adjustment. For the example, in Figure 4 the helicopter ASEL is $62 \mathrm{~dB}$ and the equivalent control noise ASEL at the 50 percent point is given as $66 \mathrm{~dB}$. Therefore, a $4 \mathrm{~dB}$ offset must be added to the A-weighted helicopter SEL to make it equivalent to a white noise having the same annoyance.

Figure 4 is not a straight line; it saturates at 0 and 100 percent. In general, the curve in Figure 4 has a sigmoid shape and, in theory, should be the integral of a normal probability function. ${ }^{7}$ With this assumption, the sigmoid shaped curve can be transformed into a straight line by either plotting the data on normal probability paper or by transforming the individual data points to their corresponding Z-scores. In this transformation it is necessary to assume that the data are a subset of an underlying distribution having a mean of 50 percent. Great care was taken to see that most data were gathered where the sigmoid curve is approximately a straight line. As a result, as is shown later, regression lines fit directly to the

${ }^{6}$ Paul D. Schomer and Robert D. Neathammer, 1987.

7 J.W. Kling and Lorran A. Riggs, Woodworth and Schlosberg's Experimental Psychology, 3d Ed., Chapter 2, "Psychophysics" (Holt, Rinehart, and Winston, Inc., 1972). 

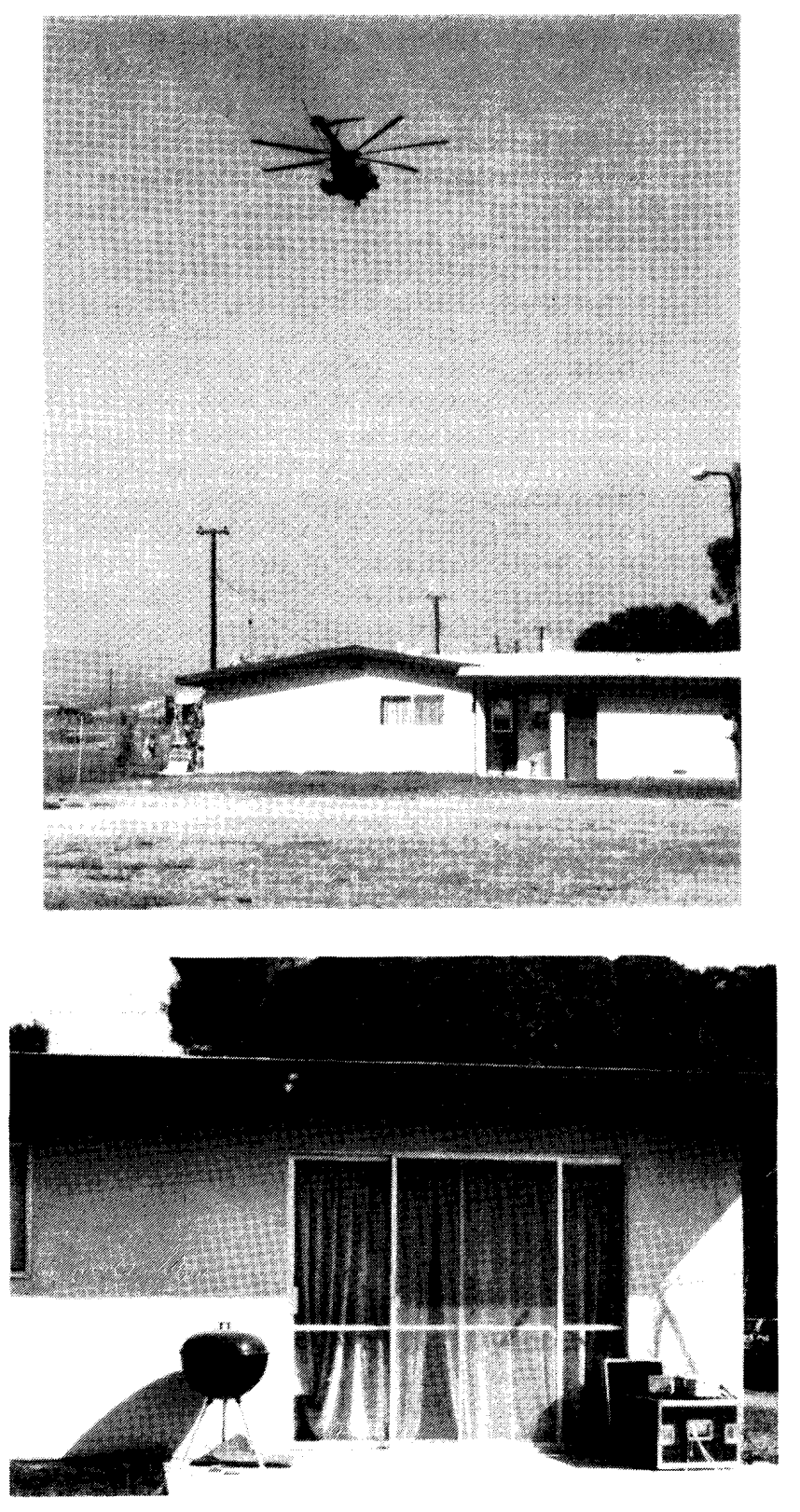

Figure 1. Two Views of MCAS Tustin Test House. 


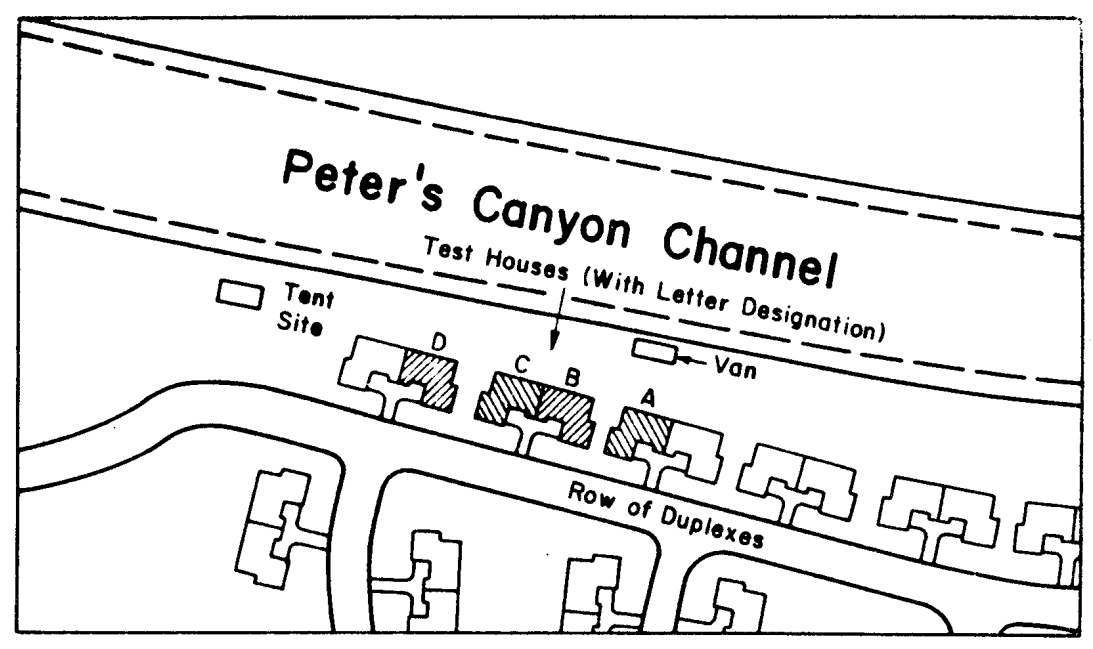

Figure 2. Layout of MCAS Tustin Test Site.
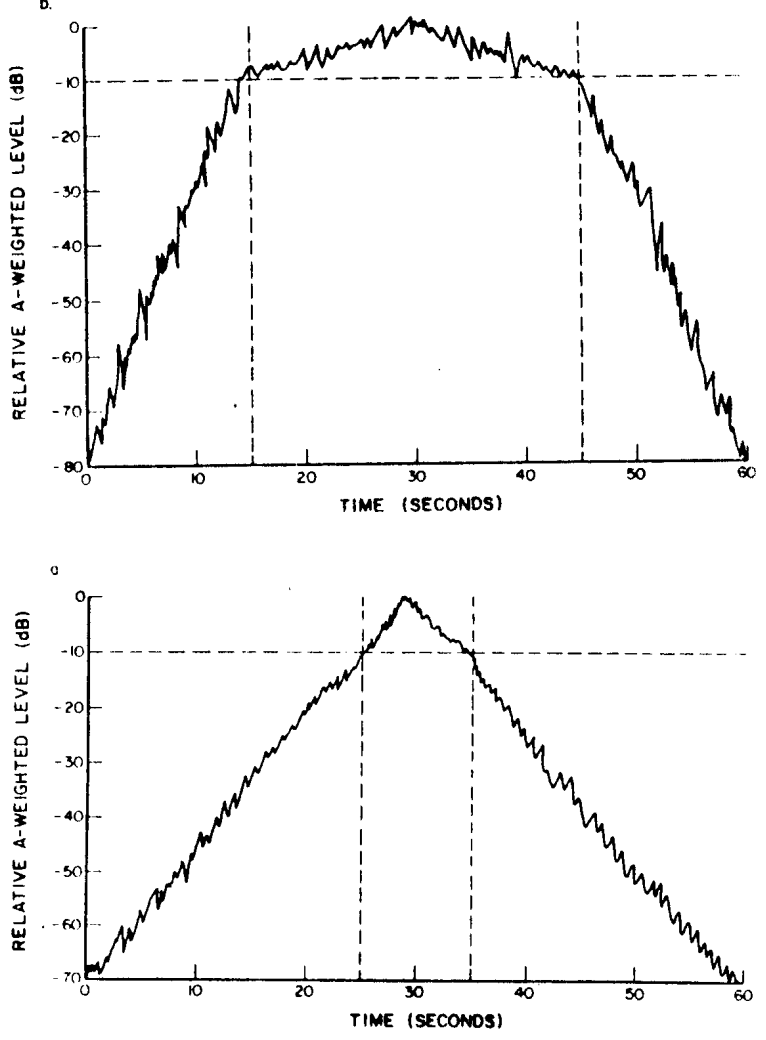

Figure 3. Two Examples of "Haystack" Distribution.

9 


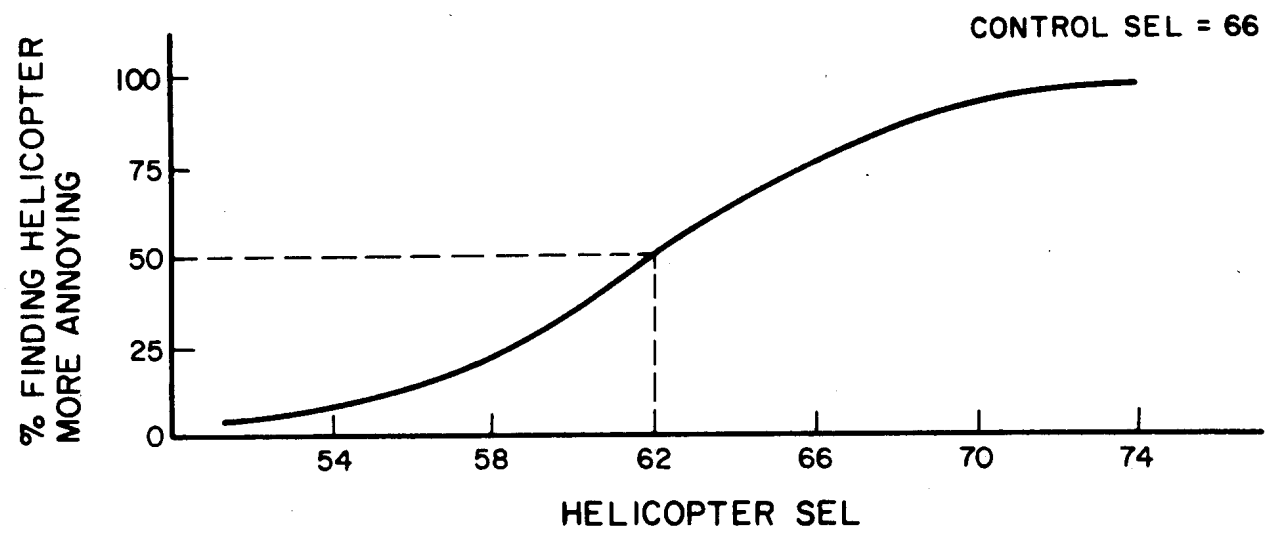

Figure 4. Typical Curve Expected for a Single White-Noise Level.

data are as good or better than lines fit to the Z-scores. So in this analysis, regression lines fit to the raw data are used.

In this test the objective was to collect information on how different helicopters are perceived differently in terms of the noise they generate. Of the six different types of helicopters used, the AH and two UH helicopters are two-bladed; the three $\mathrm{CH}$ helicopters are multibladed. Approximately 100 subjects were tested using each of the six helicopter types for a total of about 600 subjects.

It is important to note that concepts such as rattle, vibration, and loudness were not mentioned to test participants. The instructions stated that the subjects should mark their answers according to which stimulus in each pair was "more annoying or bothersome," or which sound they "would rather not hear again if given a choice." 


\section{DATA COLLECTION}

\section{The General Area}

The test site, at MCAS Tustin, is in the Los Angeles metropolitan area. As previously noted, three adjacent duplex houses (four residential units) and a field just south of these houses (Figure 2) were used. The test site was at the edge of a residential area. On the other side of the site was a cornfield 1 mile $(1.6 \mathrm{Km})$ wide and the airfield. Tests were occasionally halted when there were other helicopters in the area, but the air station rescheduled most of its helicopter maneuvers to avoid conflicting with the test.

\section{The Test Site}

The subjects were placed in four living rooms, three of which were constructed exactly the same, and the fourth had only minor differences. Since each of the quarters was actively occupied by an enlisted family, each of the living rooms was furnished slightly differently. The outdoor subjects were placed beneath a raised open-air tent (to protect them from the sun). The measurement truck, in which all the data were collected, was parked in the backyard of one of the houses. An equipment operator in the truck was in charge of coordinating the helicopter and had a good view of the ground track over which the helicopter was flying.

The helicopter flew parallel to the line of houses at $200 \mathrm{ft}$ above ground level (AGL). Four sideline distances were used, as measured from the back of the houses: $50 \mathrm{ft}, 500 \mathrm{ft}, 1000 \mathrm{ft}$, and $2000 \mathrm{ft}$. Figure 5 shows an overview of the general test site, the closest and furthest ground tracks and turns used by the helicopter, and major roads and towns in the area.

\section{The Subjects}

To recruit subjects, advertisements were put into many local papers in the Tustin area. Also, school and church groups in the area were contacted to recruit the 600 people needed for this survey. Anyone who wanted to participate was told to call a local number to sign up. Recruits were then mailed information and maps showing how to get to the site. There was a follow-up call the day before the test to make sure that participants understood all directions. All subjects were paid $\$ 40$ for participating in the test. They received the money during the break between the first and second half of the test.

The subjects came from all around the area, and varied in age, sex, and background. Table 1 shows a breakdown of the subjects by age and sex.

\section{Data Measurement Equipment}

USACERL's test truck was parked in the backyard of the first house, as shown in Figure 2. The truck contained all the instruments for analyzing and recording the sound signals gathered by equipment in the houses and at the outdoor site. Two Larson-Davis 1-in. microphones (model 2570) were placed in each living room at locations calculated to obtain a good representation of the sounds heard by the subjects. The microphone signals were passed through USACERL-developed line drivers set with $30 \mathrm{~dB}$ gain and a Pacific amplifier (model 70A-2-2245). The amplifier had a variable gain controlled by the computer 


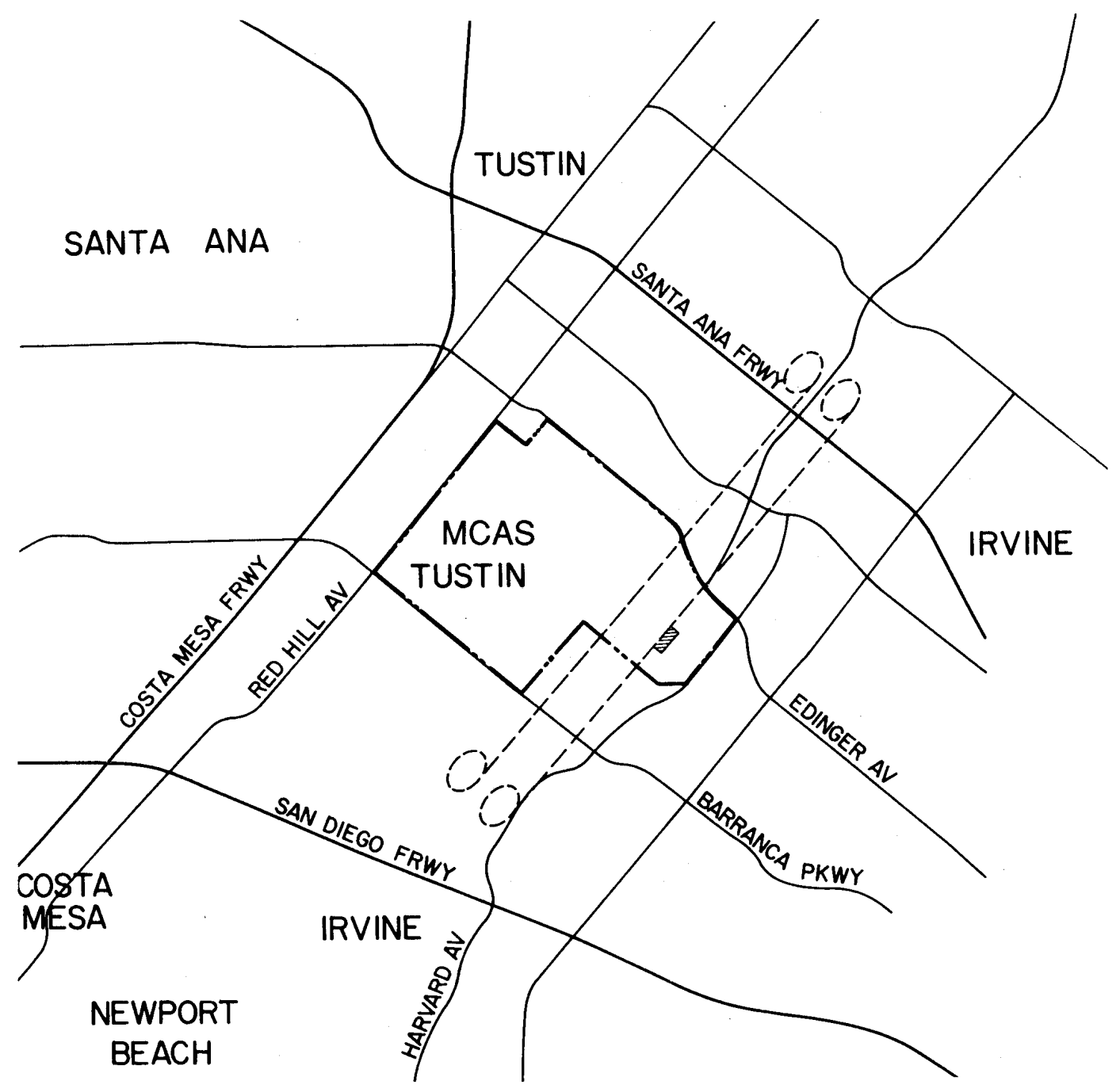

Figure 5. Overall View of Test Area. 
Table 1

Breakdown of Test Subjects by Age and Sex

\begin{tabular}{ccc}
\hline Age & Number of Male Subjects & Number of Female Subjects \\
\hline$<21$ & 60 & 64 \\
$21-30$ & 114 & 78 \\
$31-40$ & 62 & 64 \\
$41-50$ & 34 & 58 \\
$51-60$ & 30 & 55 \\
$61+$ & 42 & 70
\end{tabular}

in the truck. At the truck, the signal from cach test setting was digitally recorded using the video channel of a Panasonic videocassette recorder (VCR model AG1900) and stereo Sony pulse code modulators (model 501es) specially modified to operate from $0.1 \mathrm{~Hz}$ through $10 \mathrm{kHz}$ with no high-frequency preemphasis (instead of the normal $20 \mathrm{~Hz}$ through $20 \mathrm{kHz}$ range). The signal was analyzed using a USACERL-developed integrating noise monitor and sound exposure level meter. These instruments calculated the A-weighted SEL and A-weighted peak sound level for each stimulus.

Figure 6 illustrates the instrumentation setup. The outdoor data were taken with one B\&K 49211 -in. microphone system placed with the subjects under the tent and another installed $30 \mathrm{ft}$ directly above the test truck. An Endevco accelerometer was placed on the glass porch door of each residence, facing the line of flight of the helicopter. These data were recorded directly onto the audio channel of the VCR. Notes about each run were recorded onto a voice channel of each VCR by the operator in the measurement truck.

An IBM personal computer (PC) controlled signal amplifier gain and regulated the control noise.

\section{Control Noise}

The control noise was created by a white-noise generator and filtered by a $500 \mathrm{~Hz}$ octave band filter, and attenuated by a programmable attenuator controlled by the PC. Using the attenuator, the computer controlled the SEL and the $10 \mathrm{~dB}$ down times of the control noise.

The indoor control noise stimuli were presented at ASEL intervals of $4 \mathrm{~dB}$, from 56 through $92 \mathrm{~dB}$. Thus 10 different control noise ASELs were generated. In each run, the noise would gradually rise from inaudible to $10 \mathrm{~dB}$ below the maximum level, then rise to maximum at a different rate, and finally decay at approximately the same rate (as illustrated in Figure 3). The $10 \mathrm{~dB}$ down time of the control noise was varied according to the slant distance and type of helicopter flying by to approximate the amplitudeversus-time pattern of the helicopter's noise. 
The control noise in each house was generated by a single loudspeaker. The outdoor control noise was the same as the one used indoors except it was played $20 \mathrm{~dB}$ higher. The $20 \mathrm{~dB}$ gain was used outdoors because the A-weighted attenuation of a typical house from outdoors to indoors is normally about $20 \mathrm{~dB}$.

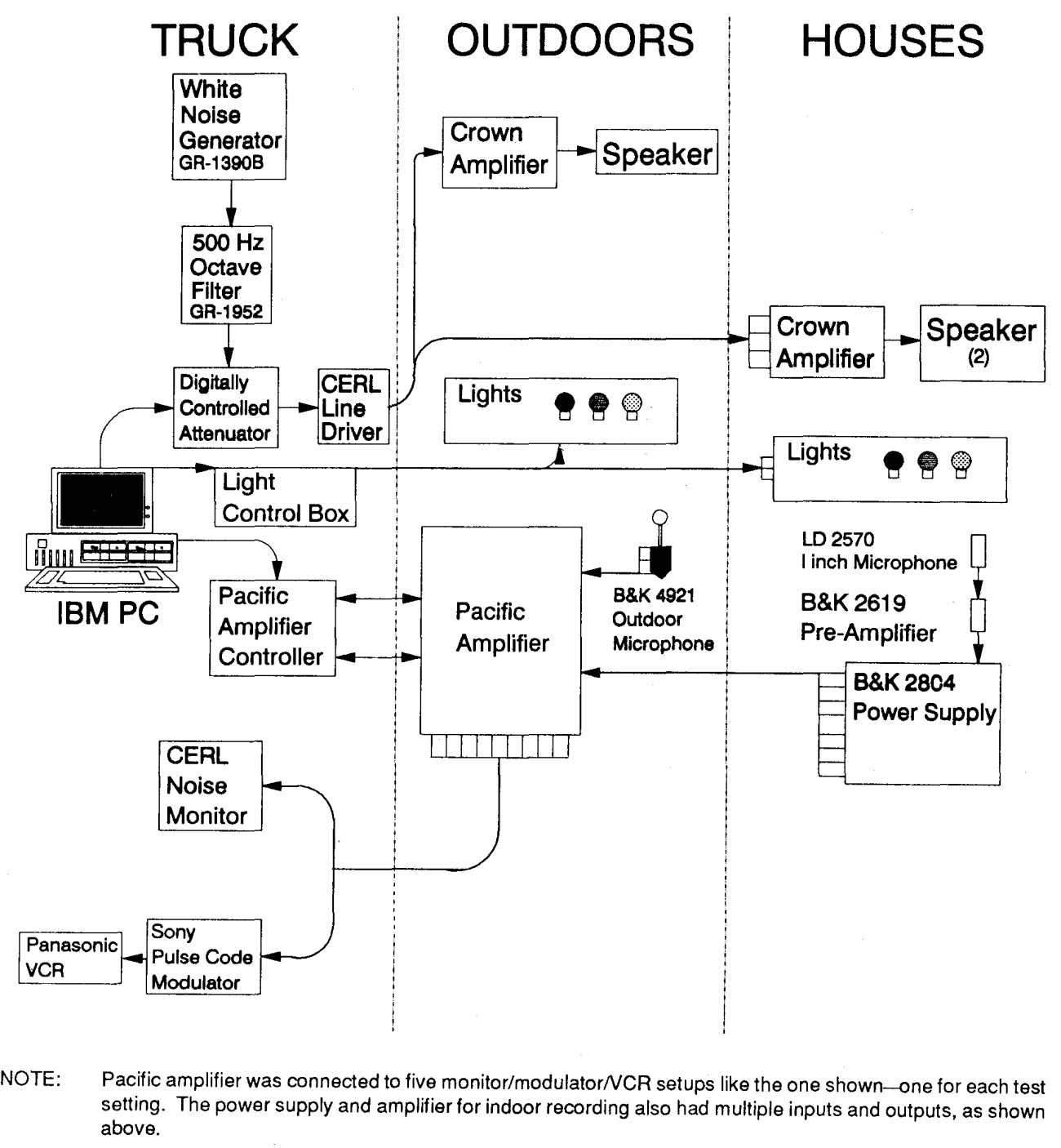

Figure 6. Data Measurement Equipment Setup. 
The test took approximately 3 hours, with the morning session starting at 9 a.m. and the afternoon session starting at 2 p.m. The participants met before the test at a parking lot outside the front gate of MCAS Tustin and were driven to the test site by bus. When they got off the bus they received information on how the test was going to be run and a folder containing two different test forms and a consent form. Figures 7, 8, and 9 respectively show the consent form, an annoyance factor form, and a follow-up form. The subjects were then split into random groups of five or six. They were taken to their test house by a USACERL research assistant, who gave them more information about how the test was to be run.

Before the actual test started, there was a pretest to make sure all participants understood what they were to do. The pretest used recorded jet airplane noise and the control white noise as an example test pair. For the first two pretest pairs, the ASEL of the two sounds in each pair differed greatly. In the first pair the first sound was clearly louder, in the second pair the second sound was clearly louder. In the third pair, the SELs of the two noises were equal. USACERL research assistants would check the participants' answers after each pretest run. The first two pretest pairs were used to verify that everyone understood the instructions. If a test subject chose the wrong answer during the pretest, the researcher would re-explain the instructions to everyone. If necessary, more pretest pairs were run until everyone fully understood the instructions.

Each run was conducted in four phases. First, a red light would be lit and subjects would concentrate on the first sound of the pair. Second, a yellow light would be lit and the participants would listen to the second sound of the pair. Each of the noises lasted for approximately 1 minute. Third, a green light would be lit and the subjects would have approximately 15 seconds to mark on the appropriate test form which noise was more annoying. During the green light, the USACERL researchers were also recording their judgment of the rattle levels on their forms. Finally all lights would be turned off, and the subjects would wait until the red light was turned on to start the next pair of sounds. When each light was turned on, a bell would also ring softly to make sure people noticed that a new phase of the run had started.

The PC in the truck controlled all of the lights and the bell along with the amplifier gains and the generation of the control noise. The operator of the PC was in radio and visual contact with the helicopter. In this way, the entire test was very precisely coordinated.

The test consisted of 46 pairs of stimuli. For half the pairs, the helicopter noise would be presented first; for the other half, the control noise would be first. Since it would have been impractical to completely randomize which source of noise came first in any pair, the order of presentation was switched every six or seven runs. The order was switched every other test session, so for one session the helicopter noise would be presented first during the first run; for the next session the control sound would be presented first during the first run.

The annoyance factor test form (Figure 8) was used by the subjects to mark which noise was more bothersome or annoying. Subjects marked the form after every pair of sounds. The subjects were also told to mark how difficult it was to make this decision. They judged difficulty in deciding on a scale of 1 to 5 , with 1 being "very easy" and 5 being "very hard." It is important to note that test participants were required to decide which sound of the pair was more annoying or bothersome for every run. Subjects were required to make a decision: they could not say the two sounds were equally annoying, but they could indicate that it was "very hard" to decide. 
You will be asked to compare the annoyance of up to 50 helicopter flyovers with the annoyance of a similar number of other sounds. You will have to listen attentively to these sounds for periods of about an hour between breaks. There will be two of these periods during the test. You may find some of the sounds unpleasantly loud or annoying. None of the sounds will be so loud or long as to impair your hearing in any way.

The only direct benefit to you for participation in the study will be your payment of $\$ 40.00$. Payment will be made at the end of the testing period.

If you have any questions about the nature of today's experiment, please ask them now. If you are satisfied with your understanding of what your participation will involve, and are willing to participate, please so indicate by signing the form below.

\section{INFORMED CONSENT FORM}

I understand that my participation as a test subject in the experiment being conducted by CERL today will require me to listen to up to 50 helicopter flyovers, and to compare their annoyance relative to an equal number of other sounds. These judgments will be made in the company of other test subjects, seated in groups, for a period of about 1 hour each. I also understand that some of the sounds I will hear may be unpleasantly loud, but that they will not pose any risk of damage to my hearing.

The only direct benefit to me for my participation in the experiment will be the payment made for my time. I understand that I can freely withdraw from participation in the experiment at any time, and that $I$ will be paid for my participation up to the time I decide to stop. I have had the opportunity to discuss the nature of the experiment, and am willing to participate in the study.

DATE : SIGNED:

Do you have any reason to believe your hearing is less than normal? Yes No

If, yes, to the best of your ability, please describe your hearing problem. (use the back side of this form if you need more room.)

Figure 7. Consent Form. 


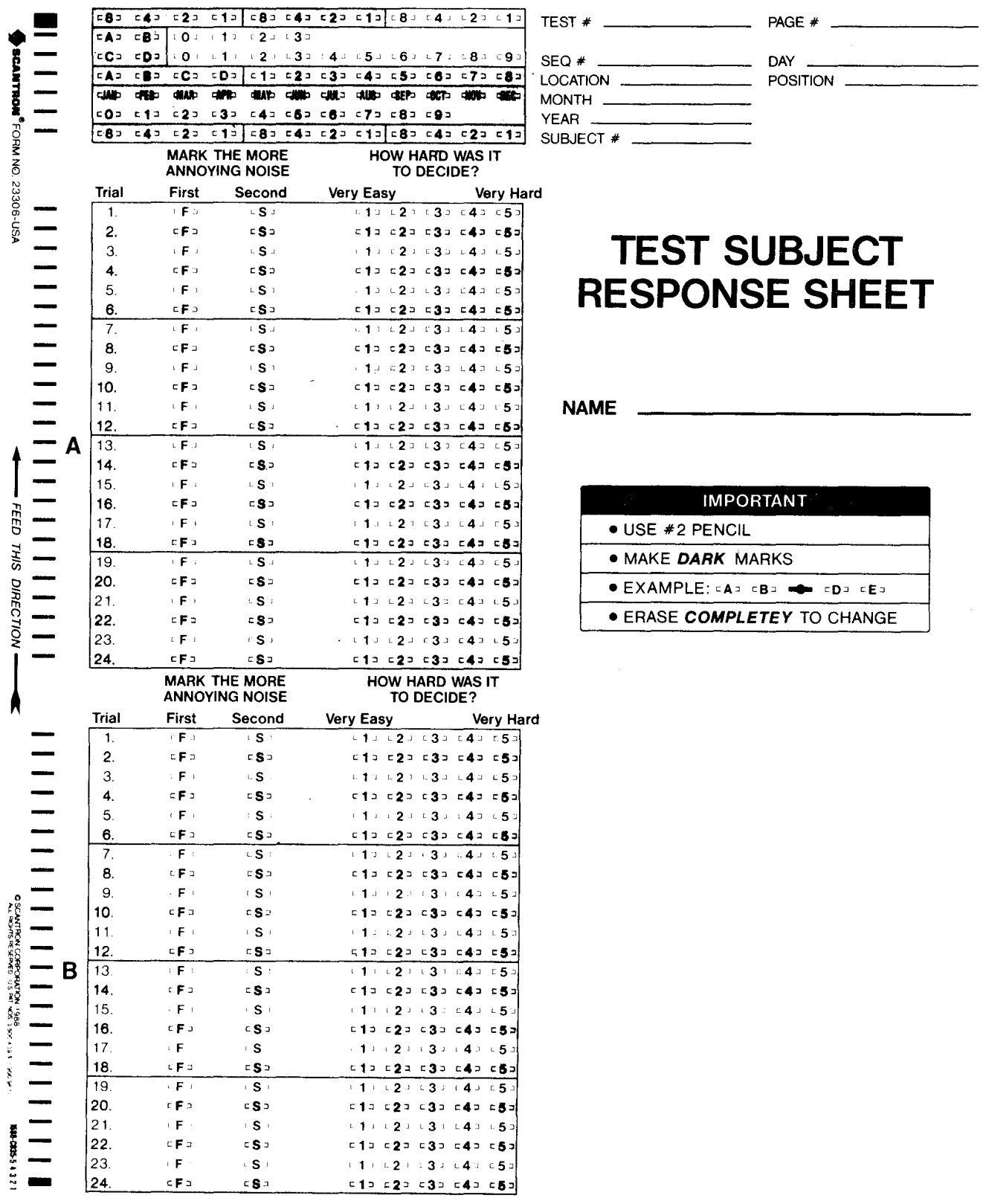

Figure 8. Annoyance Factor Form. 
After the entire test was over, the participants were asked to rate how annoying different components of the noise were on the follow-up form (Figure 9). The noise components were given four arbitrary characteristics: hissing, rumbles, rattles, and loudness. The participants were asked how each characteristic related to their judging of either event as bothersome or annoying. They rated each of the four characteristics for each sound as "not annoying," "somewhat annoying," or "very annoying."

Subject Number

During the main part of this test you have observed pairs of events. Please mark how each of the following caused you to find either event bothersome or annoying. Circle your choices.

\begin{tabular}{|c|c|c|c|c|c|c|}
\hline \multirow[b]{2}{*}{ Hissing } & \multicolumn{3}{|c|}{ Loudspeaker Event } & \multicolumn{3}{|c|}{ Helicopter Event } \\
\hline & $\begin{array}{l}\text { Not } \\
\text { Annoying }\end{array}$ & $\begin{array}{l}\text { Somewhat } \\
\text { Annoying }\end{array}$ & $\begin{array}{l}\text { Very } \\
\text { Annoying }\end{array}$ & $\begin{array}{l}\text { Not } \\
\text { Annoying }\end{array}$ & $\begin{array}{l}\text { Somewhat } \\
\text { Annoying }\end{array}$ & $\begin{array}{l}\text { Very } \\
\text { Annoying }\end{array}$ \\
\hline Rumbles & $\begin{array}{l}\text { Not } \\
\text { Annoying }\end{array}$ & $\begin{array}{l}\text { Somewhat } \\
\text { Annoying }\end{array}$ & $\begin{array}{l}\text { Very } \\
\text { Annoying }\end{array}$ & $\begin{array}{l}\text { Not } \\
\text { Annoying }\end{array}$ & $\begin{array}{l}\text { Somewhat } \\
\text { Annoying }\end{array}$ & $\begin{array}{l}\text { Very } \\
\text { Annoying }\end{array}$ \\
\hline Rattles. & $\begin{array}{l}\text { Not } \\
\text { Annoying }\end{array}$ & $\begin{array}{l}\text { Somewhat } \\
\text { Annoying }\end{array}$ & $\begin{array}{l}\text { Very } \\
\text { Annoying }\end{array}$ & $\begin{array}{l}\text { Not } \\
\text { Annoying }\end{array}$ & $\begin{array}{l}\text { Somewhat } \\
\text { Annoying }\end{array}$ & $\begin{array}{l}\text { Very } \\
\text { Annoying }\end{array}$ \\
\hline Loudness & $\begin{array}{l}\text { Not } \\
\text { Annoying }\end{array}$ & $\begin{array}{l}\text { Somewhat } \\
\text { Annoying }\end{array}$ & $\begin{array}{l}\text { Very } \\
\text { Annoying }\end{array}$ & $\begin{array}{l}\text { Not } \\
\text { Annoying }\end{array}$ & $\begin{array}{l}\text { Somewhat } \\
\text { Annoying }\end{array}$ & $\begin{array}{l}\text { Very } \\
\text { Annoying }\end{array}$ \\
\hline
\end{tabular}

Other Comments:

Figure 9. Follow-up Form. 


\section{DATA ANALYSIS}

The responses of the participants were analyzed to determine the helicopter ASEL at which 50 percent of the subjects felt that the helicopter sound was more annoying or bothersome than the control sound. Several different types of data were collected: the response data from the subjects, the rattle levels rated by the USACERL research assistants, the ASELs of the various sounds (as measured near the subjects), the nominal value of the control sound ASEL as programmed in the PC, and the acceleration level of vibrations as measured with the accelerometer mounted on the largest window facing the helicopter line of flight.

\section{Data Reduction}

The control noise was originally designed to be produced at 10 different levels, from 56 to $92 \mathrm{~dB}$, with the outdoor noise presented $20 \mathrm{~dB}$ higher than inside. Because of slight variations in the measured control levels, the pairs of noises were grouped into categories, or "bins." The control sound was divided into $4 \mathrm{~dB}$-wide bins spread over the $26 \mathrm{~dB}$ range used for comparison with the sound of each individual helicopter. The helicopter ASELs were divided into $2 \mathrm{~dB}$-wide bins.

After the pairs of sounds were grouped by control ASEL and helicopter ASEL, the percentage of people who found the helicopter noise more annoying was computed for each pair of stimuli. A simple test was applied to determine a confidence index for any of these percentage calculations. As previously mentioned, the subjects were required to determine the difficulty of deciding which noise was more annoying on a scale of 1 to 5 . In any sample where the number of subjects amounted to less than 1.5 times the average difficulty rating reported by those subjects, that datapoint was deleted.

To make sure all of the houses were equivalent sound environments, the response data were divided and analyzed by location. All of the houses showed approximately the same response $\pm 2 \mathrm{~dB}$, which is well within the expected margin of error for this test. Therefore, all indoor locations were considered to be equivalent and the data for all houses were grouped together.

Originally, as in the earlier test at Savoy, the data were also going to be divided by the level of rattle perceived by the USACERL researchers in the houses. The houses used in this test were chosen partially on the basis of their occupants reporting that rattling occurred during typical helicopter flybys. However, unlike in the earlier test, the USACERL research assistants perceived very little rattle in any of the houses. Therefore, this aspect of the Savoy test could not be replicated in the MCAS Tustin test.

Figure 10a shows a typical data plot. (Figure 10b shows a plot of the same data converted to Zscores, as discussed in the next paragraph.) A regression line was fit to the data and confidence intervals were graphed. One of these plots was produced for each control noise level and each helicopter. Plots were produced if more than three different helicopter ASELs were observed for a particular control noise ASEL. The entire set of these plots for valid indoor data is published in Appendix A. When the plots were generated, the point at which 50 percent of the subjects felt the helicopter was more annoying than the control noise was found. Error bars were statistically generated for a 95 percent confidence interval. If the crror bars fell more than \pm 20 from the 50-percent point previously described, this was judged too large and the datapoint was discarded. Thus, for the datapoints finally used, there is a 95 percent chance that 50 percent of the subjects ( \pm 20 percent) found the helicopter noise equivalent to the control noise in 


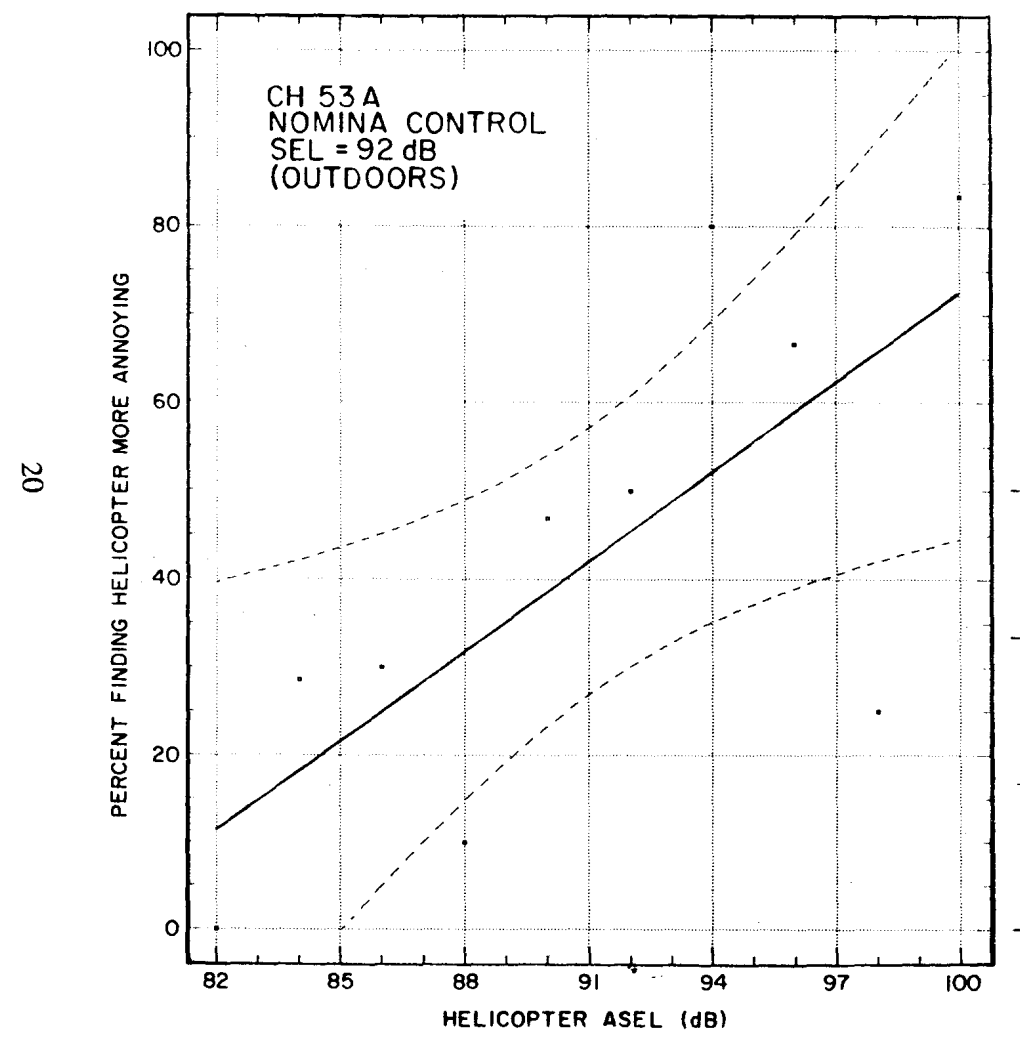

a. Typical plot of data.

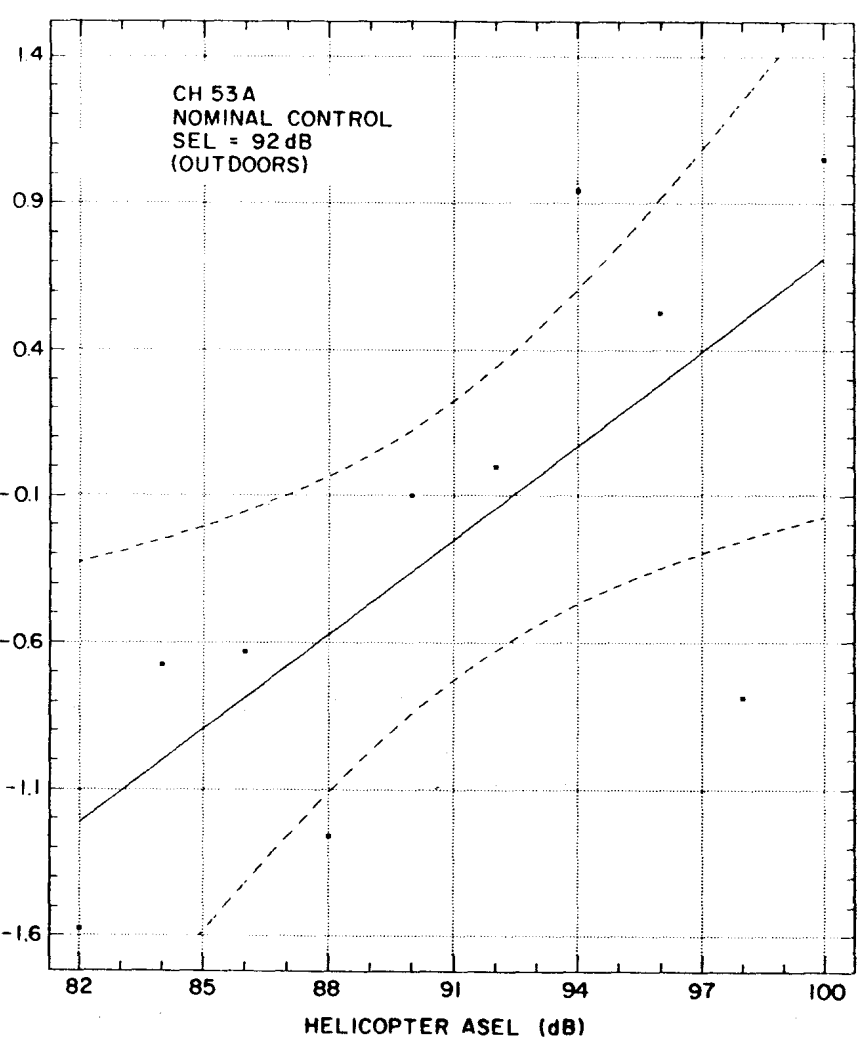

b. Same data converted to $\mathrm{Z}$-scores.

Figure 10. Data Plots for Percentage. 
terms of annoyance. An example of such discarded data is shown in Figure 11. In this example there was not sufficient helicopter data at high percentages, so the confidence interval was too large.

As noted earlier, the general shape to the data of Figure 10a is a sigmoid curve. However, care was taken to attempt to limit the data to the most "linear" region of the curve and avoid the 0 percent or 100 percent areas. As a test, Figure 10b shows a corresponding plot for the same data after they had been transformed to Z-scores. The entire set of transformed Z-score plots for valid indoor data is contained in Appendix B. Table 2 lists the resulting correlation coefficients for each plot in Appendix A and its corresponding Z-score transformed plot in Appendix B. Examination of the average correlation coefficients and the differences shows that the transformation to Z-scores provides no benefit for data analysis. Therefore, the remainder of this report uses only regression lines fit to the original subjectpercentage data.

All valid indoor points calculated from each data plot in Appendix A were grouped by helicopter and plotted. Table 3 lists these data. Figure 12 is an example plot for the CH53E. The control noise judged equivalently annoying to the helicopter noise is shown as a function of helicopter ASEL. A regression line was fit to these data. In this figure, the diagonal shows the result that would have been achieved if the helicopter sound was exactly equivalent to the control sound at the identical ASEL. The departure of the fitted line from the diagonal shows the offset or correction as a function of helicopter ASEL.

As previously noted, the valid indoor plots for all of the helicopters tested are shown in Appendix A. Inspection of these plots showed that the results seemed to be significantly affected by how many blades the helicopter had. The response curves (e.g., Figure 11) for all the two-bladed helicopters (UH1H, $\mathrm{UH} 1 \mathrm{~N}, \mathrm{AH} 1 \mathrm{~W}$ ) were very similar to one another in the region of the curve from which data were taken; all of the multi-bladed helicopters (CH53A/B, CH53E, and CH46E) had similar response curves among themselves also, but the two groups differed from each other. Figure 13 plots the indoor results for these two groups of helicopters. This figure shows the same type of data shown in Figure 12, but shows it for groups instead of individual helicopters. Table 4 lists these data.

Because less outdoor data were gathered-there was only one outdoor group but four indoor groups-less analysis could be performed on it. (Enough outdoor data were collected to create a reliable graph for the $\mathrm{AH} 1 \mathrm{~W}$, however.) In an effort to more fully develop the outdoor data, it was reasoned that since the indoor data for all multi-bladed helicopters were similar and grouped together, then all of the outdoor data for the multibladed helicopters could be also grouped together. Even with this grouping, however, there were so few outdoor subjects that much of the data lacked sufficient reliability." The graphs used to develop the individual outdoor datapoint pairs (as in Figure 10a) are shown in Appendix C. These data are summarized in Figure 13 and Table 4.

\footnotetext{
- As implied by the design of this study, the emphasis was placed on indoor testing. For test sessions attended by fewer recruits than expected, subjects were located indoors first to assure the collection of an adequate amount of indoor data. Therefore, the number of participants in outdoor tests fluctuated substantially depending on overall attendance. Ultimately this impaired the reliability of the outdoor data collected.
} 


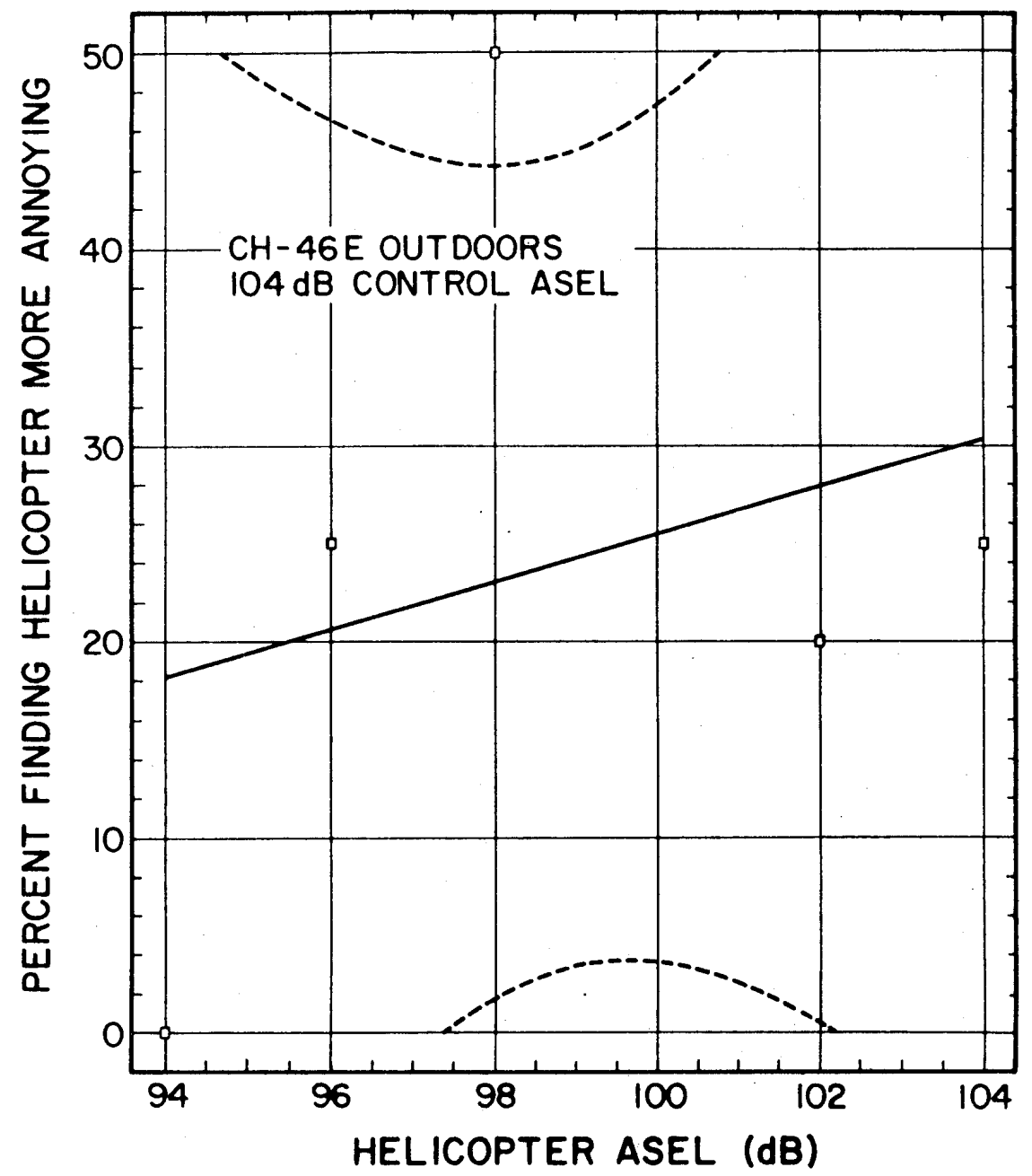

Figure 11. Example of Discarded Data. 
Table 2

Correlation Coefficients for Data

\begin{tabular}{|c|c|c|}
\hline $\begin{array}{l}\text { HELICOPTER } \\
\text { (CONTROL } \\
\text { ASEL) }\end{array}$ & $\begin{array}{c}\text { CORRELATION } \\
\text { COEFFICIENTS } \\
\text { FOR PERCENTS }\end{array}$ & $\begin{array}{l}\text { CORRELATION } \\
\text { COEFFICIENTS } \\
\text { FOR Z-SCORES }\end{array}$ \\
\hline CH53A(60)IN & 0.884 & 0.865 \\
\hline CH53A(68)IN & 0.867 & 0.818 \\
\hline CH53A(72)IN & 0.891 & 0.893 \\
\hline CH53A(80)IN & 0.786 & 0.833 \\
\hline AH1W(100)OUT & 0.708 & 0.695 \\
\hline AH1W(80)OUT & 0.700 & 0.701 \\
\hline AH1W(84)OUT & 0.677 & 0.693 \\
\hline AH1W(92)OUT & 0.687 & 0.645 \\
\hline AH1W(68)IN & 0.934 & 0.970 \\
\hline AH1W(78)IN & 0.923 & 0.922 \\
\hline AH1W(80)IN & 0.753 & 0.744 \\
\hline AH1W(84)IN & 0.718 & 0.718 \\
\hline CH46E(88)OUT & 0.874 & 0.801 \\
\hline CH46E(92)OUT & 0.741 & 0.841 \\
\hline CH46E(96)OUT & 0.777 & 0.843 \\
\hline CH53A(92)OUT & 0.732 & 0.725 \\
\hline CH53A(96)OUT & 0.750 & 0.791 \\
\hline CH53E(100)OUT & 0.829 & 0.906 \\
\hline CH53E(92)OUT & 0.431 & 0.571 \\
\hline CH53E(96)OUT & 0.734 & 0.885 \\
\hline $\mathrm{CH} 46 \mathrm{E}(100) \mathrm{IN}$ & 0.745 & 0.757 \\
\hline $\mathrm{CH} 46 \mathrm{E}(84) \mathrm{IN}$ & 0.801 & 0.847 \\
\hline $\mathrm{CH} 46 \mathrm{E}(92) \mathrm{IN}$ & 0.904 & 0.826 \\
\hline $\mathrm{CH} 46 \mathrm{E}(92) \mathrm{IN}$ & 0.817 & 0.797 \\
\hline CH53A(88)IN & 0.720 & 0.690 \\
\hline CH53A(92)IN & 0.832 & 0.832 \\
\hline CH53A(96)IN & 0.915 & 0.901 \\
\hline CH53E(100)IN & 0.924 & 0.929 \\
\hline CH53E(96)IN & 0.850 & 0.799 \\
\hline $\mathrm{CH} 46 \mathrm{E}(64) \mathrm{IN}$ & 0.925 & 0.869 \\
\hline $\mathrm{CH} 46 \mathrm{E}(68) \mathrm{IN}$ & 0.941 & 0.939 \\
\hline $\mathrm{CH} 46 \mathrm{E}(72) \mathrm{IN}$ & 0.942 & 0.937 \\
\hline CH46E(76)IN & 0.983 & 0.972 \\
\hline C.H46E(84)IN & 0.852 & 0.856 \\
\hline
\end{tabular}


Table 2 (Cont'd)

\begin{tabular}{lrc}
\hline $\begin{array}{l}\text { HELICOPTER } \\
\text { (CONTROL }\end{array}$ & $\begin{array}{r}\text { CORRELATION } \\
\text { COEFFICIENTS } \\
\text { FOR PERCENTS }\end{array}$ & $\begin{array}{r}\text { CORRELATION } \\
\text { COEFFICIENTS } \\
\text { FOR Z-SCORES }\end{array}$ \\
ASEL) & 0.965 & 0.953 \\
CH53E(68)IN & 0.850 & 0.784 \\
CH53E(72)IN & 0.900 & 0.889 \\
CH53E(76)IN & 0.857 & 0.856 \\
CH53E(84)IN & 0.971 & 0.962 \\
CH53E(92)IN & & \\
& 0.894 & 0.810 \\
UH1H(68)IN & 0.852 & 0.772 \\
UH1H(72)IN & 0.963 & 0.967 \\
UH1H(80)IN & & \\
& 0.459 & 0.392 \\
UH1N(56)IN & 0.898 & 0.865 \\
UH1N(64)IN & 0.984 & 0.908 \\
UH1N(68)IN & 0.974 & 0.949 \\
UH1N(72)IN & 0.910 & 0.886 \\
UH1N(76)IN & 0.956 & 0.957 \\
UH1N(80)IN & & \\
& 39.980 & 39.763 \\
TOTAL & 48.000 & 48.000 \\
COUNT & & \\
& 0.833 & 0.828 \\
AVERAGE & &
\end{tabular}


Table 3

Offset Data for Indoor Test Locations (by Helicopter)

\begin{tabular}{|c|c|c|c|c|c|}
\hline \multicolumn{2}{|c|}{ a. UH1H } & \multicolumn{2}{|c|}{ b. CH53A } & \multicolumn{2}{|c|}{ c. CH53E } \\
\hline $\begin{array}{c}\text { Control } \\
\text { ASEL (dB) }\end{array}$ & $\begin{array}{c}\text { Helicopter } \\
\text { equivalent }(\mathrm{dB})\end{array}$ & $\begin{array}{l}\text { Control ASEL } \\
\text { (dB) }\end{array}$ & $\begin{array}{l}\text { Helicopter } \\
\text { equivalent } \\
\text { (dB) }\end{array}$ & $\begin{array}{l}\text { Control ASEL } \\
\text { (dB) }\end{array}$ & $\begin{array}{c}\text { Helicopter } \\
\text { equivalent }(\mathrm{dB})\end{array}$ \\
\hline 68 & 61 & 60 & 53 & 68 & 66 \\
\hline 72 & 64 & 68 & 64 & 72 & 61 \\
\hline 76 & 66 & 72 & 66 & 76 & 66 \\
\hline \multirow[t]{3}{*}{80} & 64 & 76 & 71 & 80 & 72 \\
\hline & & 80 & 73 & 84 & 76 \\
\hline & & & & 92 & 79 \\
\hline \multicolumn{2}{|c|}{ d. AHIW } & \multicolumn{2}{|c|}{ c. $\mathrm{UH} 1 \mathrm{~N}$} & \multicolumn{2}{|c|}{ f. $\mathrm{CH} 46 \mathrm{E}$} \\
\hline $\begin{array}{l}\text { Control } \\
\text { ASEL } \\
\text { (dB) }\end{array}$ & $\begin{array}{l}\text { Helicopter } \\
\text { equivalent } \\
\text { (dB) }\end{array}$ & $\begin{array}{l}\text { Control } \\
\text { ASEL } \\
\text { (dB) }\end{array}$ & $\begin{array}{c}\text { Helicopter } \\
\text { equivalent } \\
\text { (dB) }\end{array}$ & $\begin{array}{l}\text { Control } \\
\text { ASEL } \\
\text { (dB) }\end{array}$ & $\begin{array}{c}\text { Helicopter } \\
\text { equivalent } \\
\text { (dB) }\end{array}$ \\
\hline 64 & 54 & 64 & 58 & 64 & 57 \\
\hline 68 & 59 & 68 & 60 & 68 & 58 \\
\hline 72 & 64 & 72 & 62 & 72 & 63 \\
\hline 76 & 66 & 76 & 66 & 76 & 66 \\
\hline 80 & 67 & 80 & 69 & 84 & 77 \\
\hline 84 & 71 & 84 & 73 & & \\
\hline
\end{tabular}

\section{Frequency-Weighted Results}

Figure 13 shows that, for each helicopter grouping (outdoors or indoors), the offset between the control sound and the equivalent helicopter sound becomes greater as the ASEL of the helicopter sound increases. The data clearly show a relationship between the helicopter ASEL and the resulting decibel offset from the equivalently annoying control noise. Again, as in the Savoy study, the results show that A-weighting did not provide an adequate description of human annoyance by helicopter noise because the offsets were not constant. For the multi-bladed helicopters, the offsets ranged from around $7 \mathrm{~dB}$ at low helicopter ASEL to around $10 \mathrm{~dB}$ at the highest helicopter ASEL. The offset was found to rise from 6 to $13 \mathrm{~dB}$ for the two-bladed helicopters. These results are quite similar to the Savoy results for "a little" rattle, ${ }^{8}$ which was the only condition found at Tustin.

${ }^{8}$ Paul D. Schomer and Robert D. Neathammer, 1987. 


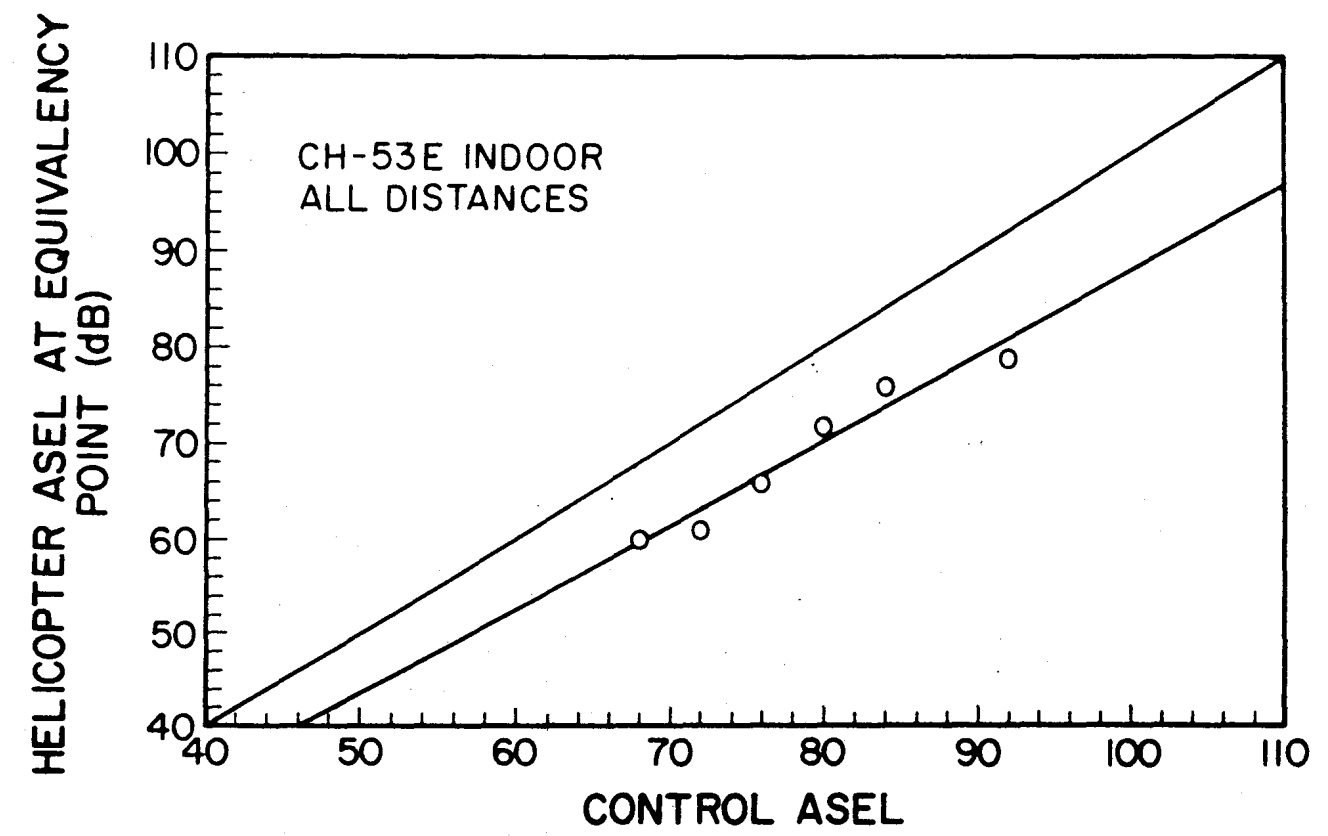

Figure 12. Offset as a Function of Control ASEL for CH-53E. 


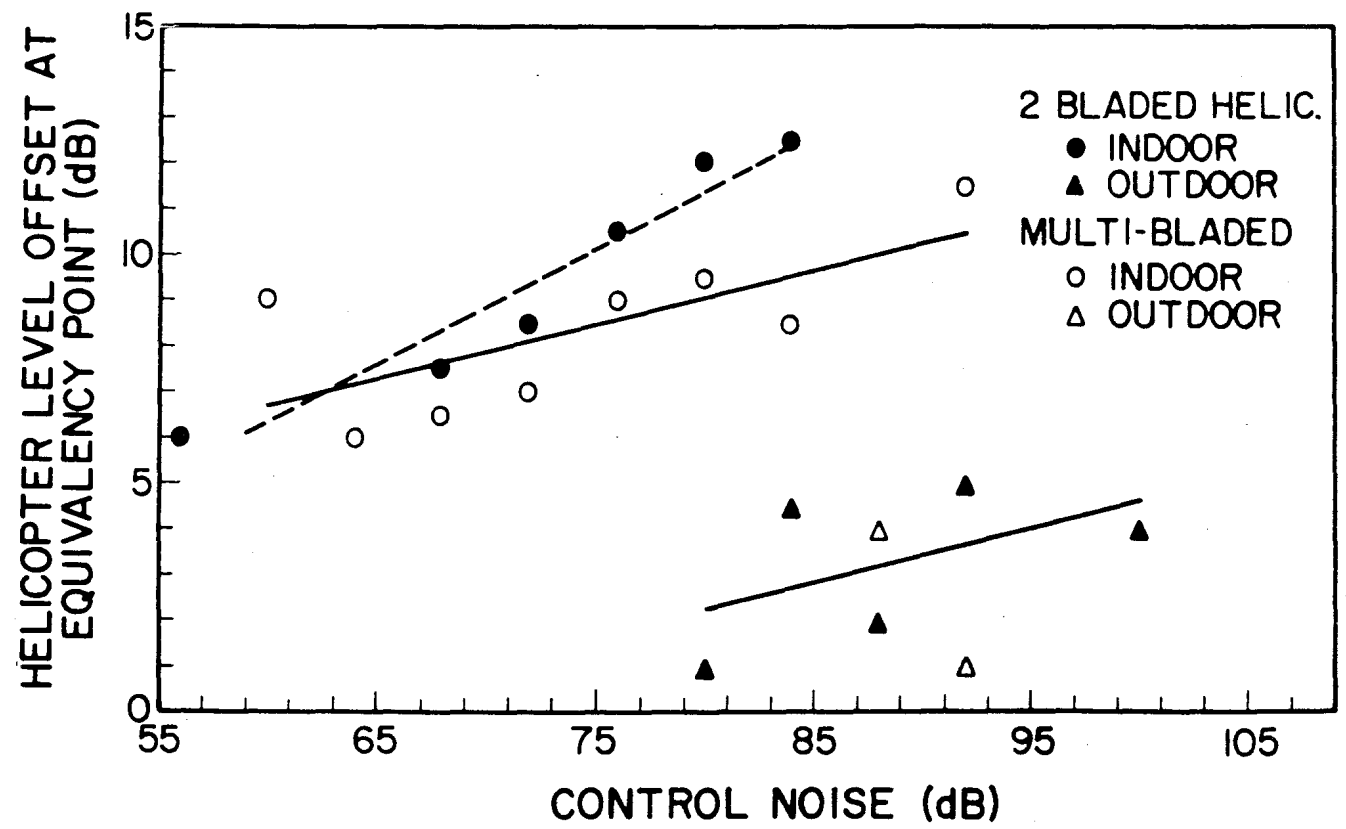

Figure 13. Offset as a Function of Control ASEL for Helicopters Grouped by Number of Blades. 
Table 4

Offset Data Grouped by Number of Blades and Test Environment

\begin{tabular}{|c|c|c|c|c|c|c|c|}
\hline \multicolumn{2}{|c|}{$\begin{array}{l}\text { MULTIBLADED } \\
\text { INDOOR }\end{array}$} & \multicolumn{2}{|c|}{$\begin{array}{l}\text { 2-BLADED } \\
\text { INDOOR }\end{array}$} & \multicolumn{2}{|c|}{$\begin{array}{c}\text { MULTIBLADED } \\
\text { OUTDOOR } \\
\end{array}$} & \multicolumn{2}{|c|}{$\begin{array}{l}\text { 2-BLADED } \\
\text { OUTDOOR }\end{array}$} \\
\hline $\begin{array}{c}\text { Control } \\
\text { ASEL (dB) }\end{array}$ & $\begin{array}{l}\text { Offset } \\
\text { (dB) }\end{array}$ & $\begin{array}{c}\text { Control } \\
\text { ASEL } \\
\text { (dB) }\end{array}$ & $\begin{array}{l}\text { Offset } \\
(\mathrm{dB})\end{array}$ & $\begin{array}{c}\text { Control } \\
\text { ASEL } \\
\text { (dB) }\end{array}$ & Offset (dB) & $\begin{array}{c}\text { Control } \\
\text { ASEL } \\
\text { (dB) }\end{array}$ & Offset (dB) \\
\hline 60 & 9 & 56 & 6 & 88 & 4 & 80 & 1 \\
\hline 64 & 6 & 68 & 7.5 & 92 & 1 & 84 & 4.5 \\
\hline 68 & 6.5 & 72 & 8.5 & & & 88 & 2 \\
\hline 72 & 7 & 76 & 10.5 & & & 92 & 5 \\
\hline 76 & 9 & 80 & 12 & & & 100 & 4 \\
\hline 80 & 9.5 & 84 & 12.5 & & & & \\
\hline 84 & 8.5 & & & & & & \\
\hline 92 & 11.5 & & & & & & \\
\hline
\end{tabular}

To check the hypothesis that a different weighting system might provide a more constant offset, some of the data were reanalyzed using the C-weighting scale ${ }^{9}$ (typically used in measuring blast noise and sonic boom). The offset values changed, but the change did not result in a constant offset from the control noise level. This indicates that the $\mathrm{C}$-weighting scale is just as inappropriate a measure for helicopter noise as the A-weighting scale.

The data seem to indicate that helicopter noise should be measured with a loudness measure such as International Organization for Standardization (ISO) $532 \mathrm{~b}^{10}$ This measure would take into account the fact that human response to helicopter noise is not a constant function of frequency, but relies on a variety of frequency, duration, and amplitude factors, most of which are not taken into account by the simple weighting curves now commonly used. The most important factor, however, would be the loudness of the noise-not in the common sense of the term, but as defined by ISO 532b. Research on loudness indicates that if one noise is louder than another but their ASELs are equal, then people find the louder noise (as measured by ISO 532b) more annoying. " Loudness as measured by ISO 532b, then, may be a better measure than ASEL for assessing annoyance. The possibility of using this measure is now under investigation. Qualitatively, the results shown in Figure 13 are explained by this loudness hypothesis.

\section{Effect of Distance on Subjects' Response}

One other hypothesis that could explain the variable, helicopter-level-dependent offset between helicopter noise and the control noise would involve the sideline distance between the subjects and the helicopter. The subjects may be more annoyed when hearing that the helicopter was very close to the test houses that when it was farther away. This hypothesis was tested.

\footnotetext{
7A ANSI S 12.9-1988.

${ }^{10}$ International Standard ISO 532b, Method for Calculating Loudness Level (ISO, 1975)

$"$ E. Zwicker, "Meaningful Noise Measurement and Effective Noise Reduction," Noise Control Engineering Journal, Vol 29, No. 3 (1987), pp 66-76
} 
The data from the multibladed helicopters were grouped together to form one large database. Similarly, all of the data from the two-bladed helicopters were collected into a second large set. Data from these two groups were split by the four sideline distances of $50 \mathrm{ft}, 500 \mathrm{ft}, 1000 \mathrm{ft}$, and $2000 \mathrm{ft}$. Then the data, so divided, were analyzed in the same fashion as before. Response curves were generated for each sideline distance and helicopter type (multibladed or two-bladed).

Obviously, when a helicopter is close to the house, the noise from that helicopter will be louder, and more people will be annoyed than when it is farther away. However, each side line distance generated approximately the same regression line on the helicopter response curve (Figure 14). Therefore the effect of distance on the subjects' determination of noise-induced annoyance was judged to be minimal.

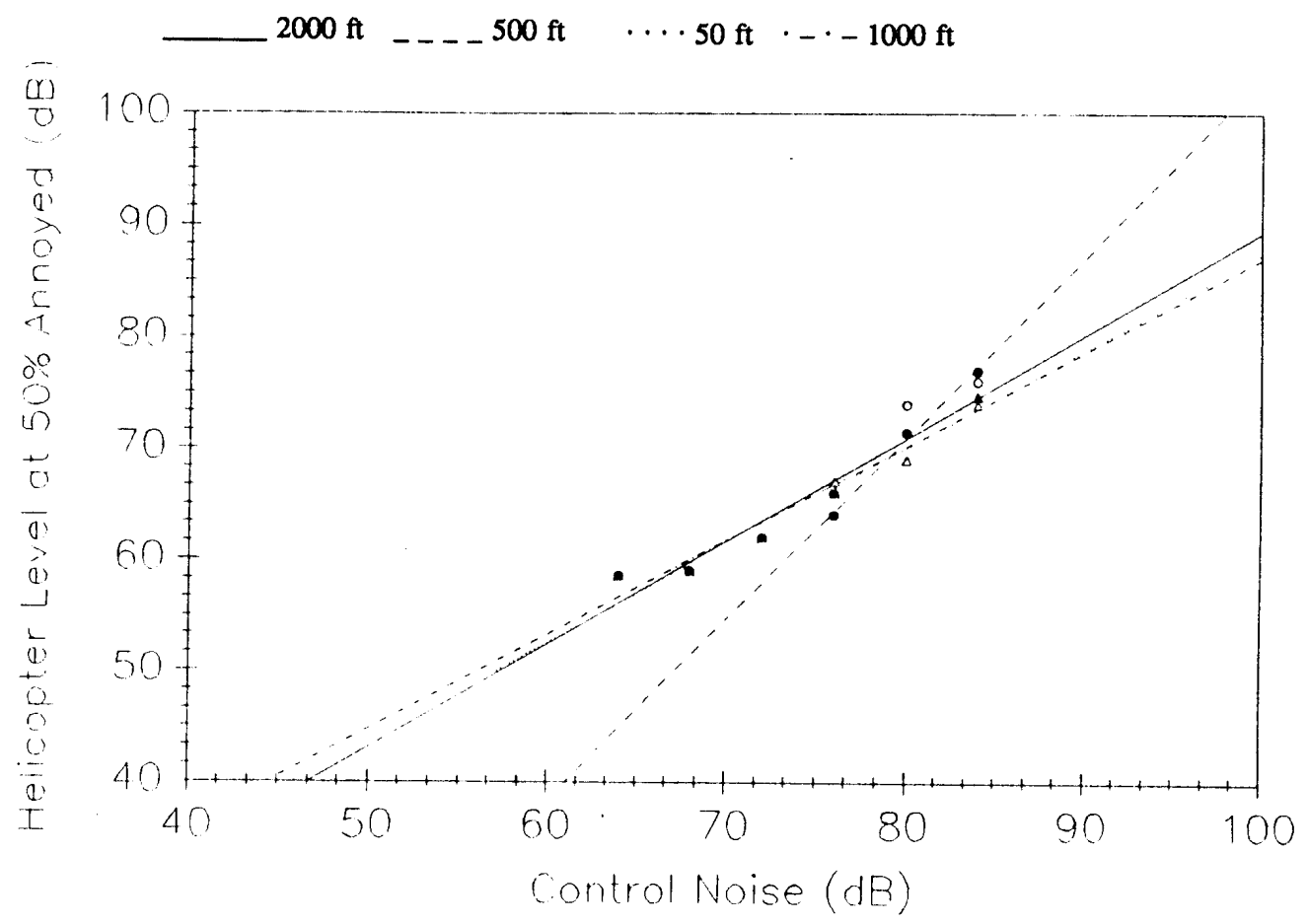

Figure 14. Subject Response to Different Sideline Distances. 


\section{CONCLUSIONS AND RECOMMENDATIONS}

Overall, the additional data collected at MCAS Tustin indicates that the A-weighted measurement scale is inadequate for the assessment of helicopter noise. The $\mathrm{C}$-weighting scale provides no discemible improvement over the A-scale. A correction must be added to the helicopter noise measured by either scale in order to assess a helicopter sound in a way that accurately corresponds to people's perceptions.

Use of A-weighting to assess helicopter sounds requires an offset which varies with helicopter ASEL. This offset changes based on the type of helicopter being used: two-bladed helicopter or multibladed helicopter.

For two-bladed helicopters, a correction factor of approximately $10 \mathrm{~dB}$ should be added to the ASEL of helicopter sound noise as measured indoors. An $8 \mathrm{~dB}$ correction factor should be added to the ASEL of a multibladed helicopter as measured indoors. These correction factors are the approximate averages of the decibel offsets found and shown in Figure 13 and Table 4.

Further analysis of this data should be performed to specifically assess the use of a loudness scale such as ISO 532b as a way to measure human response to helicopter noise.

METRIC CONVERSION TABLE

$$
\begin{aligned}
1 \mathrm{mi} & =1.61 \mathrm{~km} \\
1 \mathrm{ft} & =0.305 \mathrm{~m} \\
1 \mathrm{in} & =2.540 \mathrm{~cm}
\end{aligned}
$$




\section{REFERENCES}

Air Installations Compatible Use Zones (AICUZ), DOD Instruction 4165.57 (DOD, November 8, 1977).

ANSI 512.9-1988, Quantities and Procedures for Description and Measurement of Environmental Sound, Part 1 (New York, 1988).

AR 200-1, Environmental Protection and Enhancement, Chapter 7, Environmental Noise Abatement Program (Headquarters, Department of the Army, Washington, D.C., 15 June 1982).

Averbuch, Aaron, et al., True-Integrating Environmental Noise Monitor and Sound-Exposure Level Meter, Vol I-IV, Technical Report TR N-41/ADA060958/ADA072002/ADA083320/ADA083321 (USACERL, May 1978, June 1979, March 1980).

Guidelines for Preparing Environmental Impact Statements on Noise, Report of Working Group 69, Committee on Hearing, Bioacoustics and Biomechanics, Assembly of Behavioral and Social Sciences, The National Research Council (National Academy of Science, Washington, DC, 1977).

International Standard ISO 532b, Method for Calculating Loudness Level (ISO, 1975).

Kling, J.W., and Lorran A. Riggs, Woodworth and Schlosberg's Experimental Psychology, 3d ed., Chapter 2, "Psychophysics" (Holt Rinehart and Winston, Inc., 1972).

Molino, John A., Should Helicopter Noise Be Measured Differently From Other Aircraft Noise? - A Review of Psychoacoustic Literature, NASA Contractor Report 3609 (NASA, November 1982).

Ollerhead, J.B., Laboratory Studies of Scales for Measuring Helicopter Noise, NASA Contractor Report 3610, (NASA, November 1982).

Protective Noise Levels; Condensed Version of EPA Levels Document, EPA 550/9-79-100 (EPA, Office of Noise Abatement and Control, November 1978).

Schomer, Paul D., and Robert D. Neathammer, "The Role of Helicopter Noise-Induced Vibration and Rattle in Human Response," Journal of the Acoustical Society of America, Vol 81, No. 4 (April 1987), pp 966-976.

Schomer, Paul D., and Robert D. Neathammer, The Role of Vibration and Rattle in Human Response to Helicopter Noise, TR N-85/14 (USACERL, September 1985).

Zwicker, E., "Meaningful Noise Measurement and Effective Noise Reduction," Noise Control Engineering Journal, Vol 29, No. 3 (1987), pp 66-76. 
APPENDIX A

PLOTS OF MCAS TUSTIN INDOOR TEST DATA ARRANGED BY HELICOPTER IN ASCENDING ORDER OF CONTROL SEL

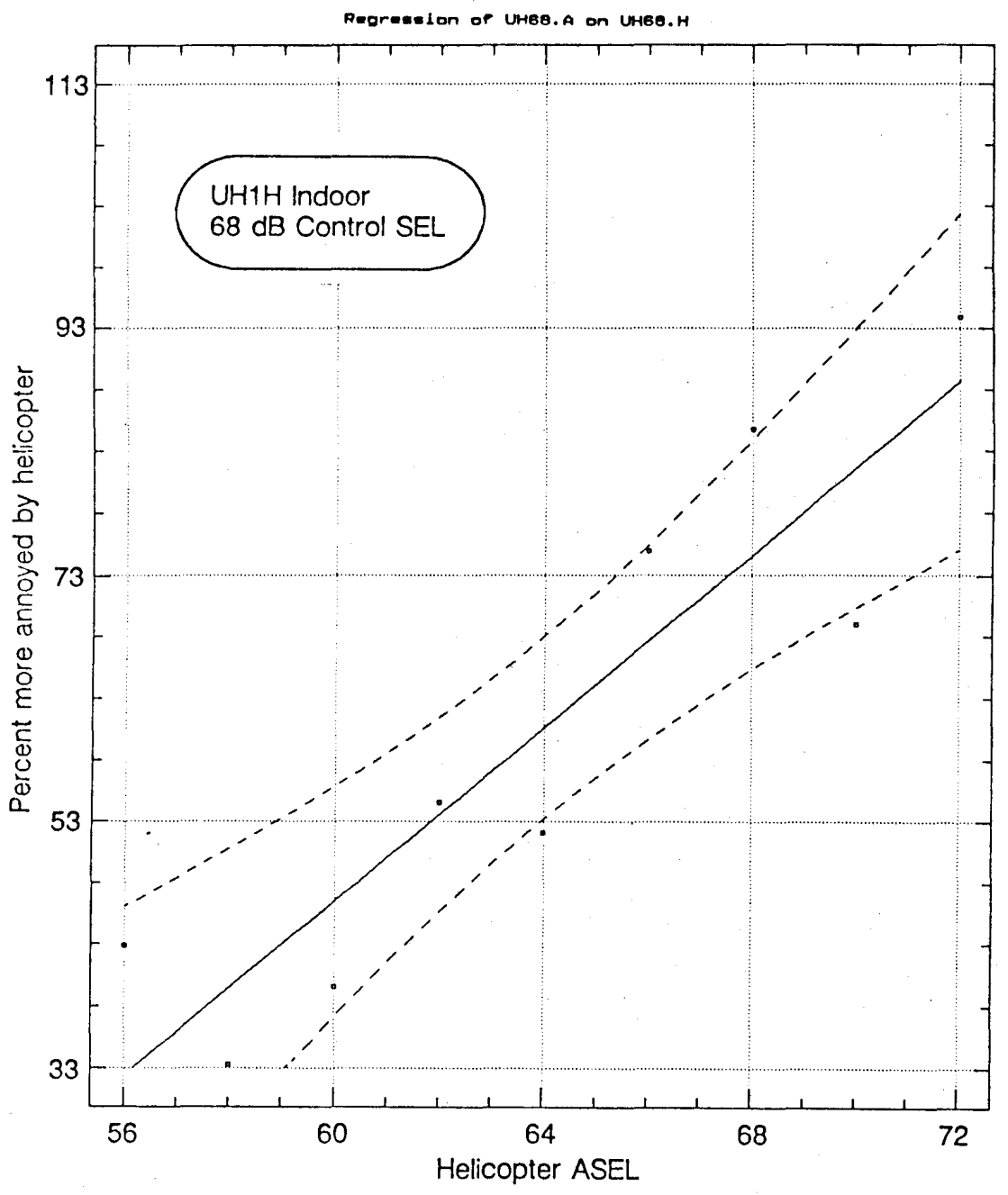


Regreseion of UH72.A on UH72.H

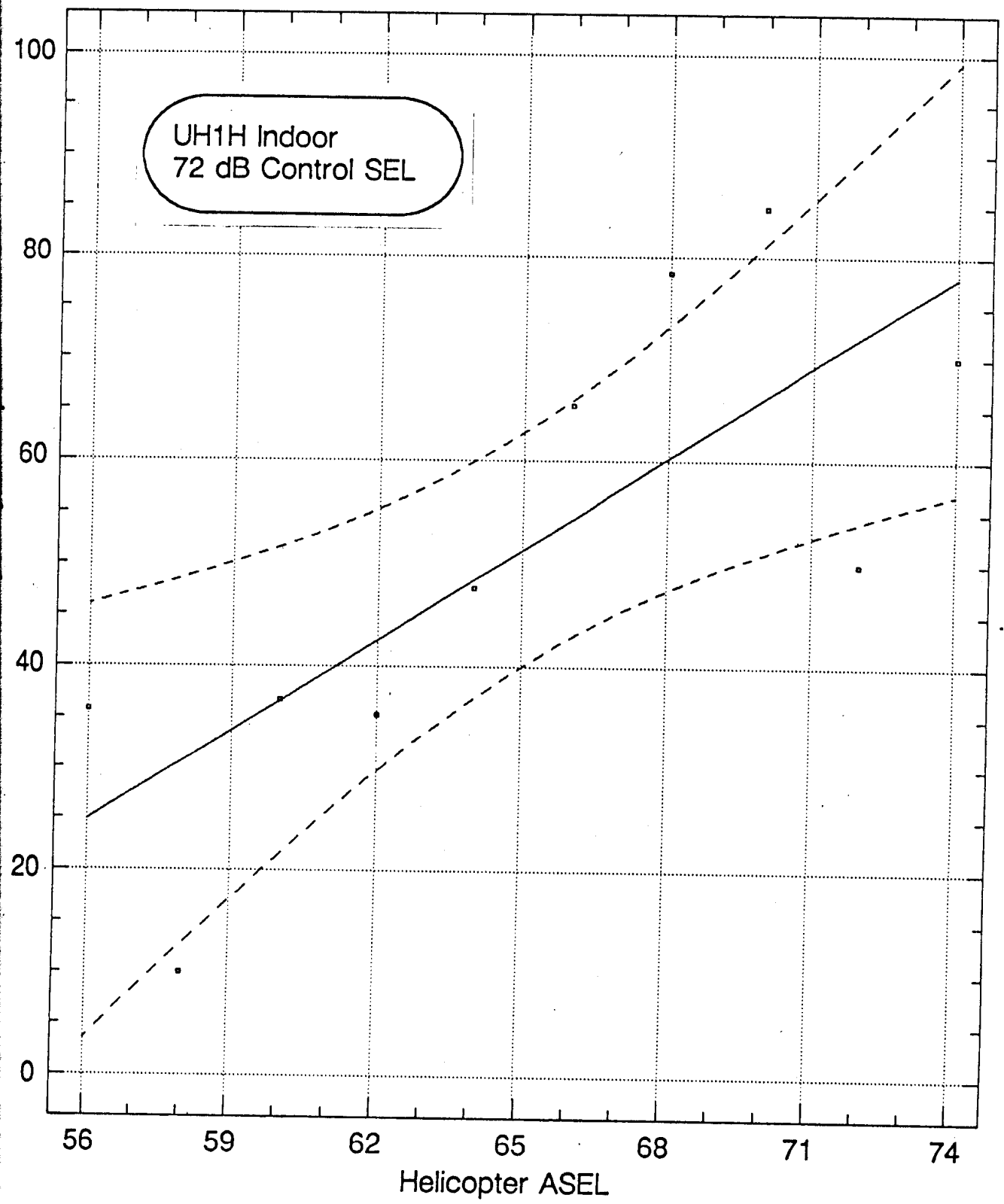


Regression of UH80.A on UH80.H

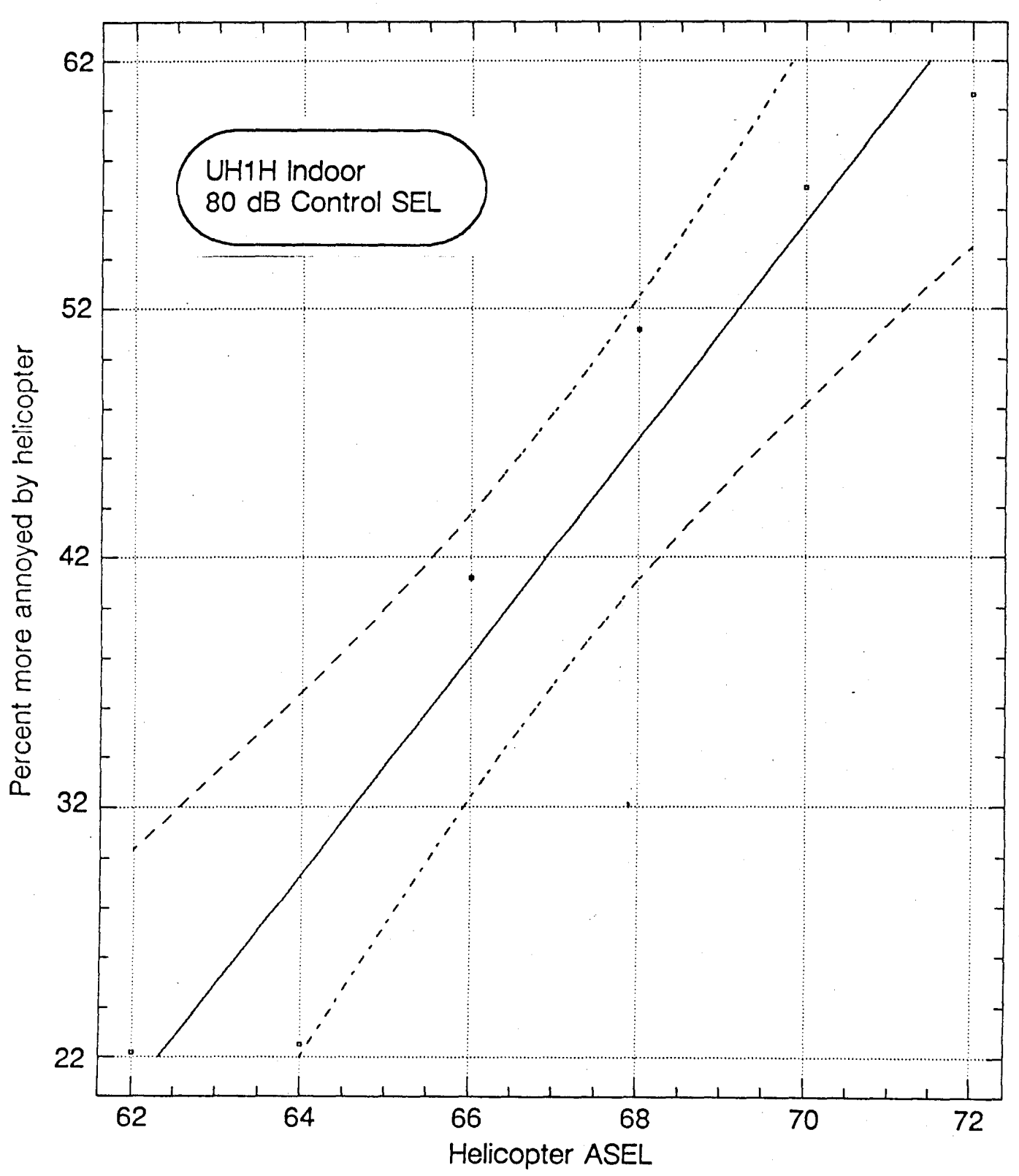

c 

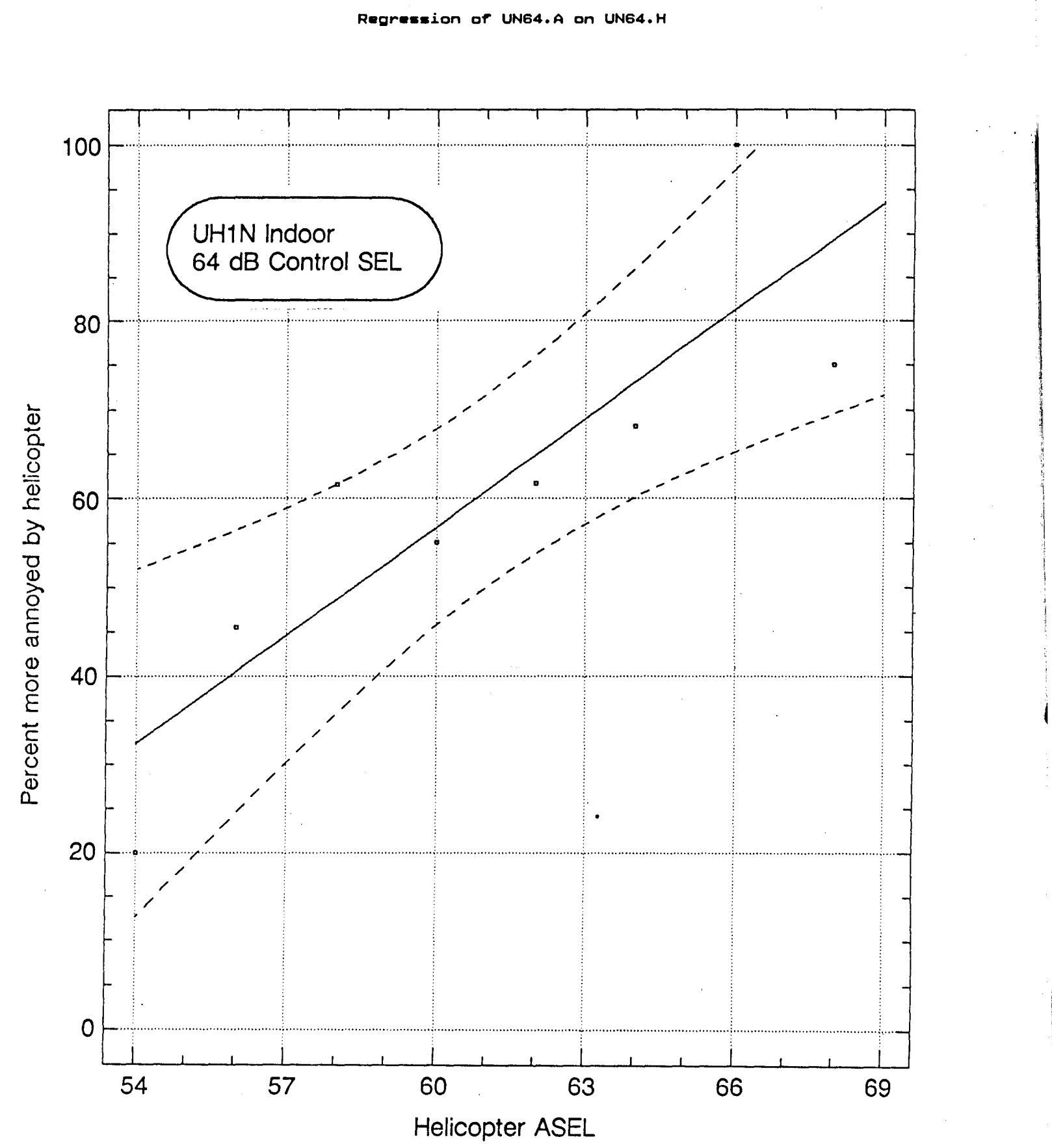


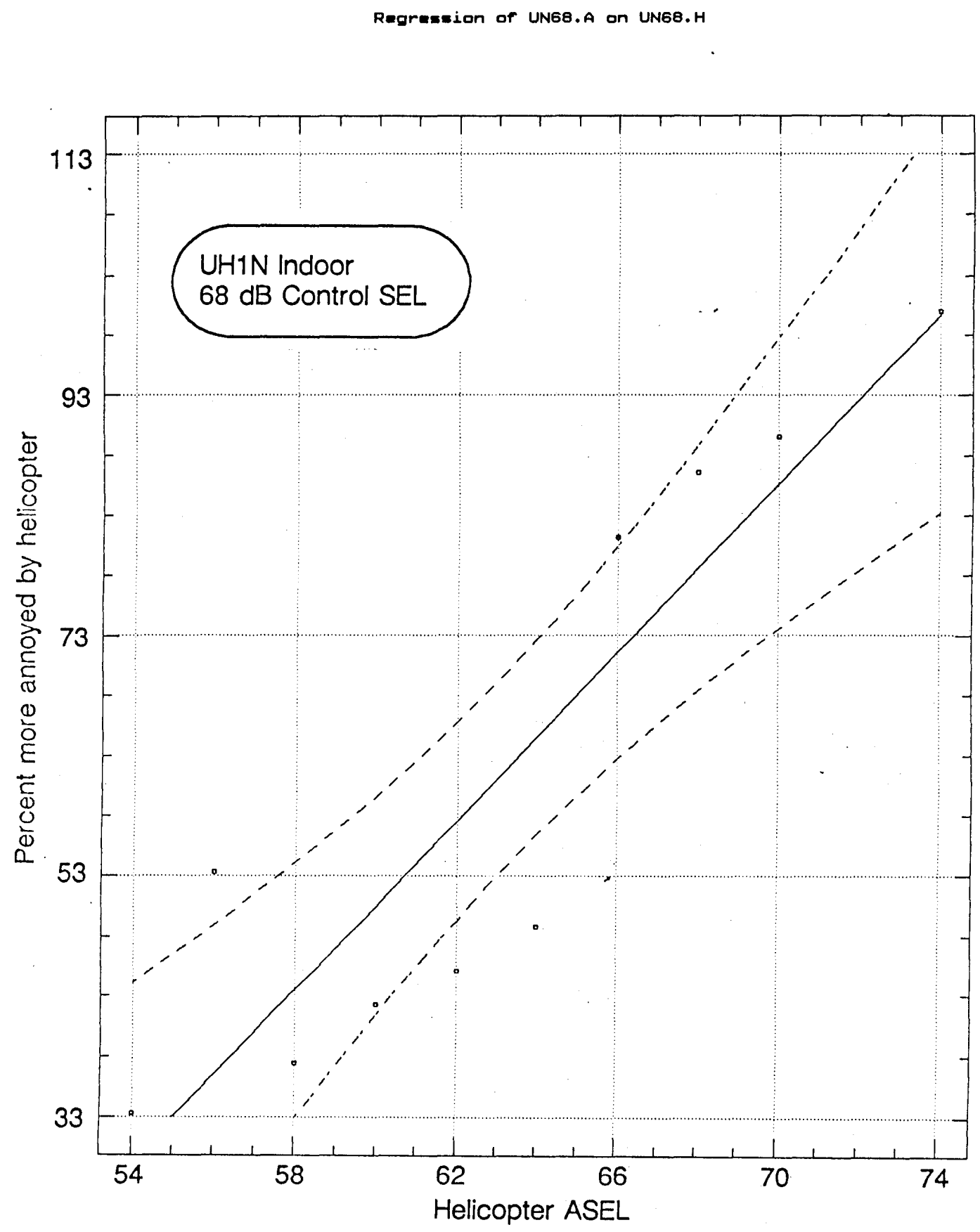

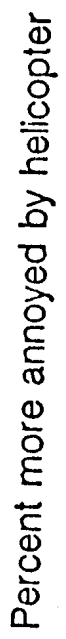


Regreseion of UN72.A on UN72.H

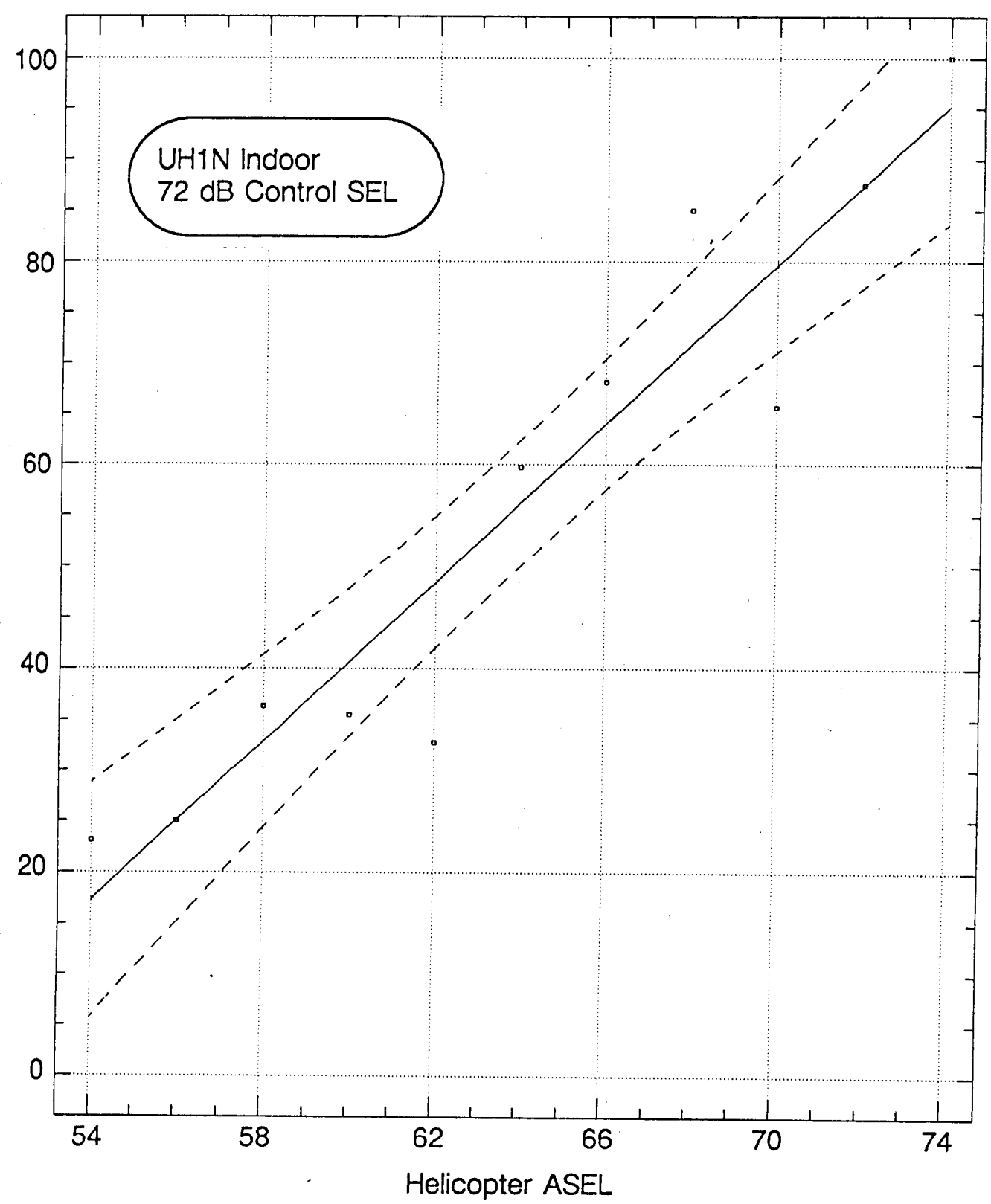

37 
Regression of UN76.A on UN76.H

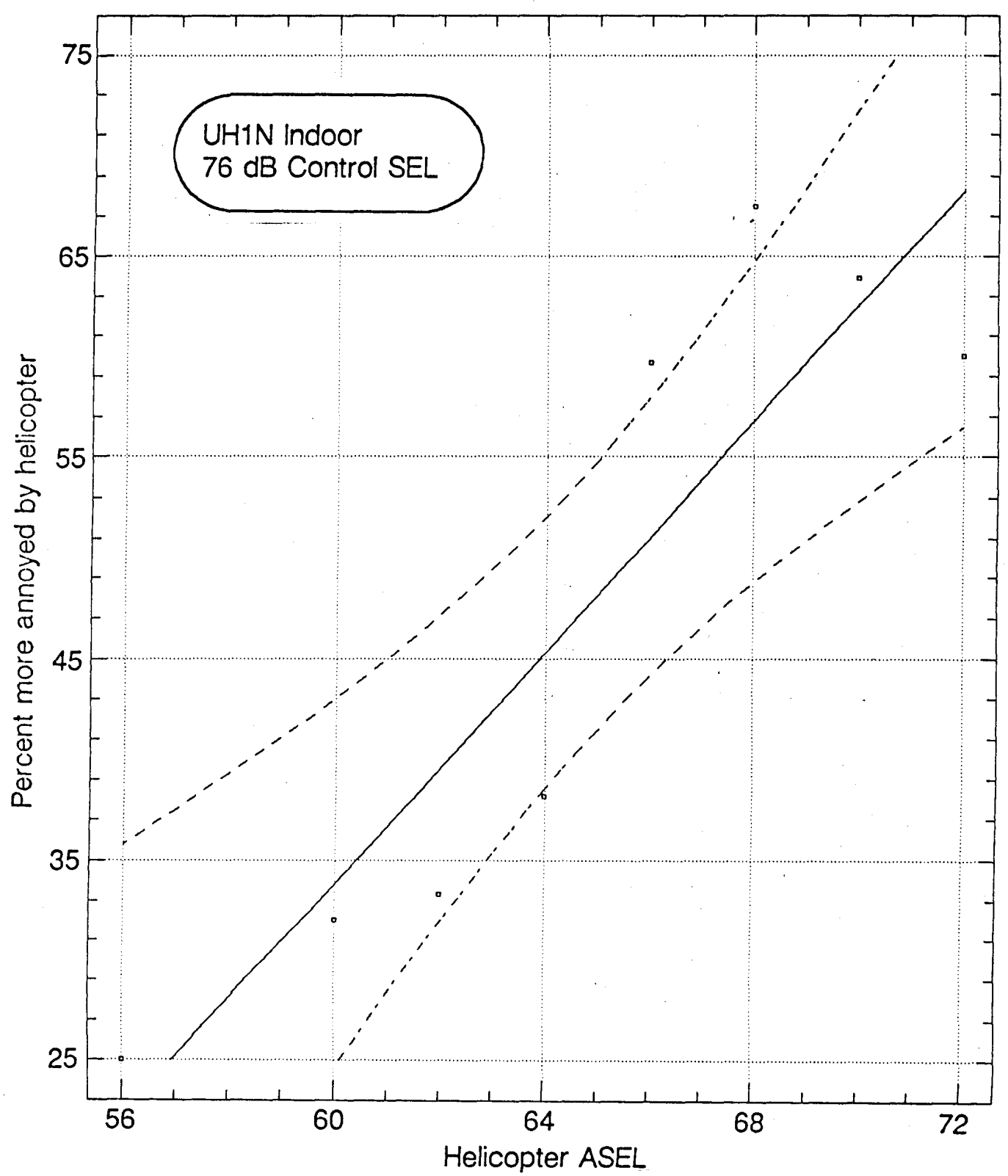


Regression of UNBO.A on UNBO.H

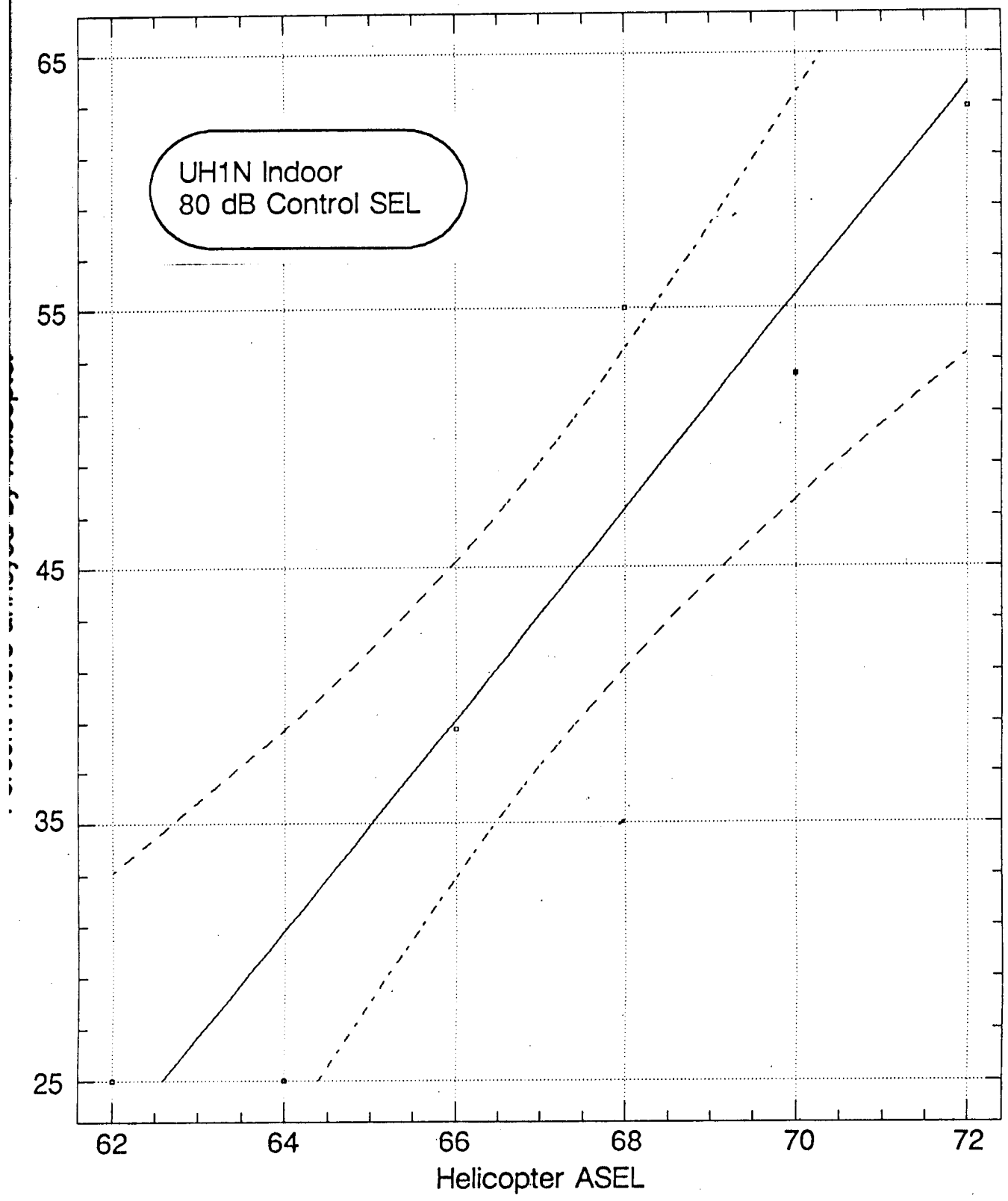


Regression of AH68.A on AH68.H

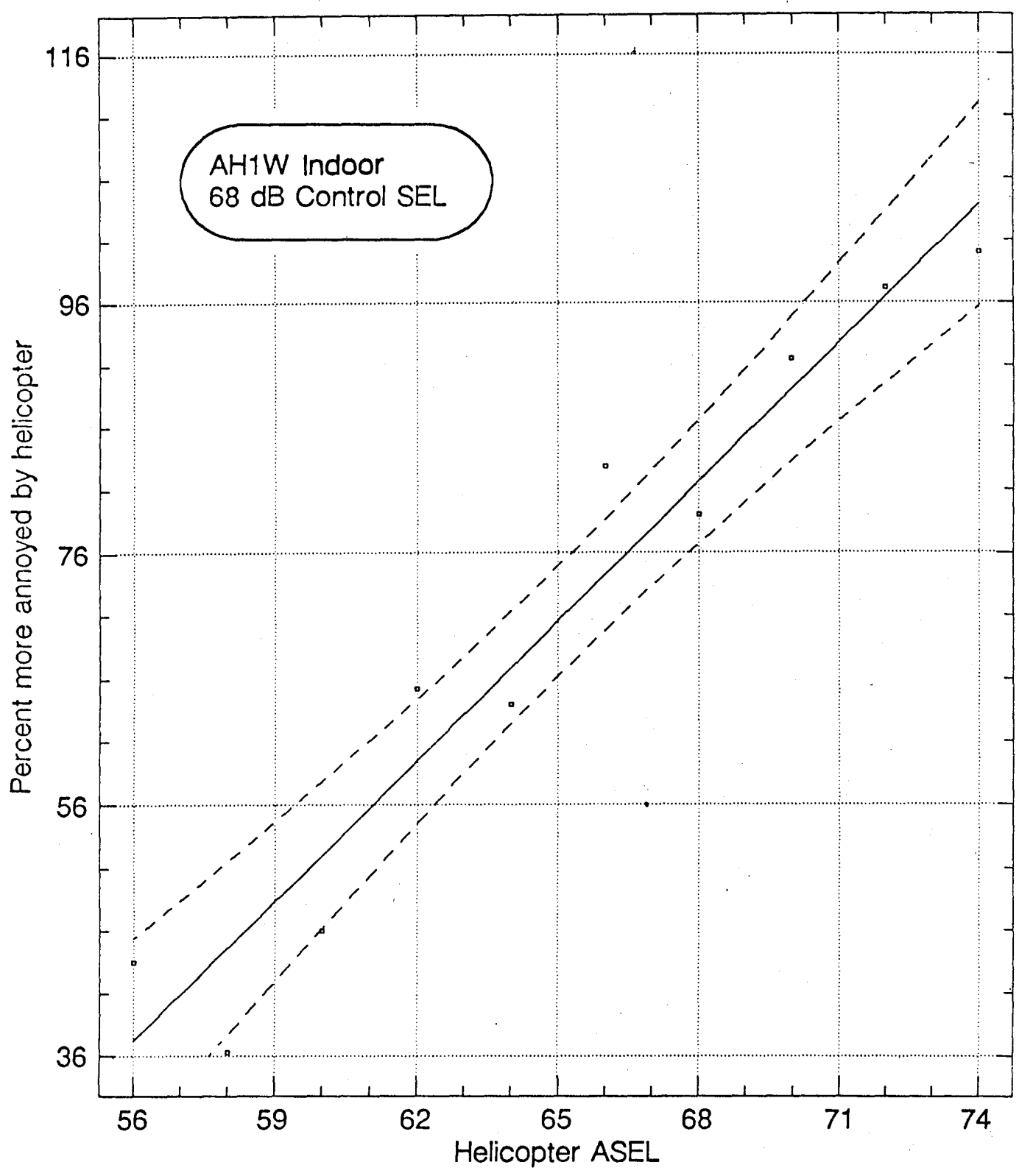


Regression of AH76.A on AH76.H

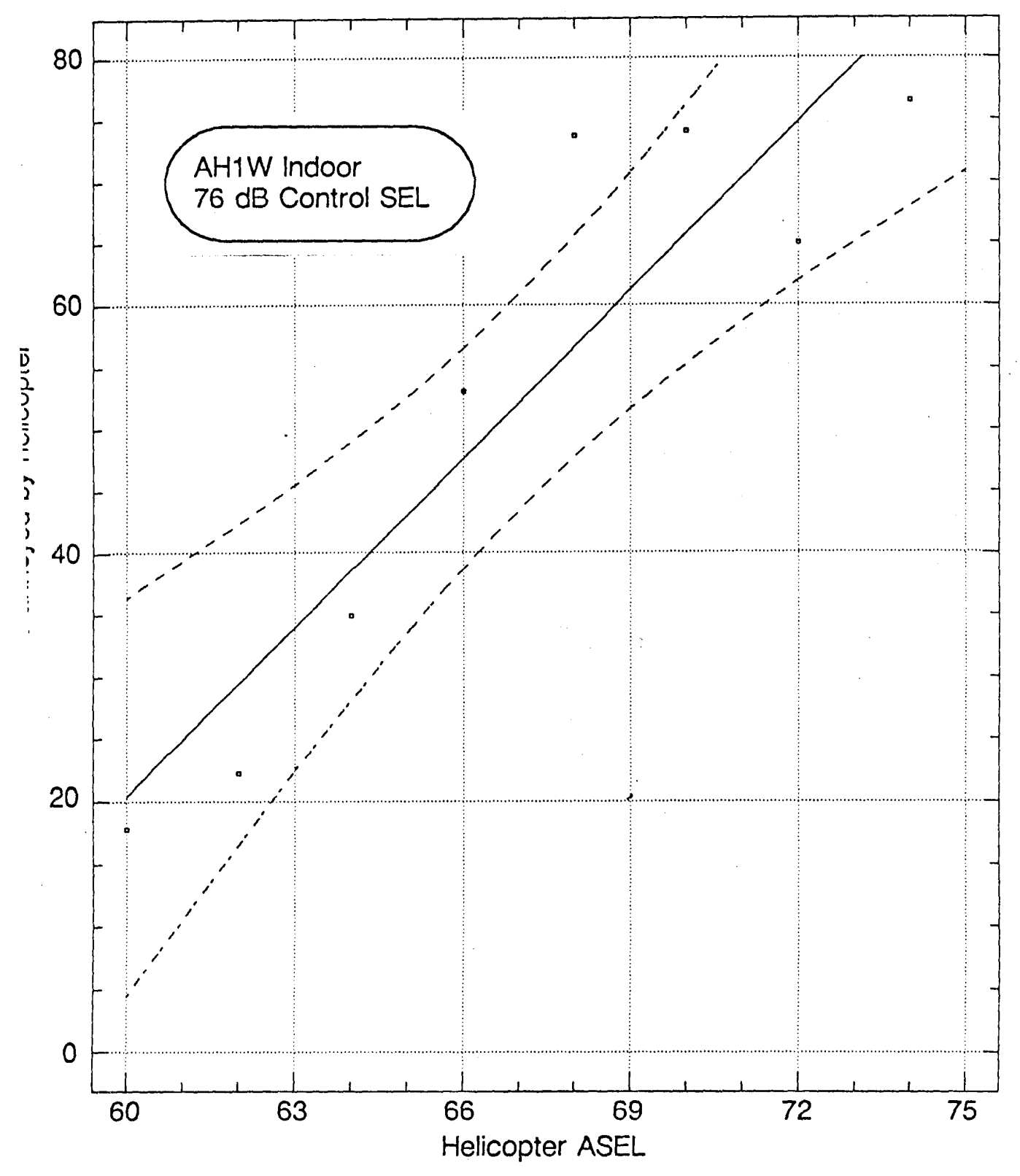

41 
Regreseion of AHBO.A on AHBO.H

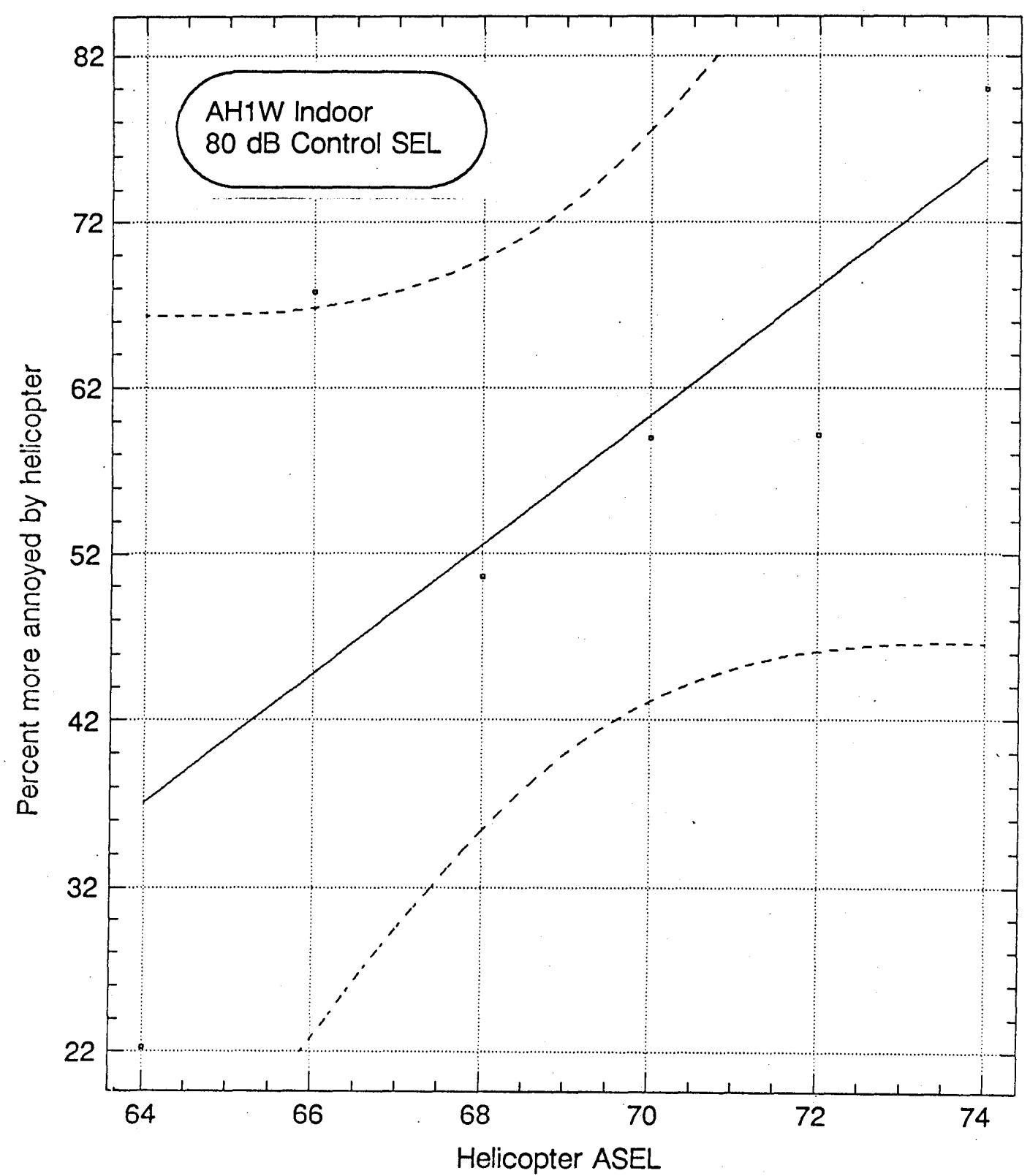


Regression of AHB4.A on AHB4.H

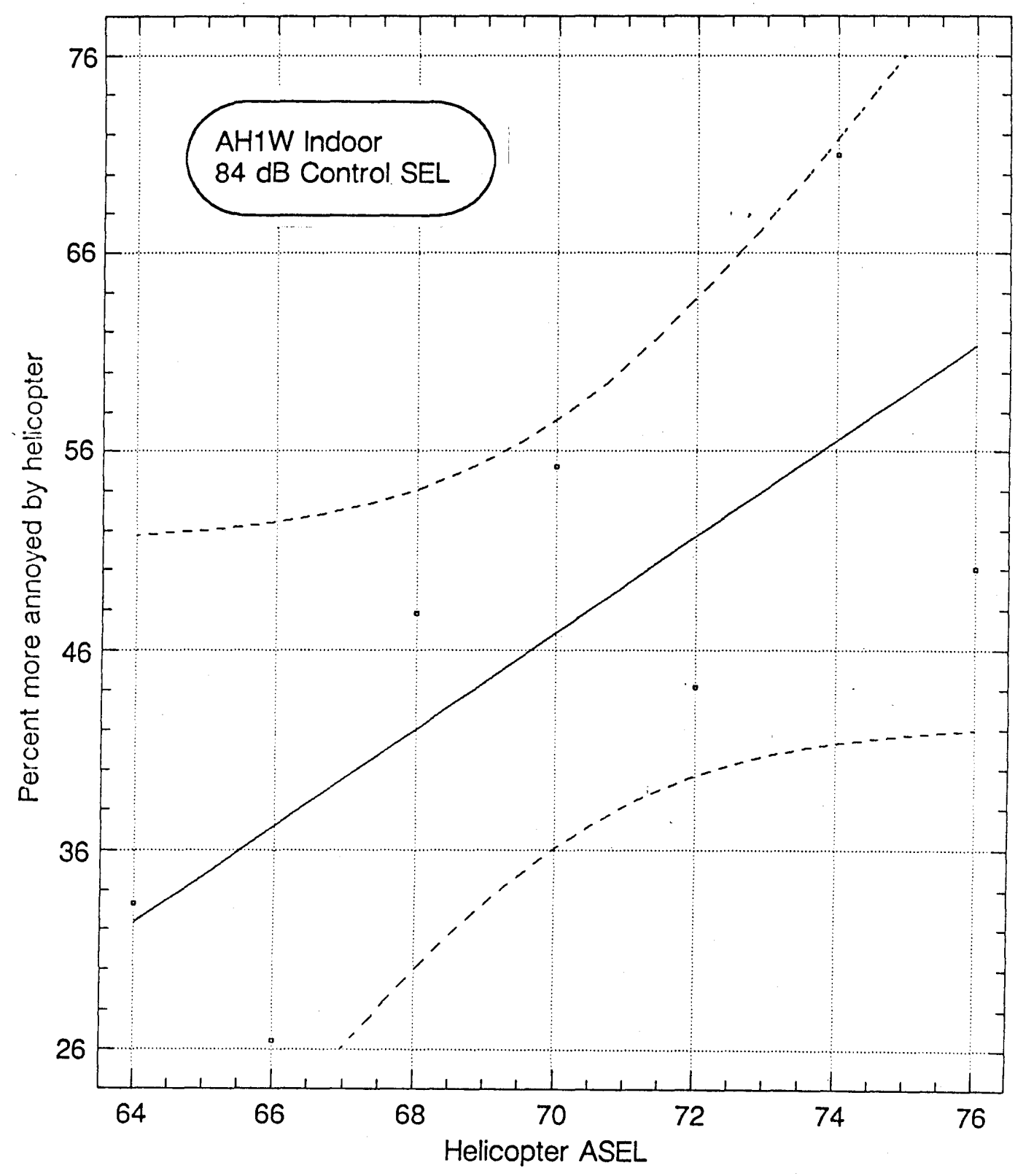


Regremeion of A5360.A on A5360.H

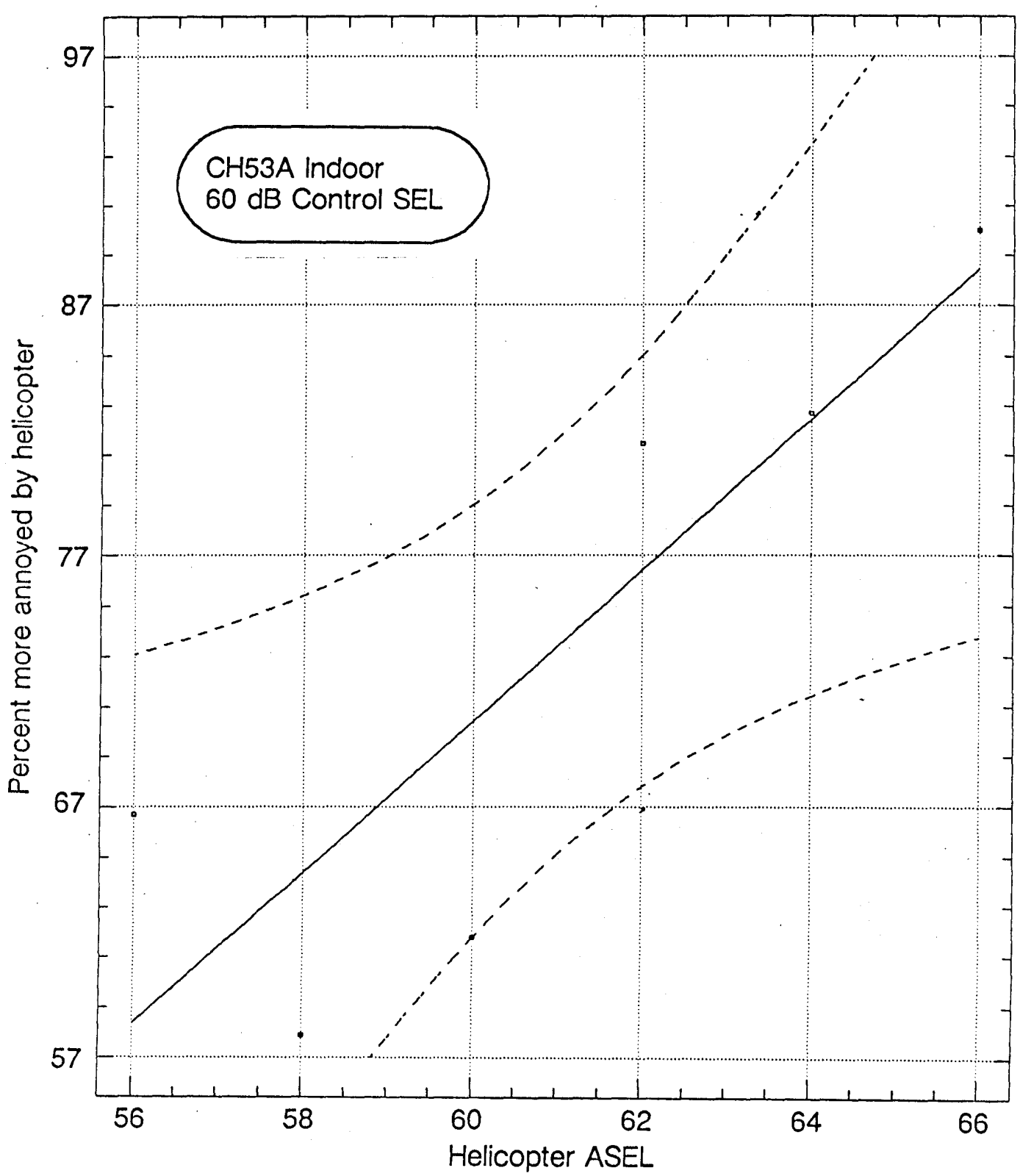




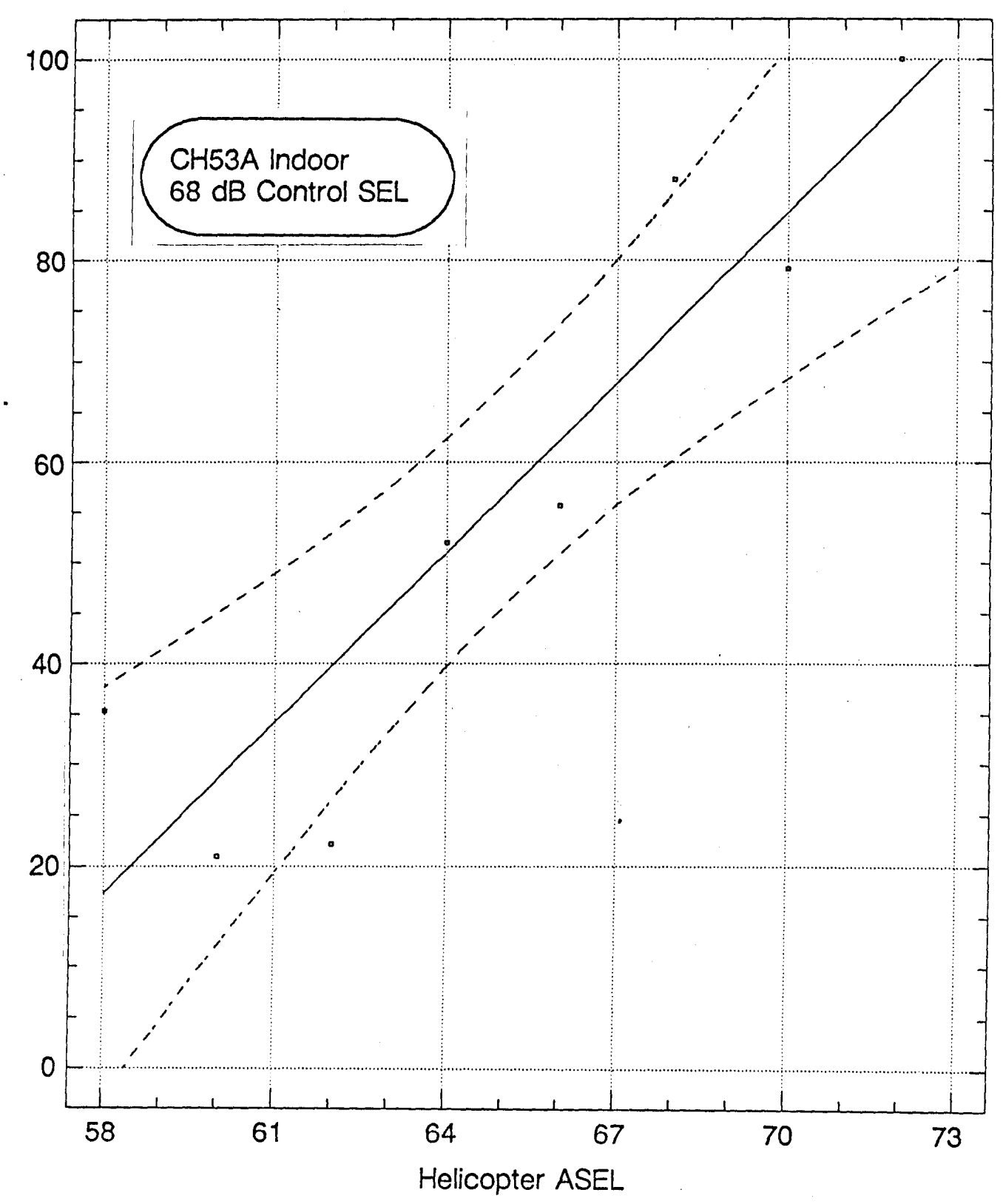




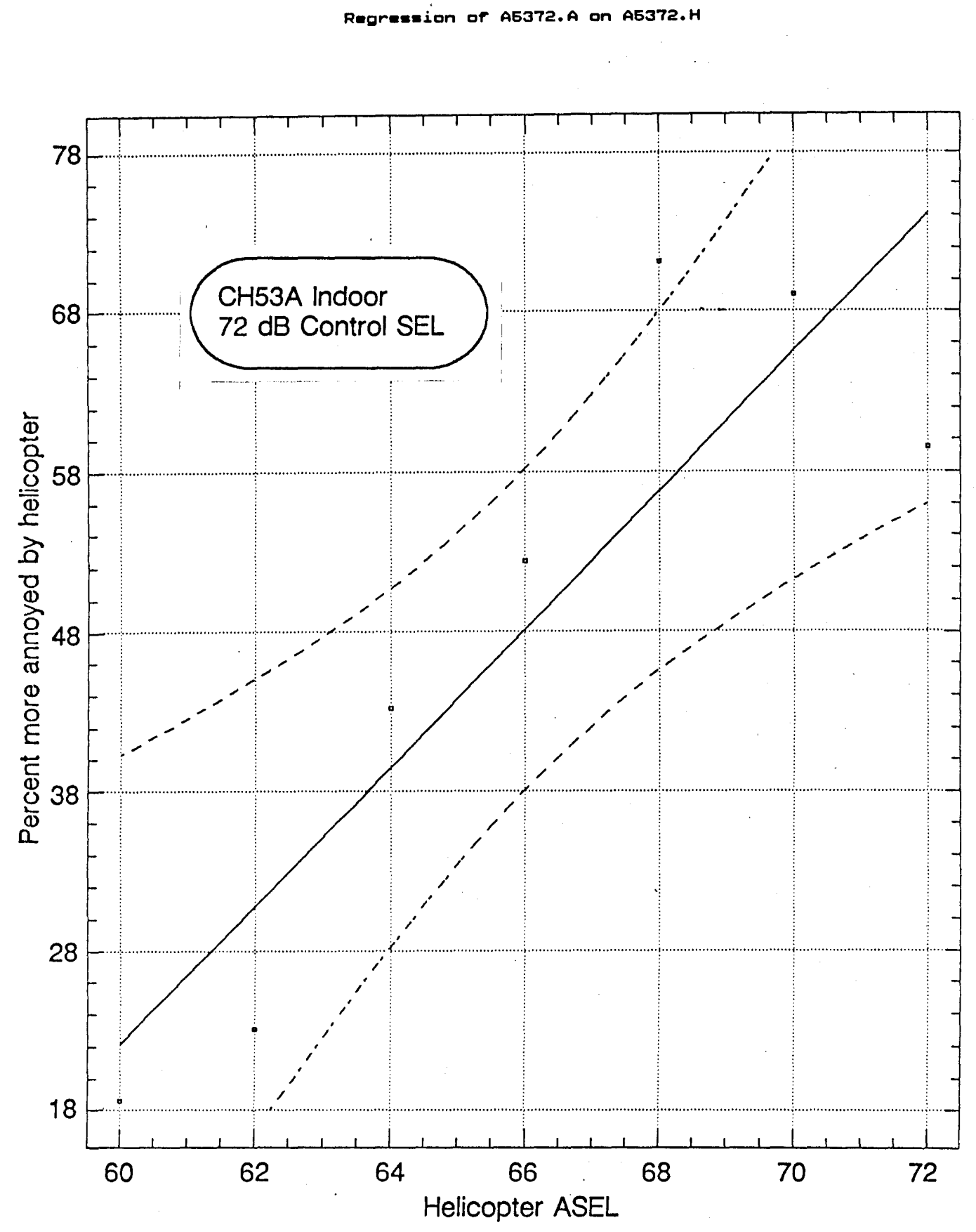

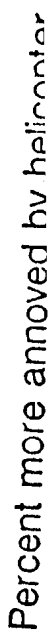


Regreseion of A5380.A on A5380.H

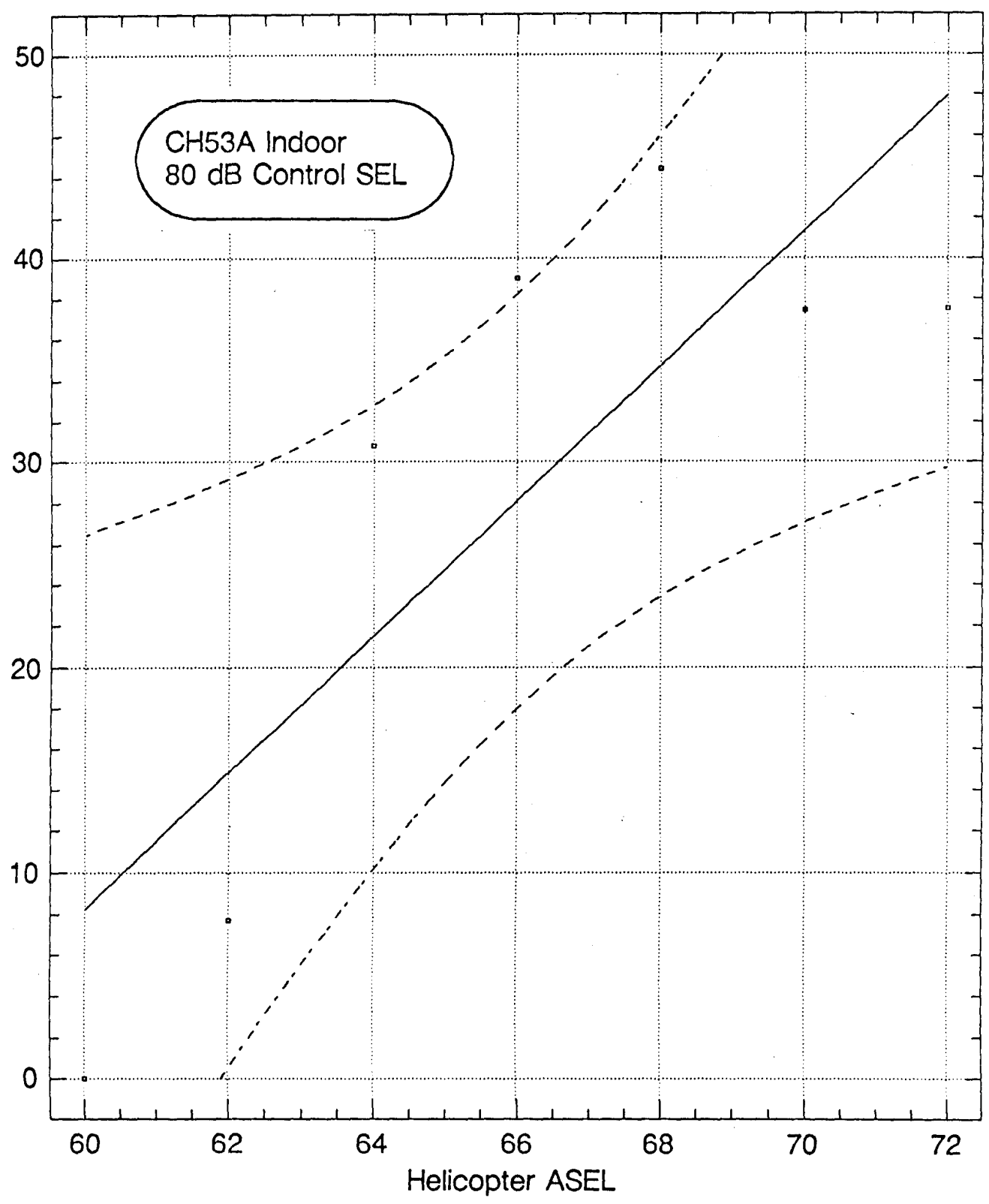

47 


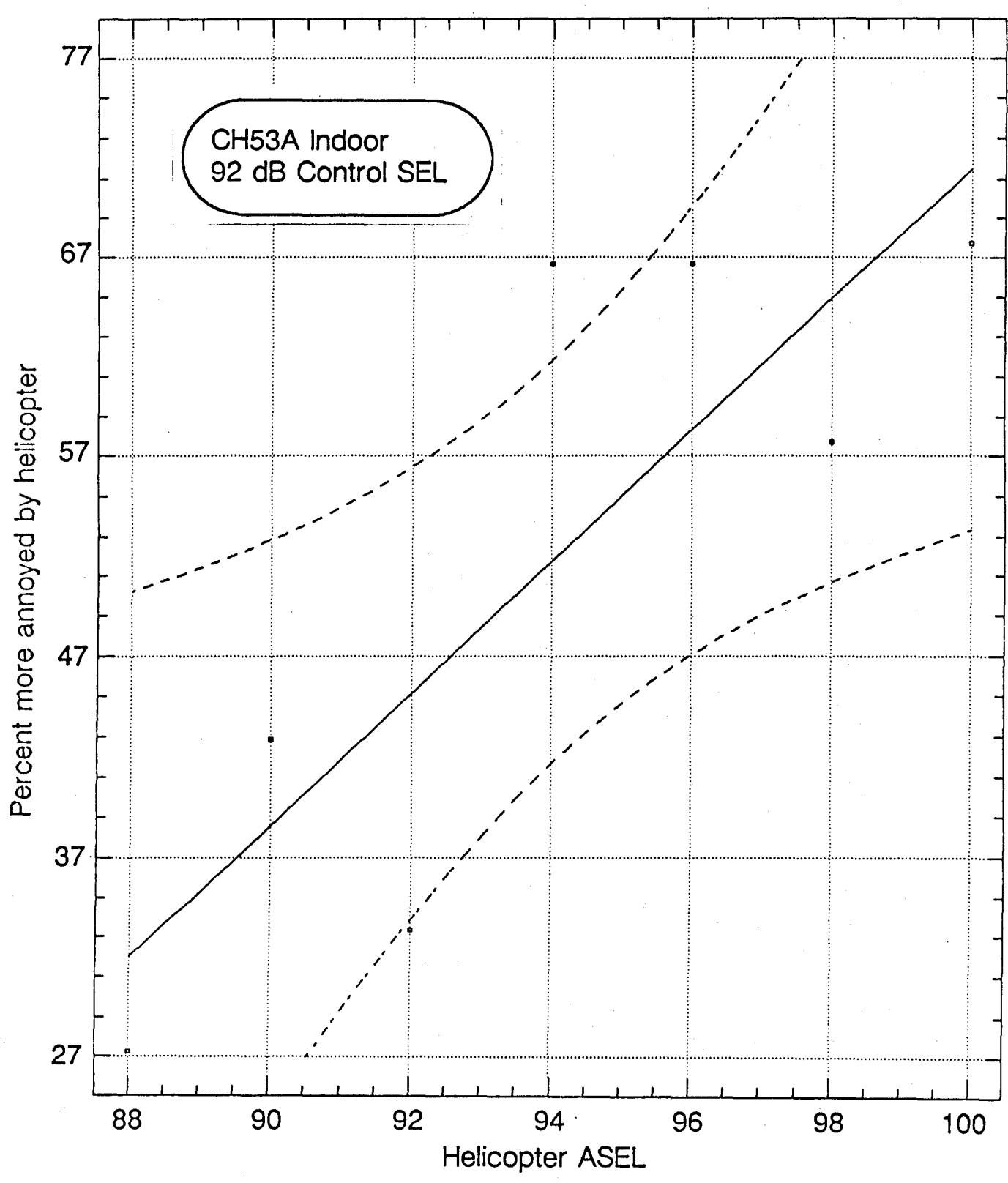

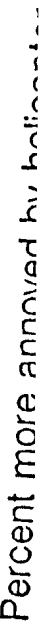


Regreseion of E6376.A on E6376.H

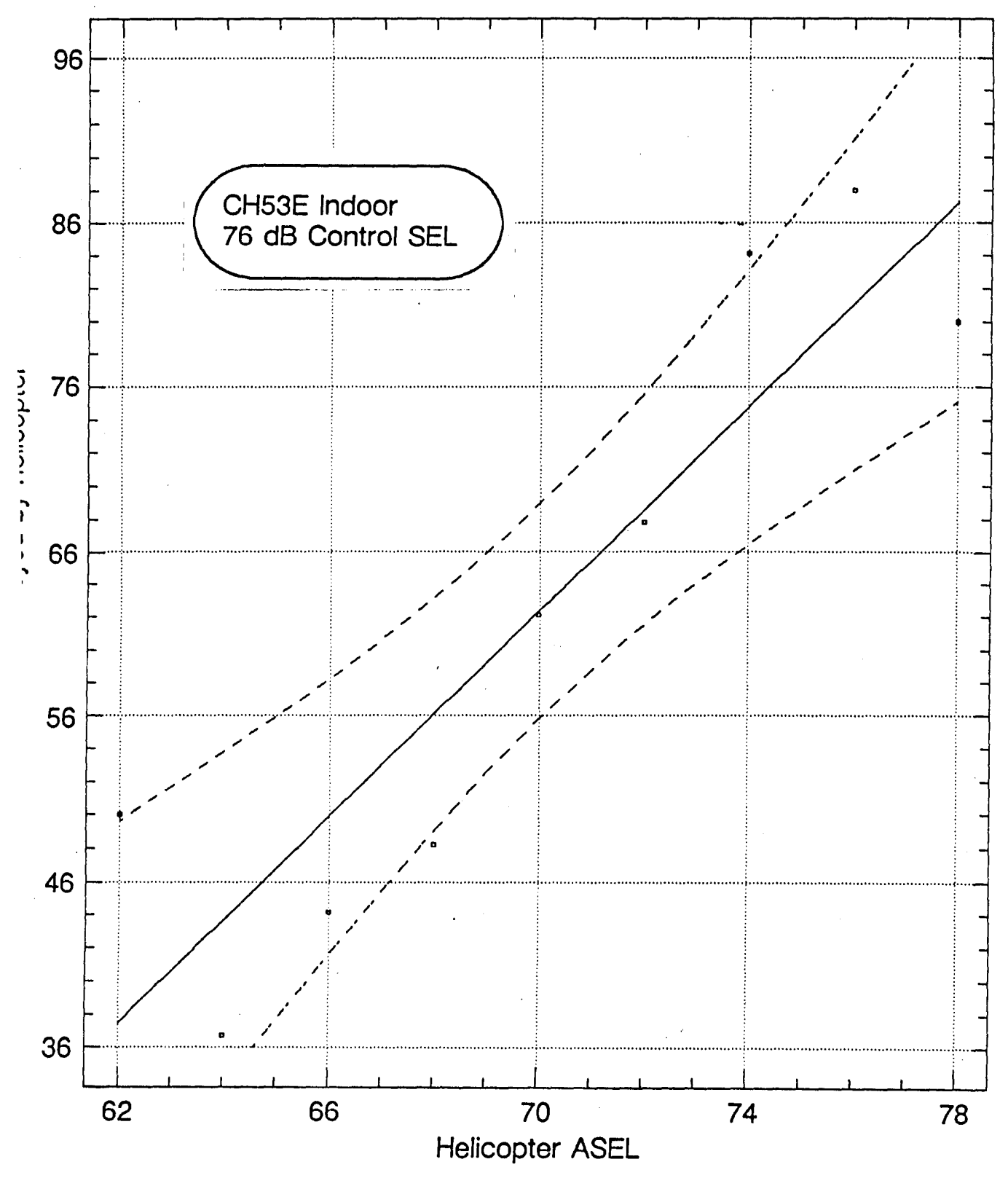


Regreseion of E6380.A on E6380.H

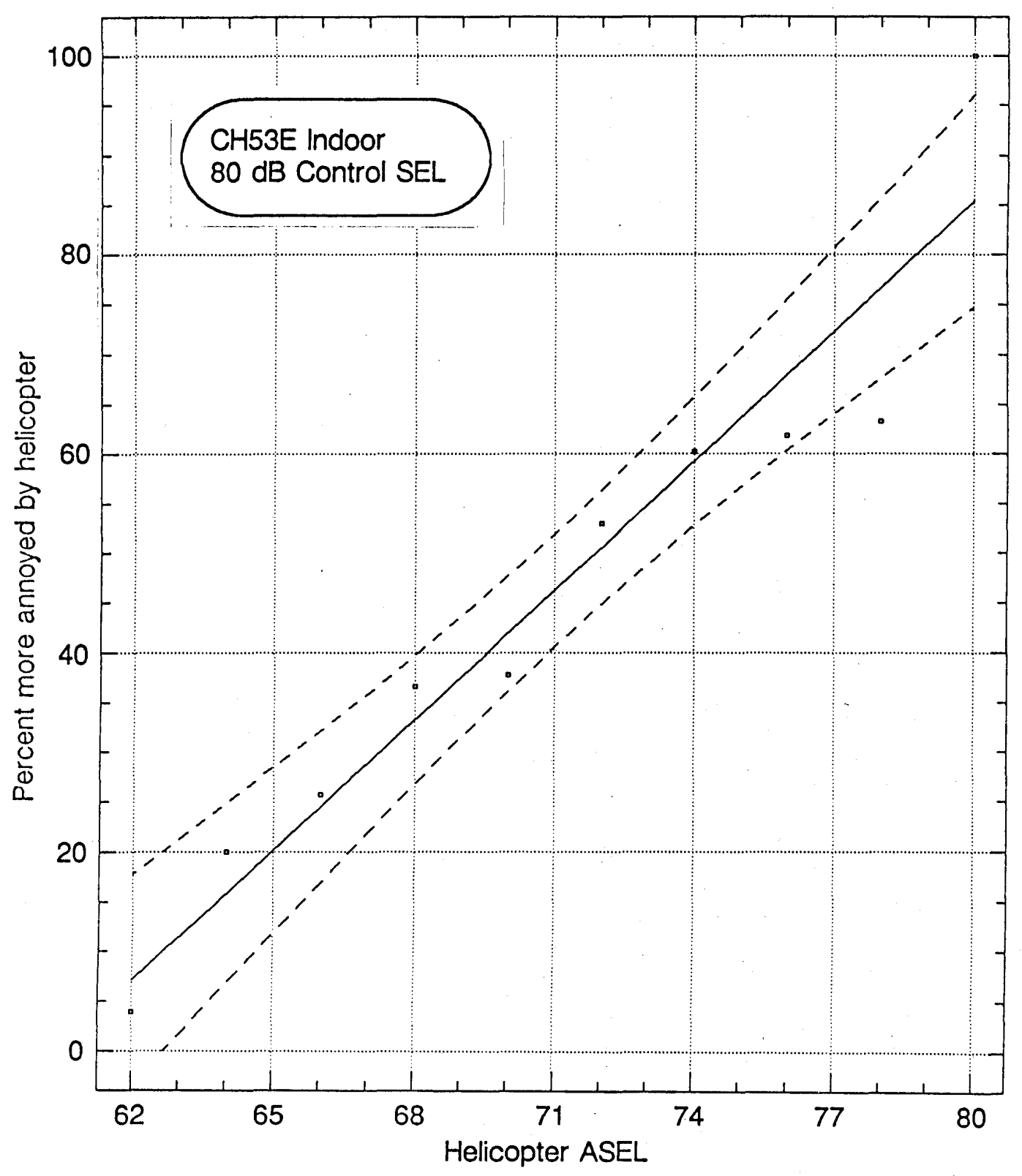

$:$
$\vdots$
$\vdots$
$\vdots$
$\vdots$
$c$
$\vdots$
$\vdots$
$\vdots$
0
0
$\vdots$
$\vdots$
0 
Regreseion of E5392.A on E5392.H

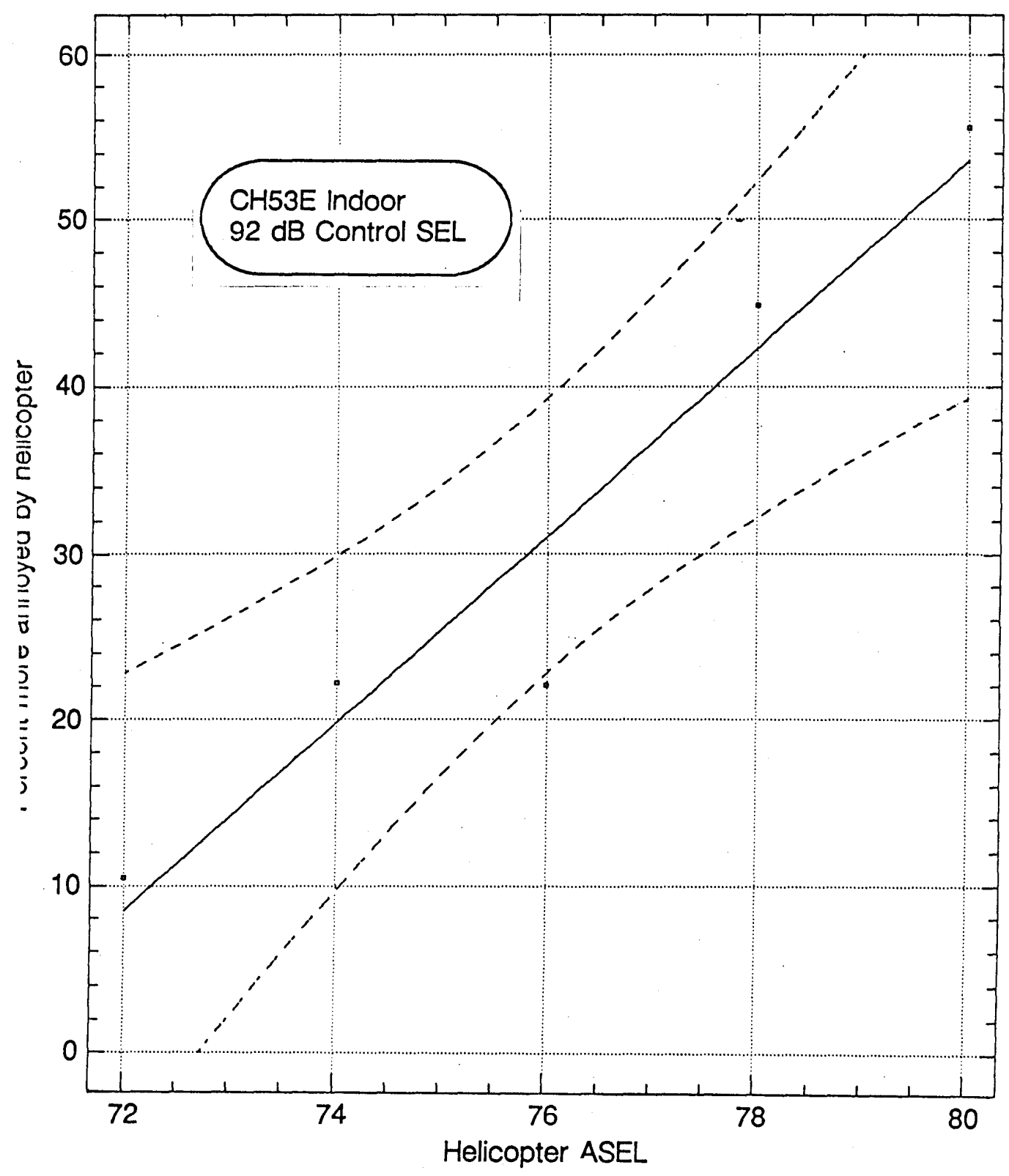


Regreseion of E4668.A on E4668.H

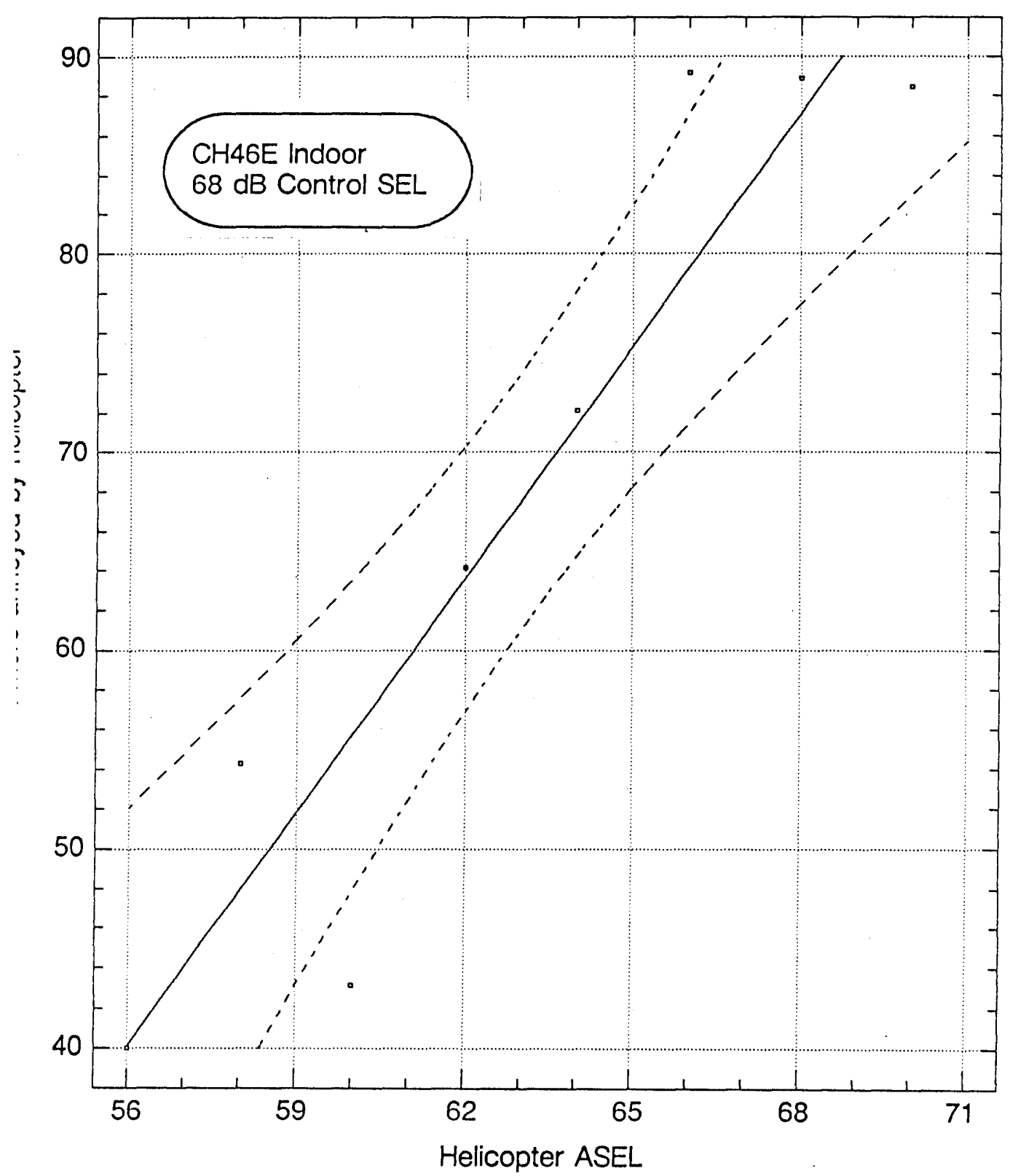


Regrexsion of E4672. A on E4672.H

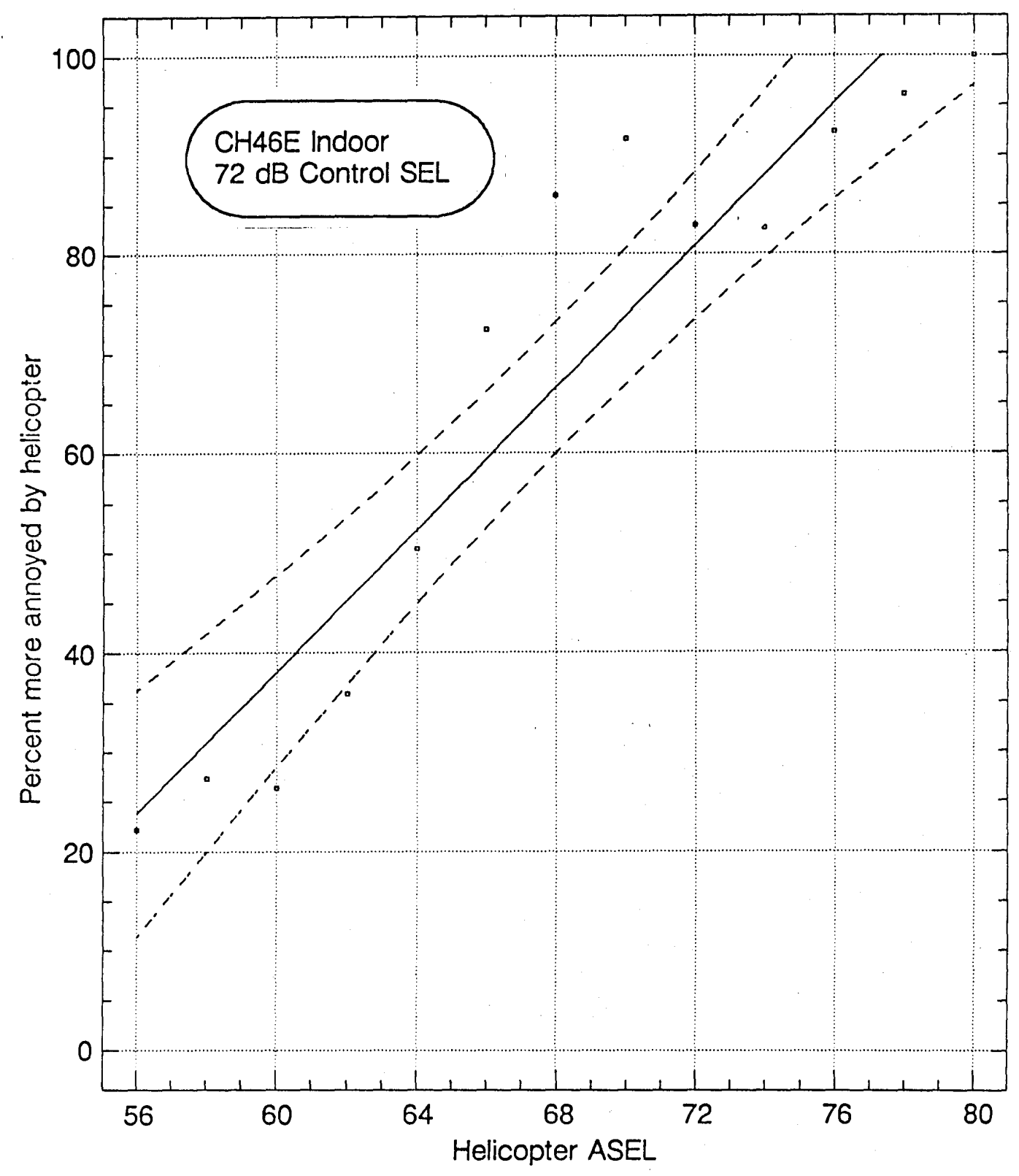


Regreseion of E4676.A on E4676.H

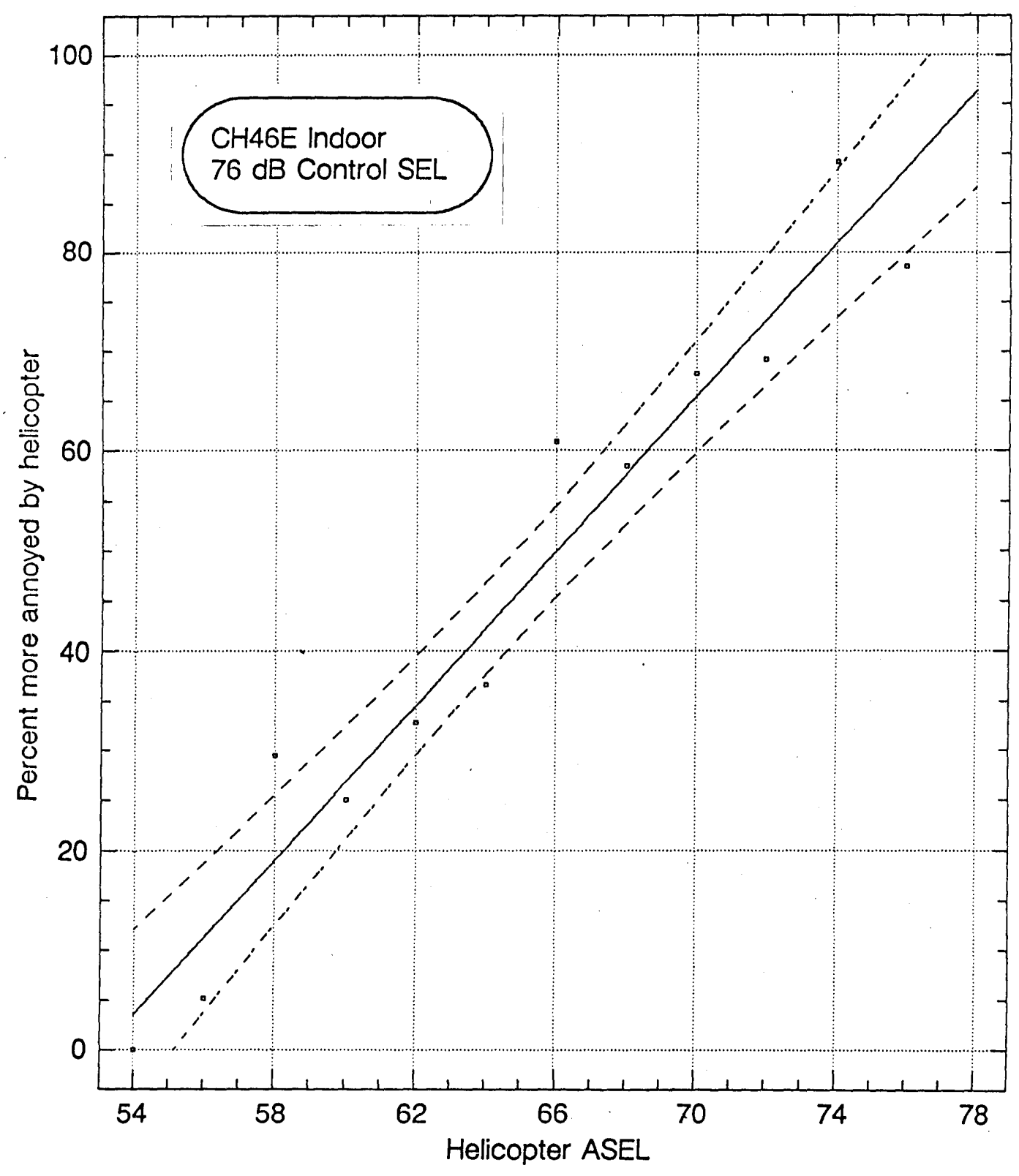


Regreasion of E4684.A on E4684.H

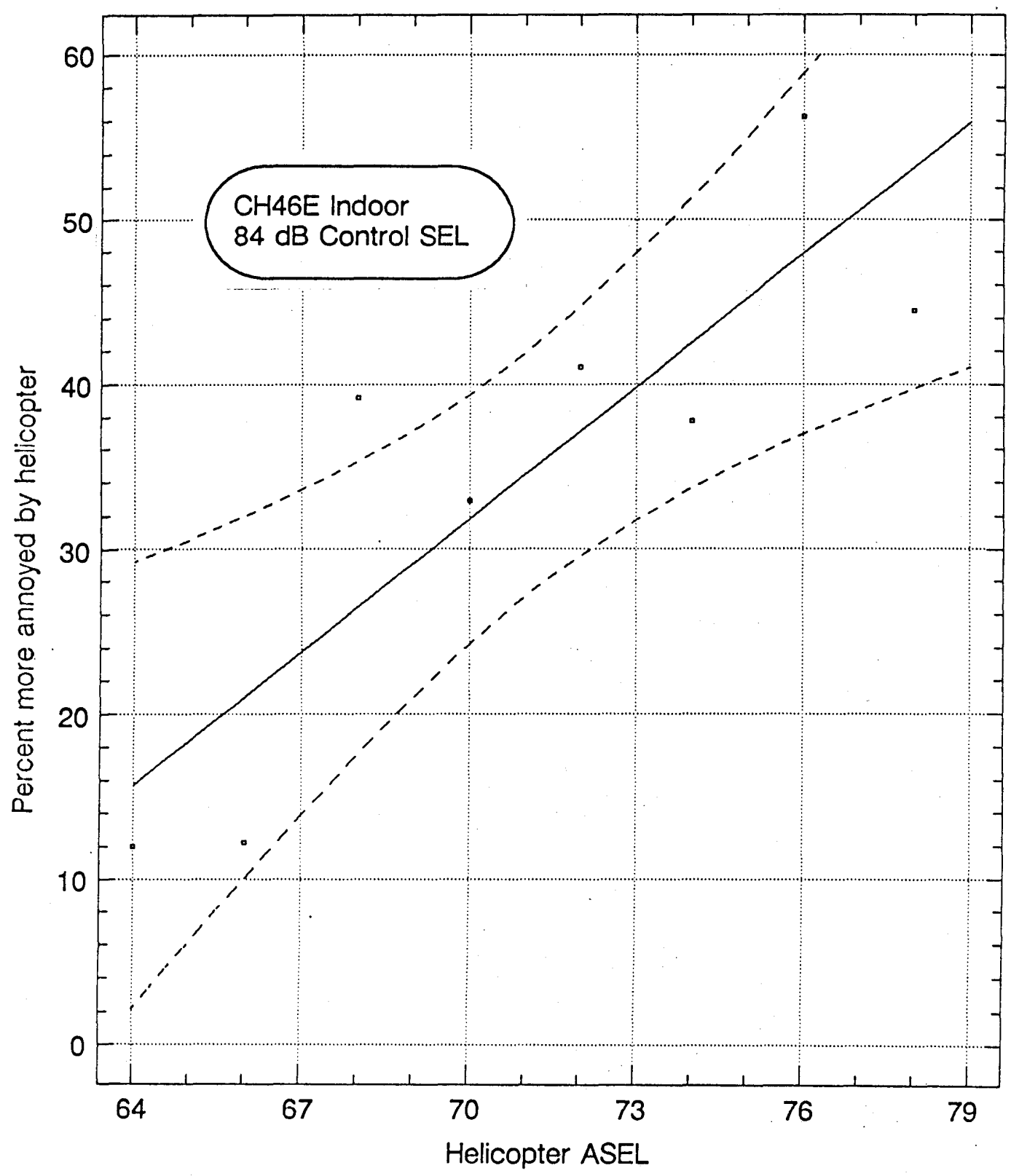


APPENDIX B

PLOTS OF MCAS TUSTIN INDOOR TEST DATA CONVERTED TO Z-SCORES ARRANGED BY HELICOPTER IN ASCENDING ORDER OF CONTROL SEL

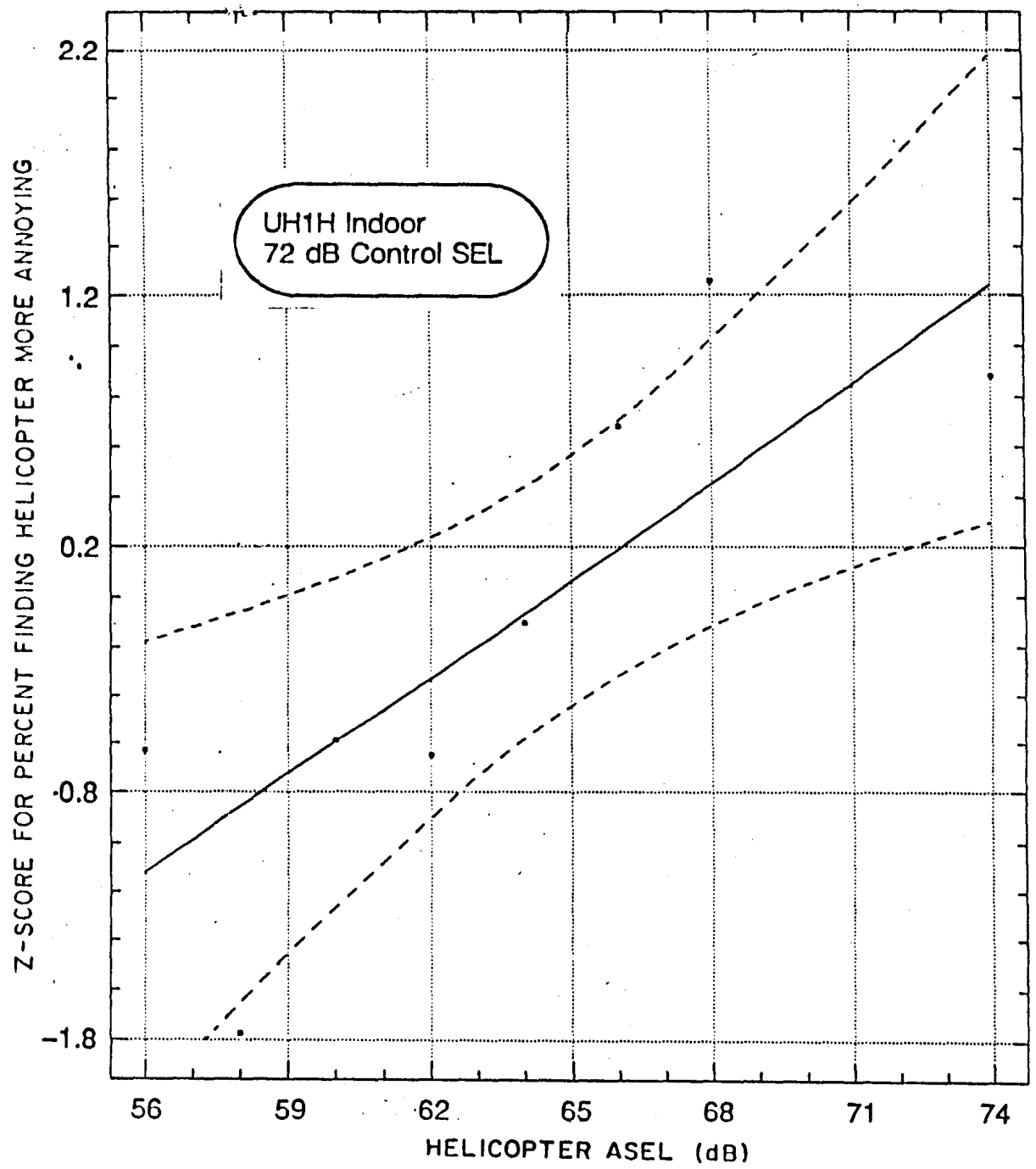




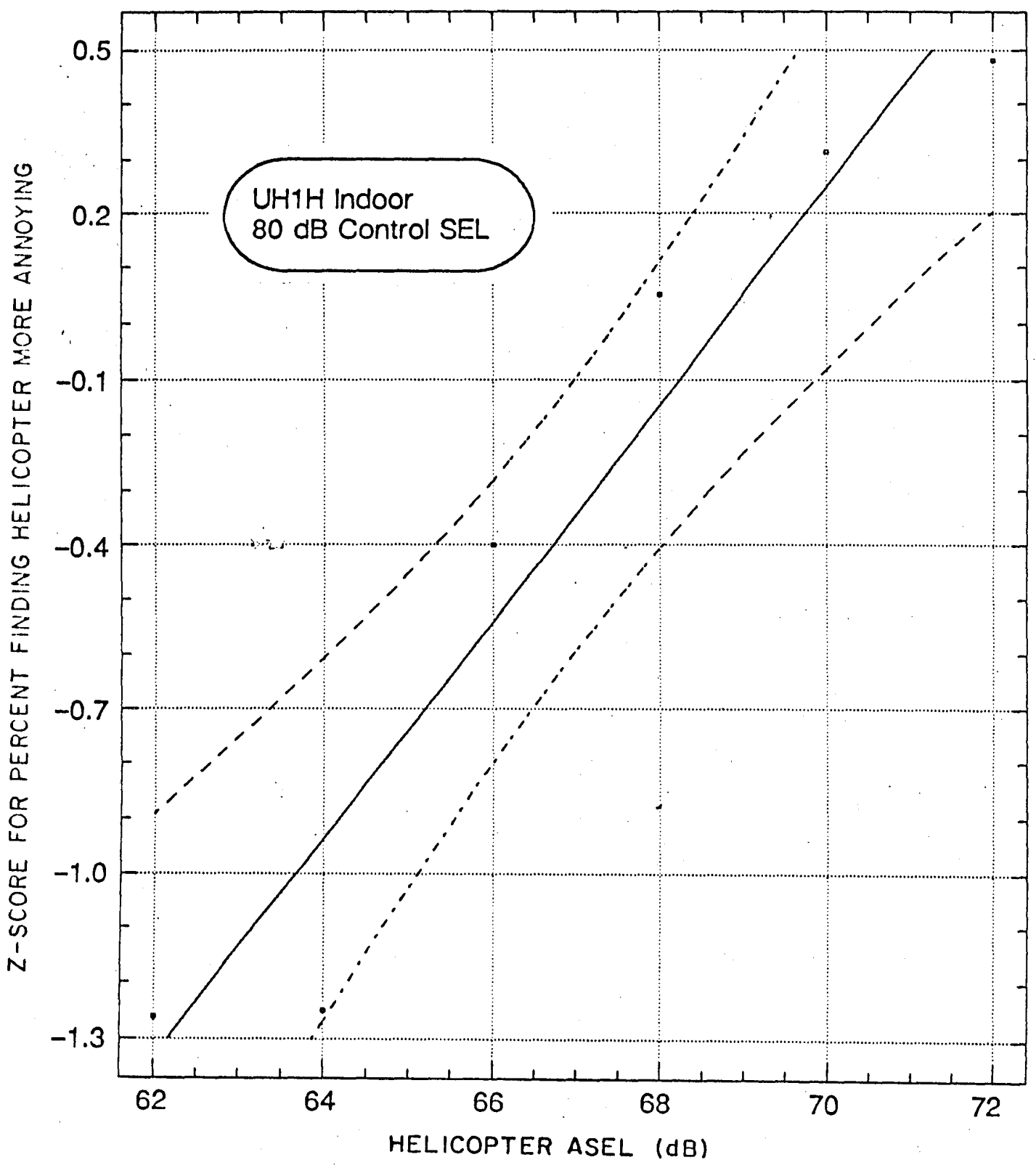

58 


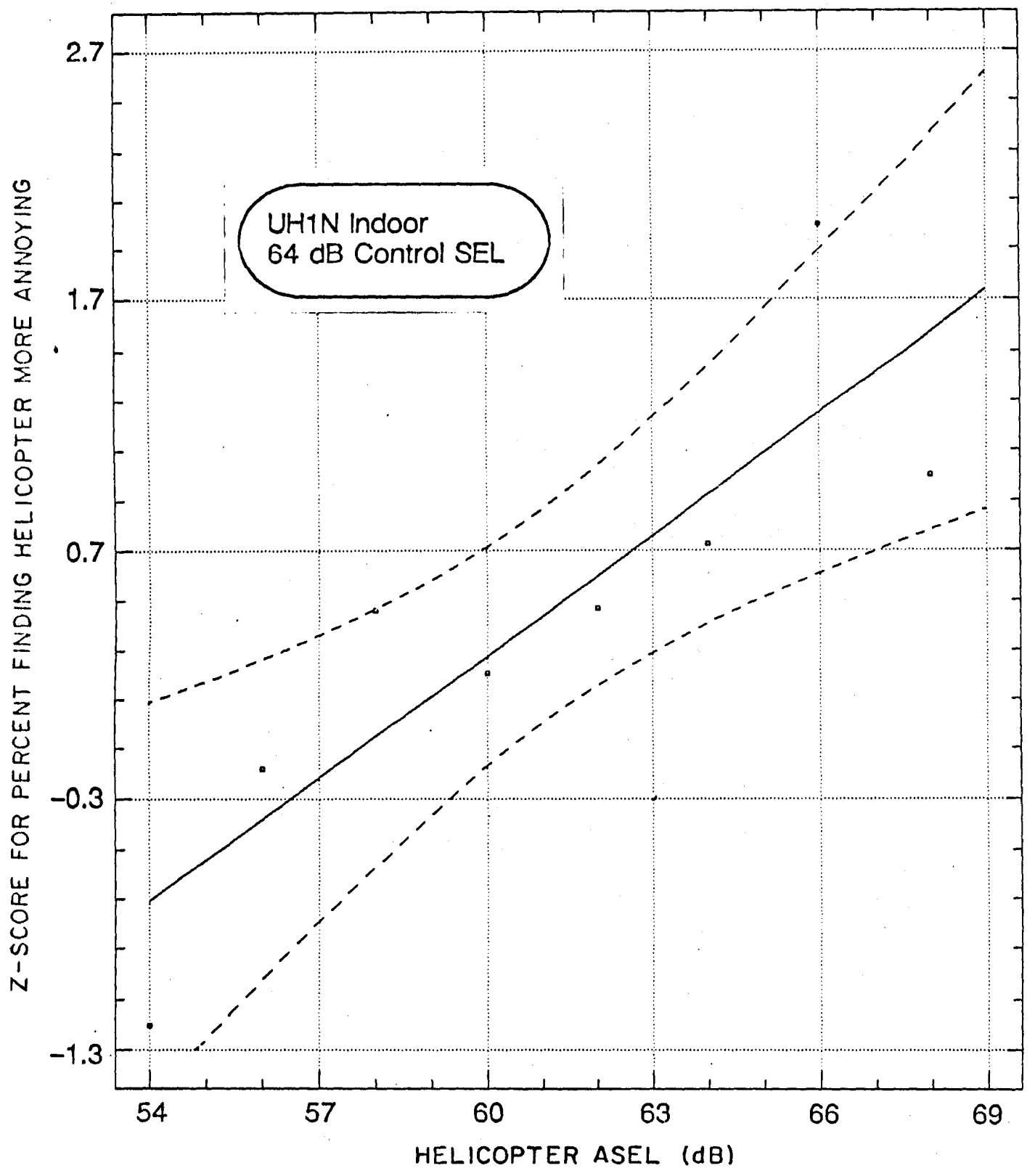

59 


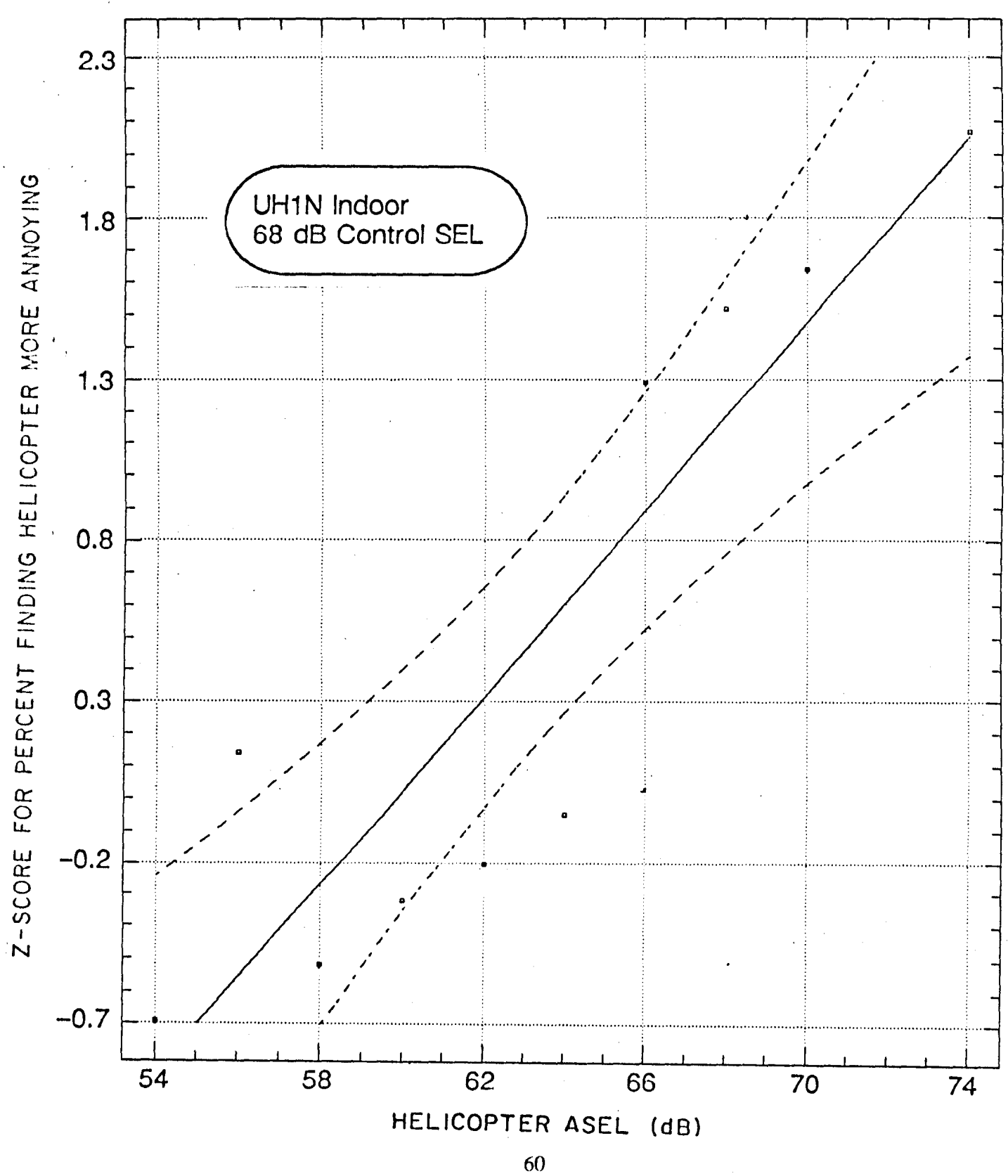




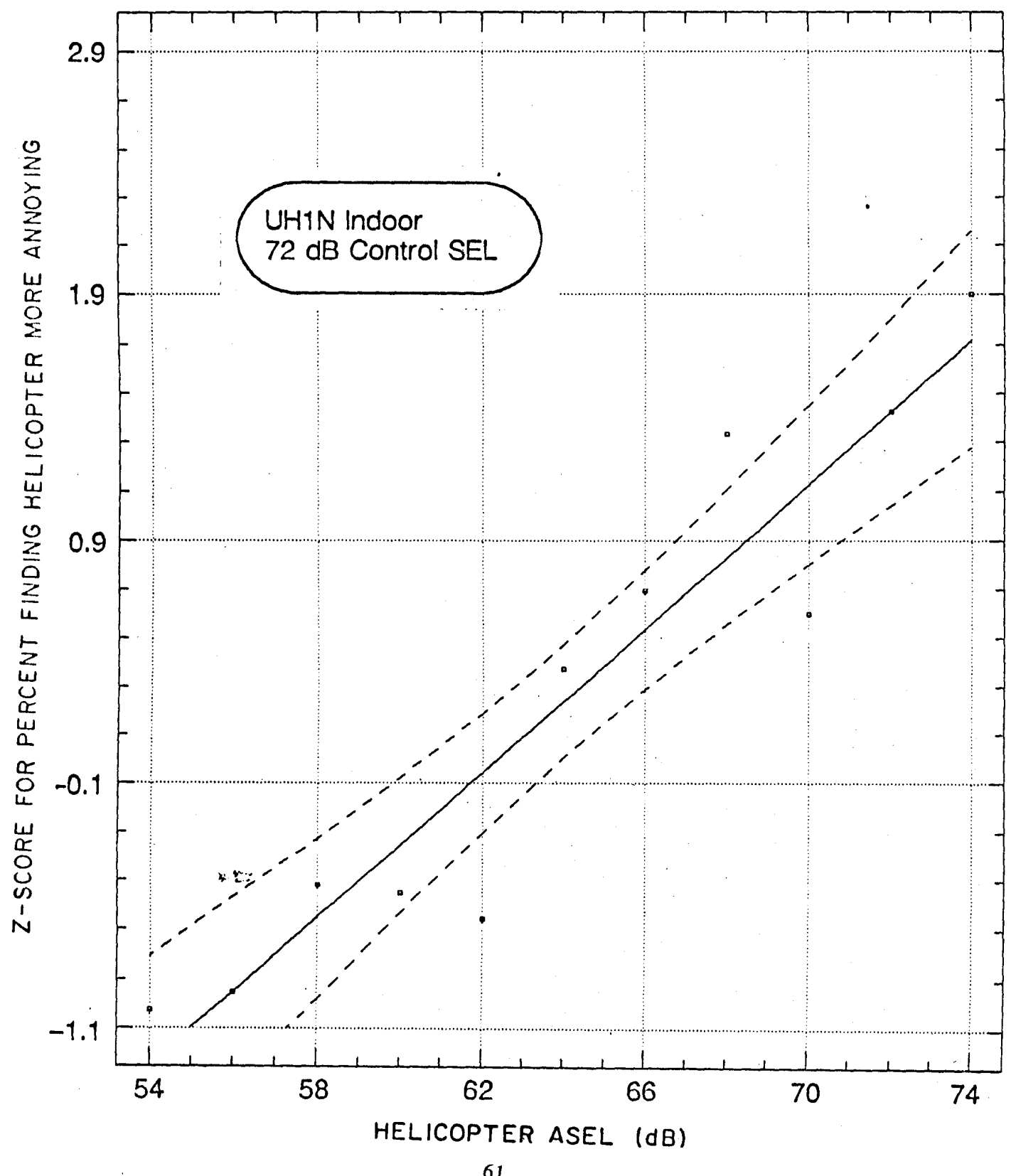

61 


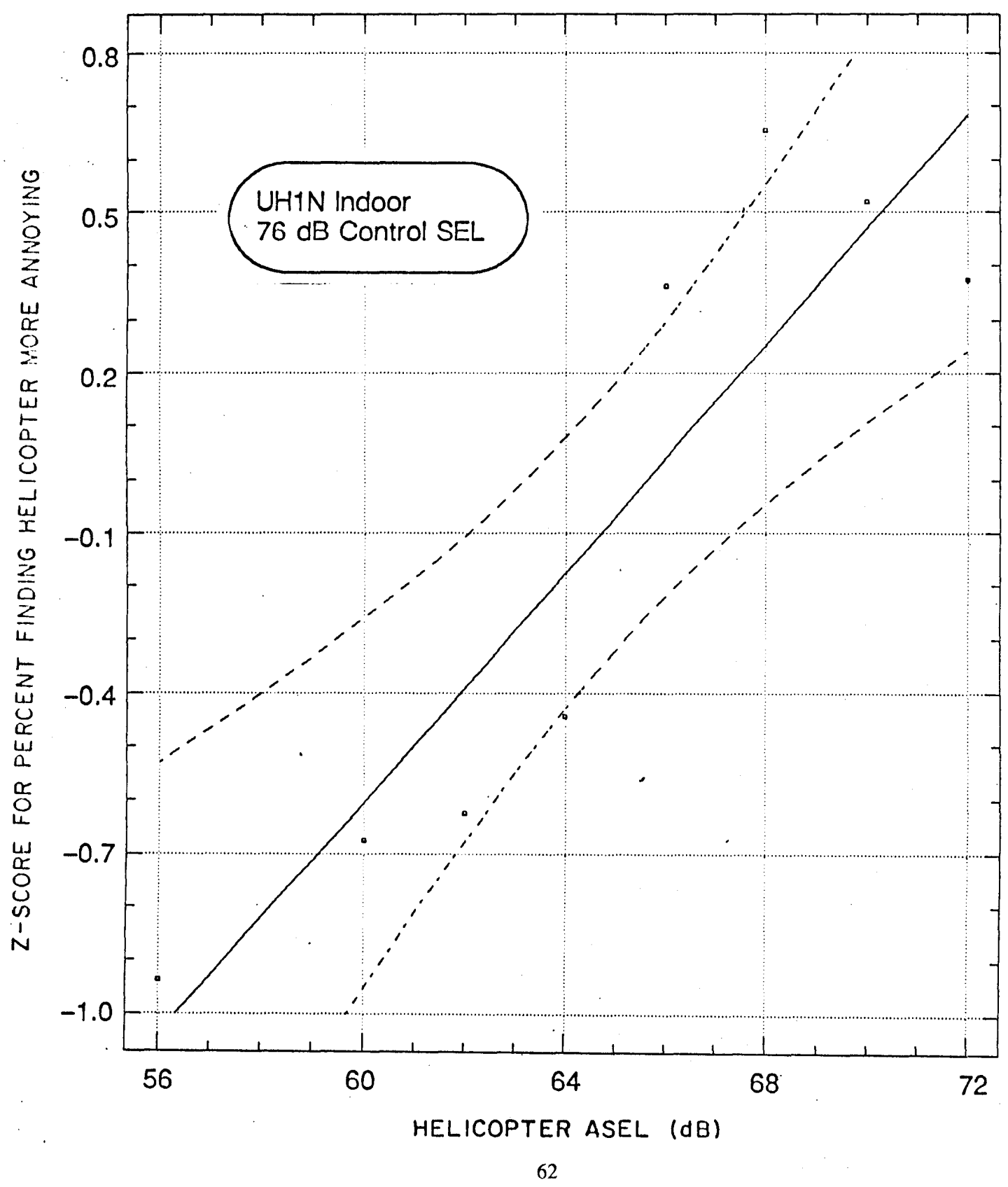




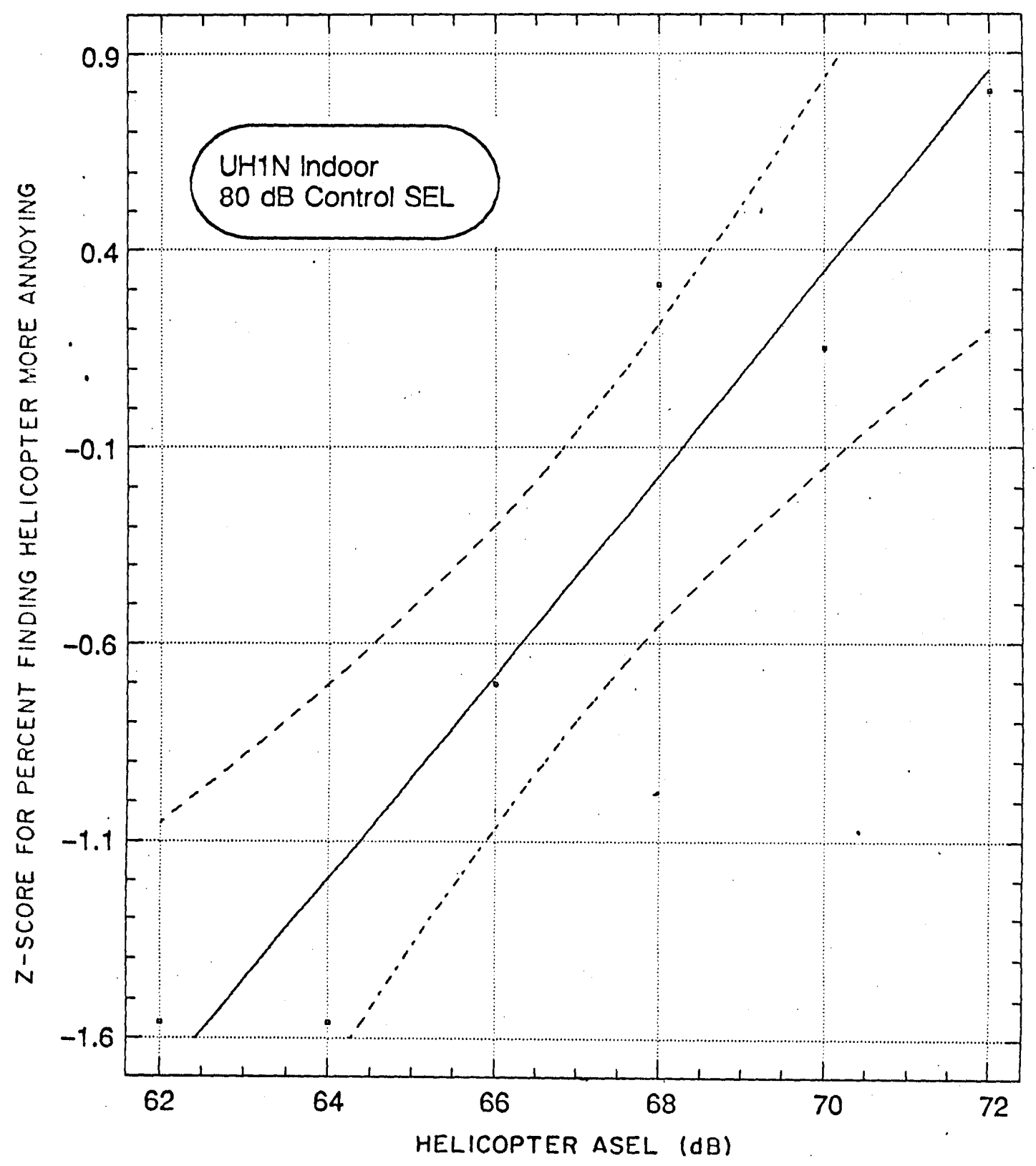

63 
Regression of AH68.Z on AH68.H

AHIW Indoo

$68 \mathrm{~dB}$ Control SEL

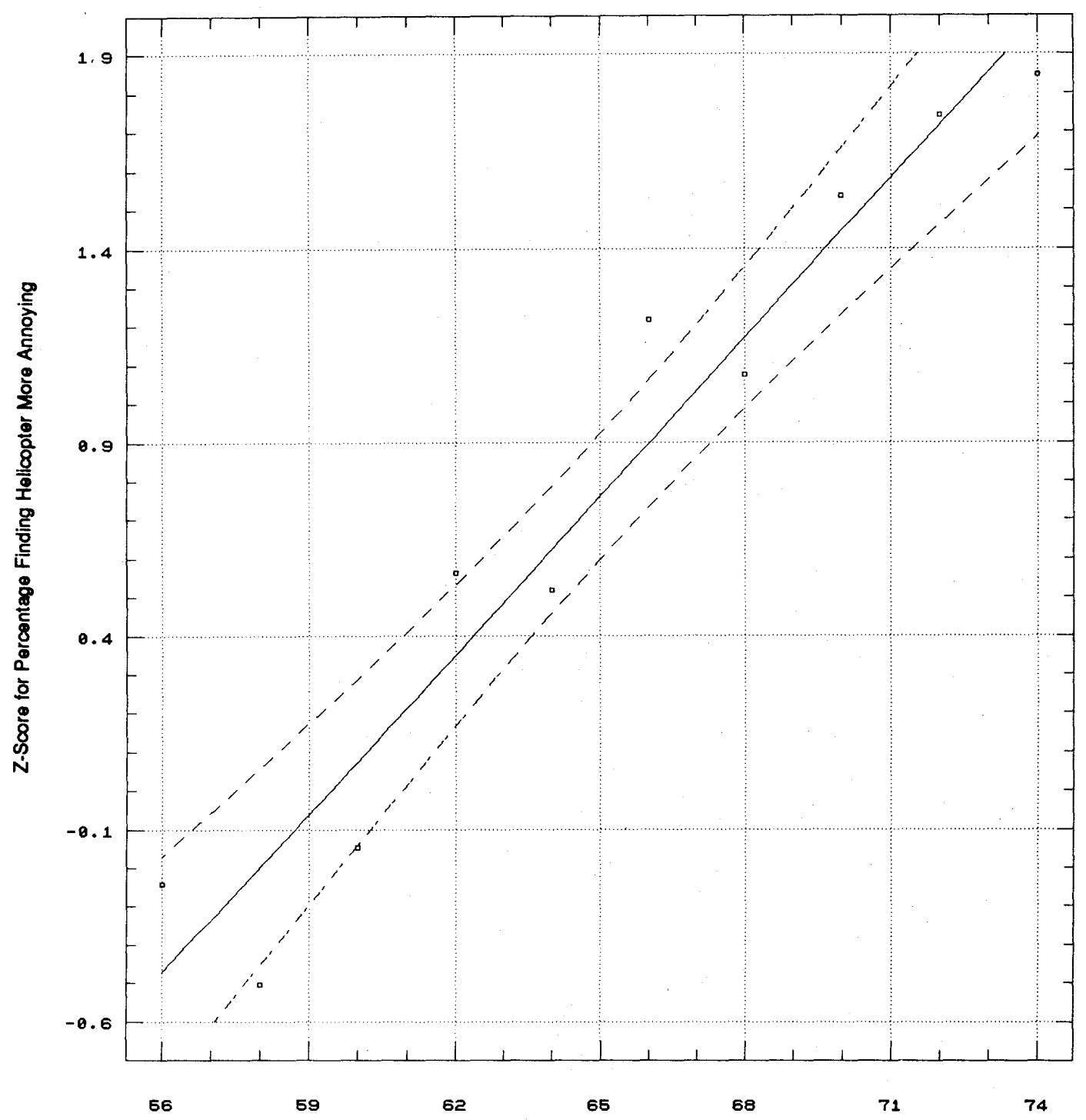

Helicopter ASEL (dB) 


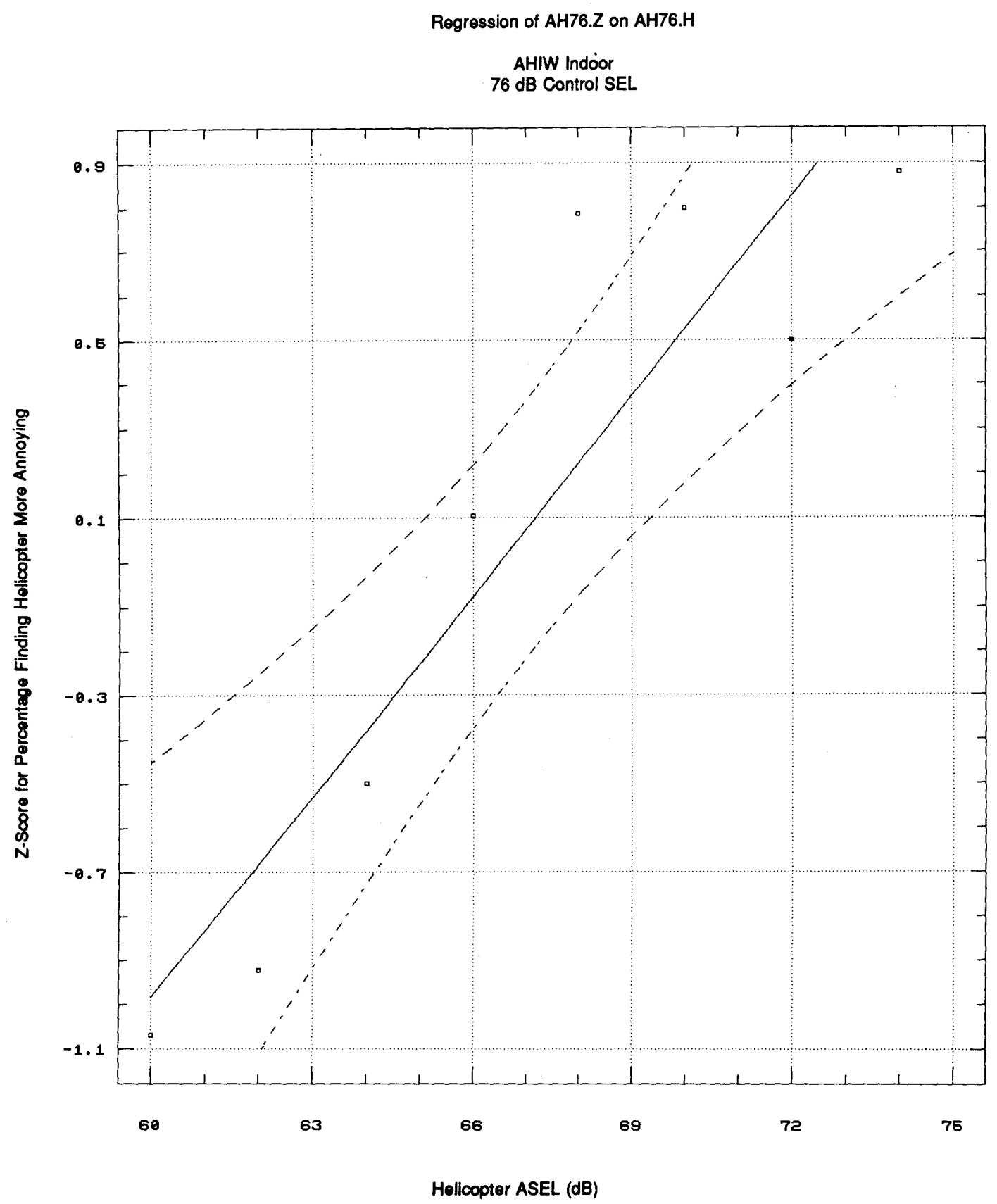


Regression of $\mathrm{AH} 80 . \mathrm{Z}$ on $\mathrm{AH} 80 . \mathrm{H}$

AHIW Indoor

$80 \mathrm{~dB}$ Control SEL

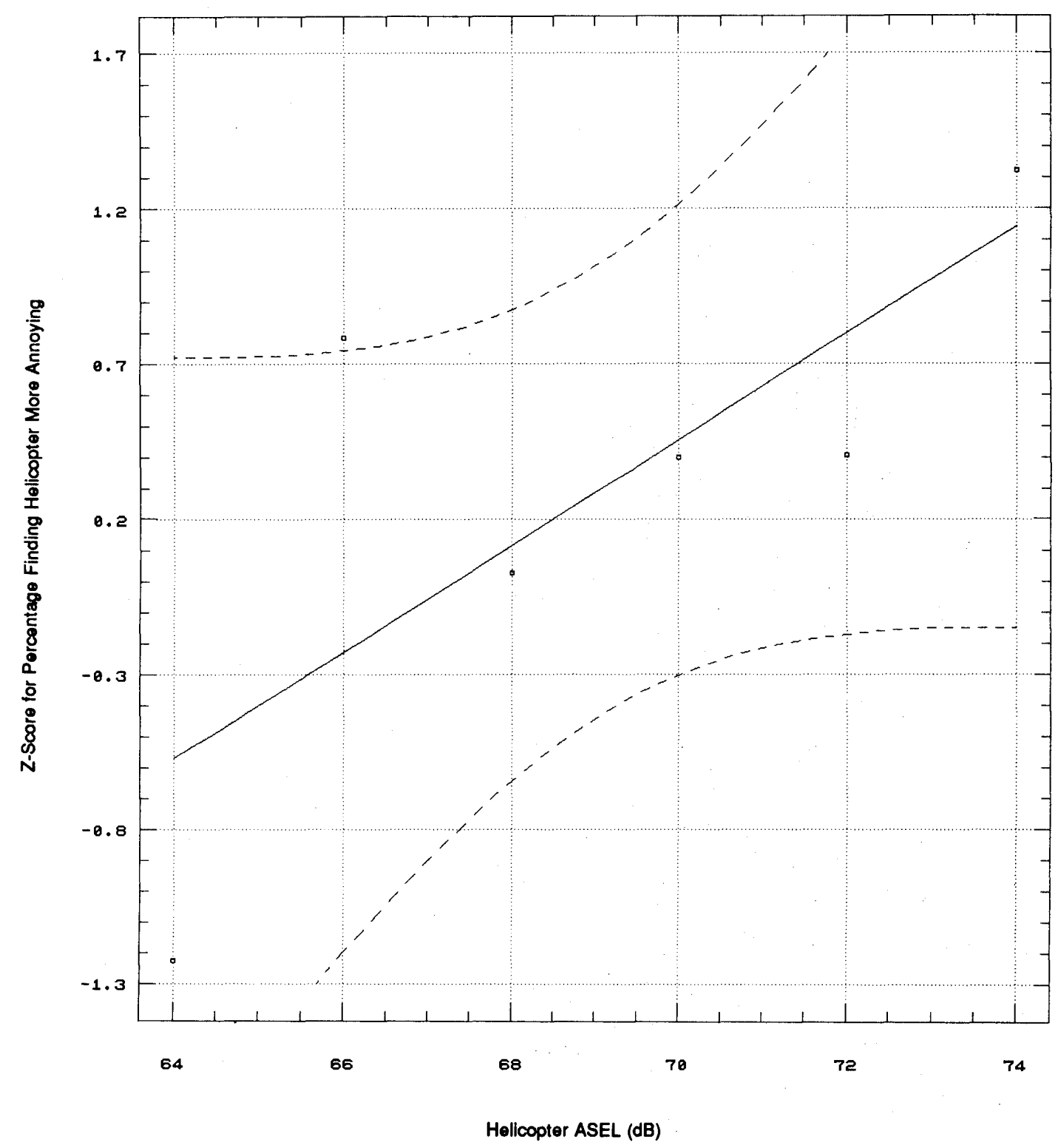




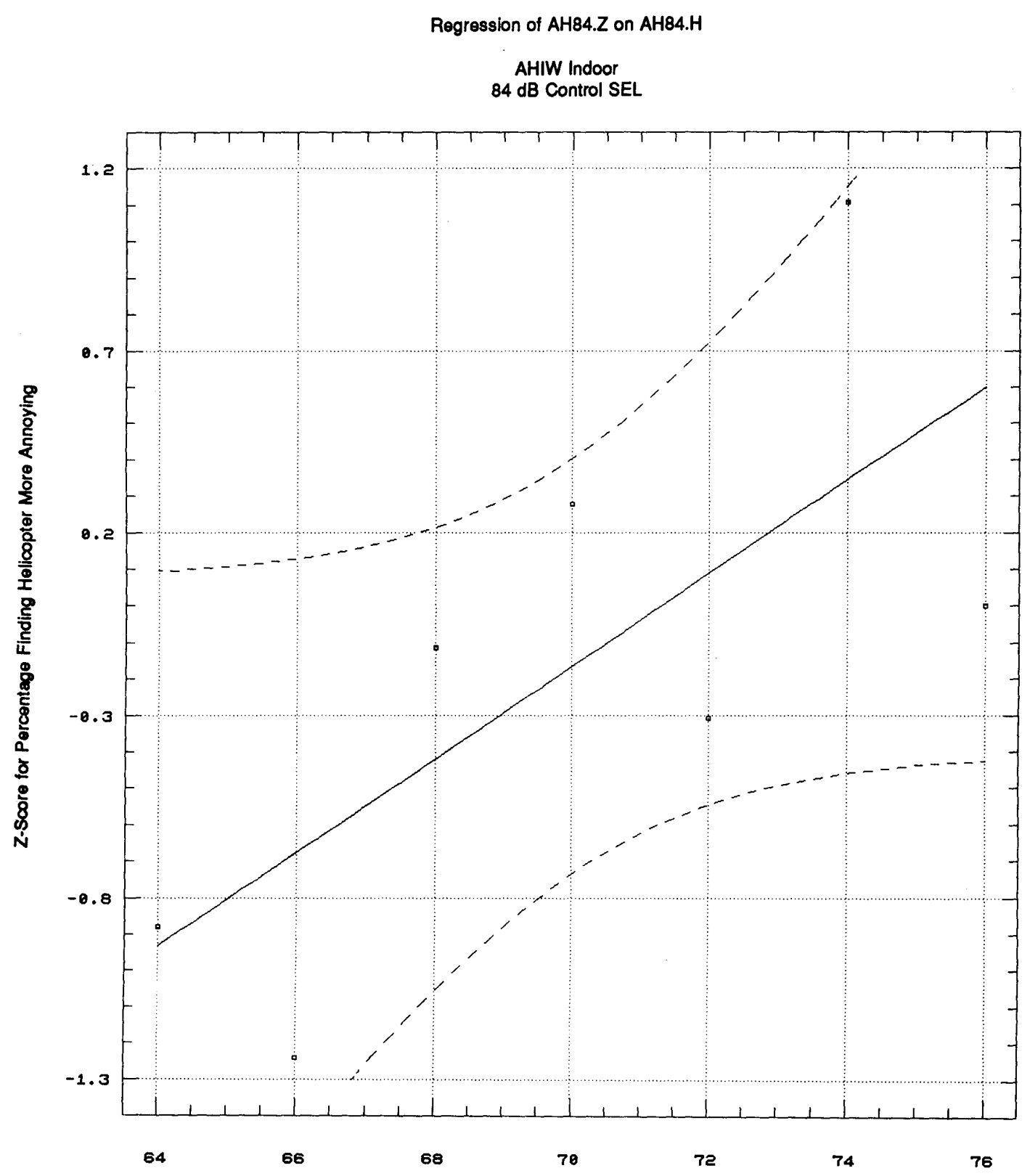

Helicopter ASEL (dB)

67 
Regression of A5360.Z on A5360.H

CH53A Indoor

$60 \mathrm{~dB}$ Control SEL

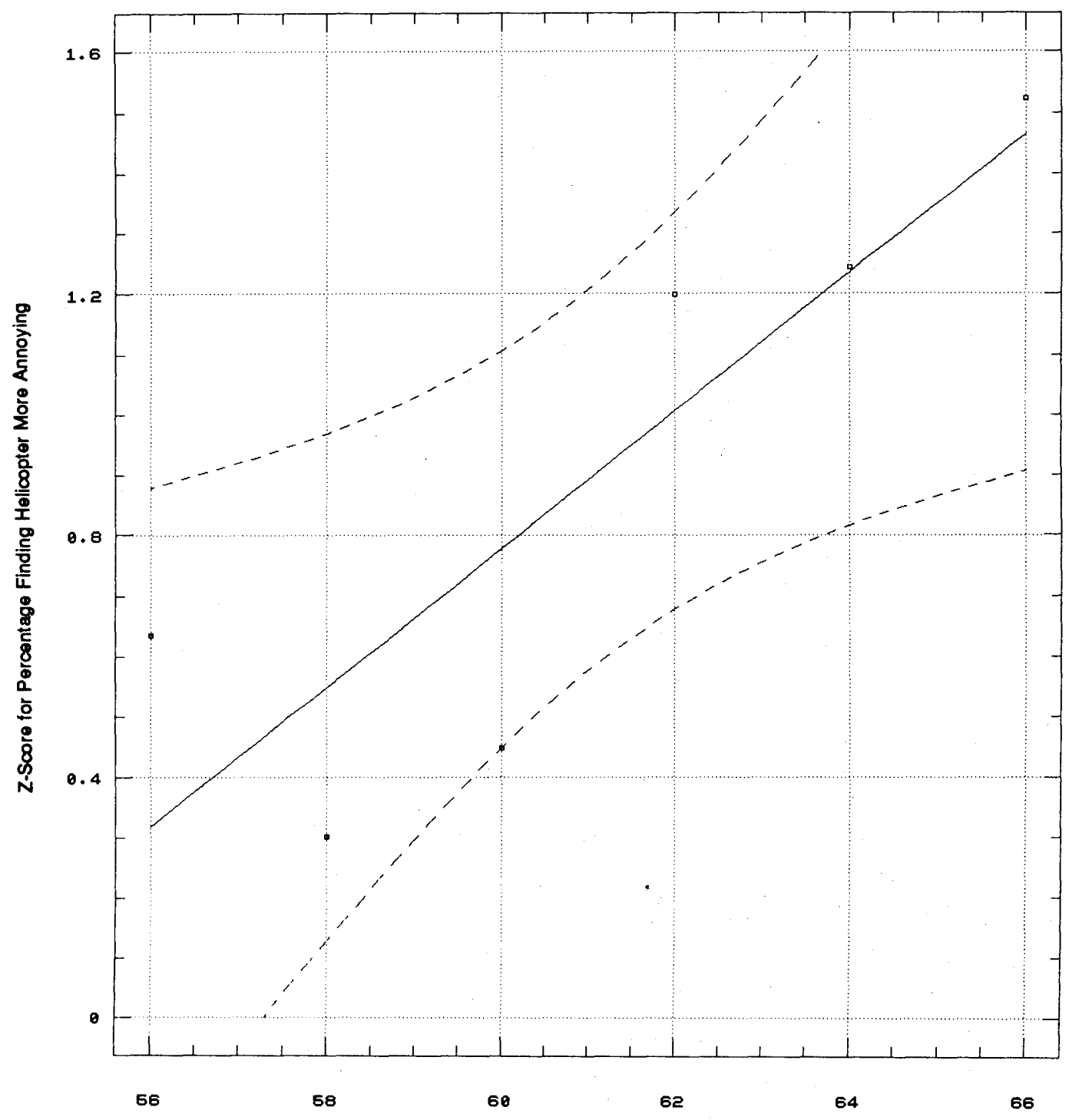

Helicopter ASEL (dB) 
Regression of A5368.Z on A5368.H

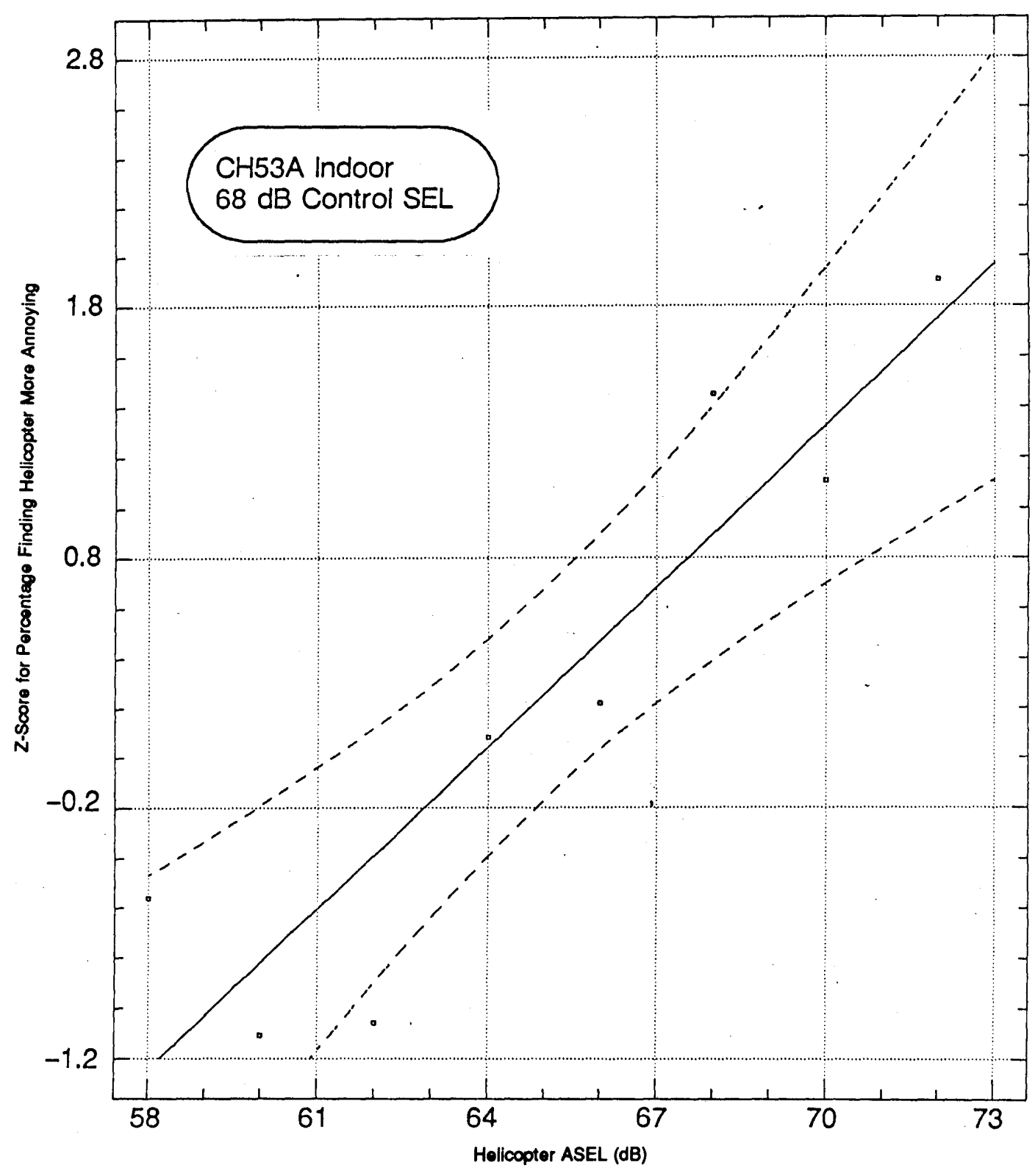




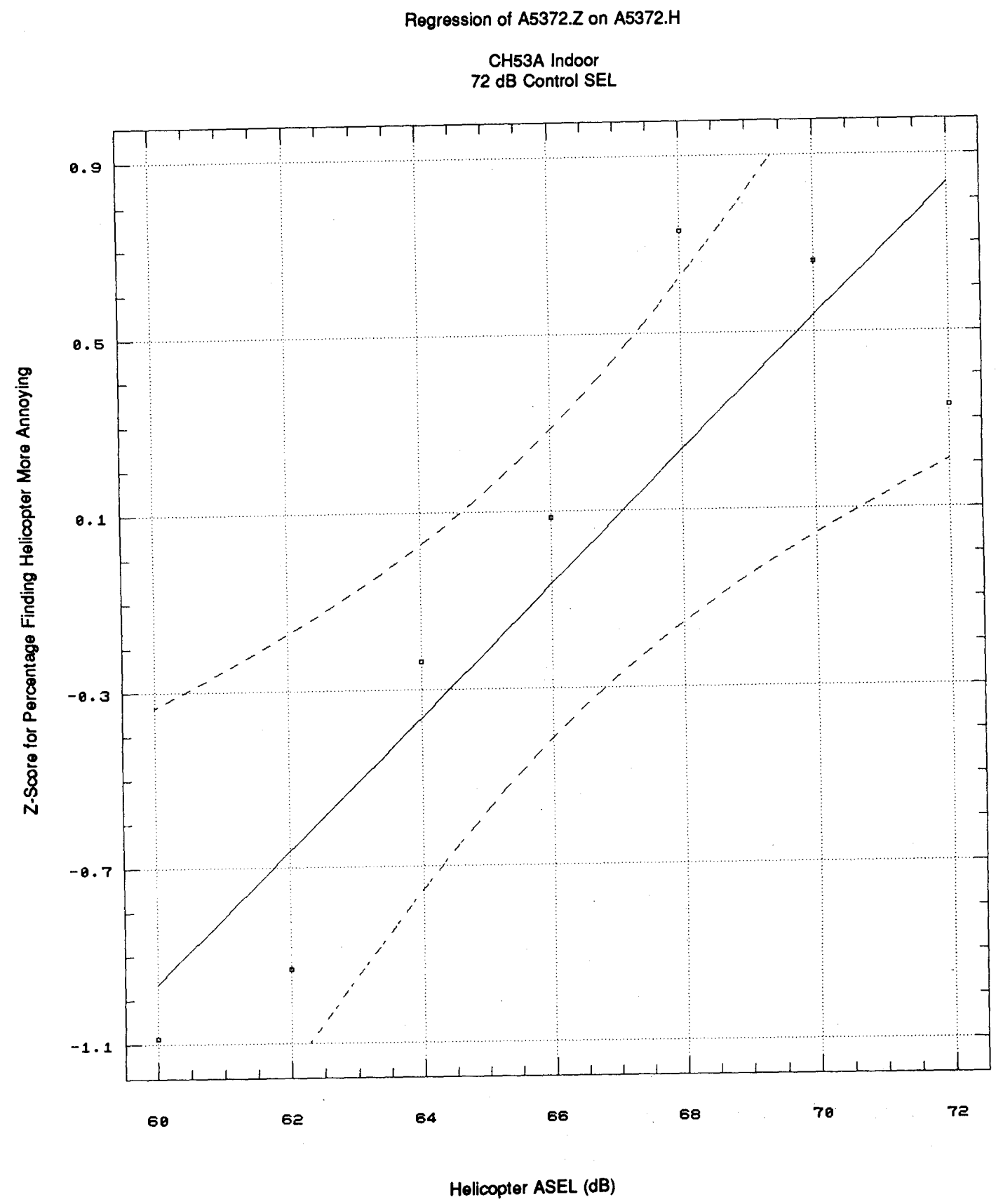

70 
Regression of $\mathrm{A} 5380 . \mathrm{Z}$ on $\mathrm{A} 5380 . \mathrm{H}$

CH53A Indoor

$80 \mathrm{~dB}$ Control SEL

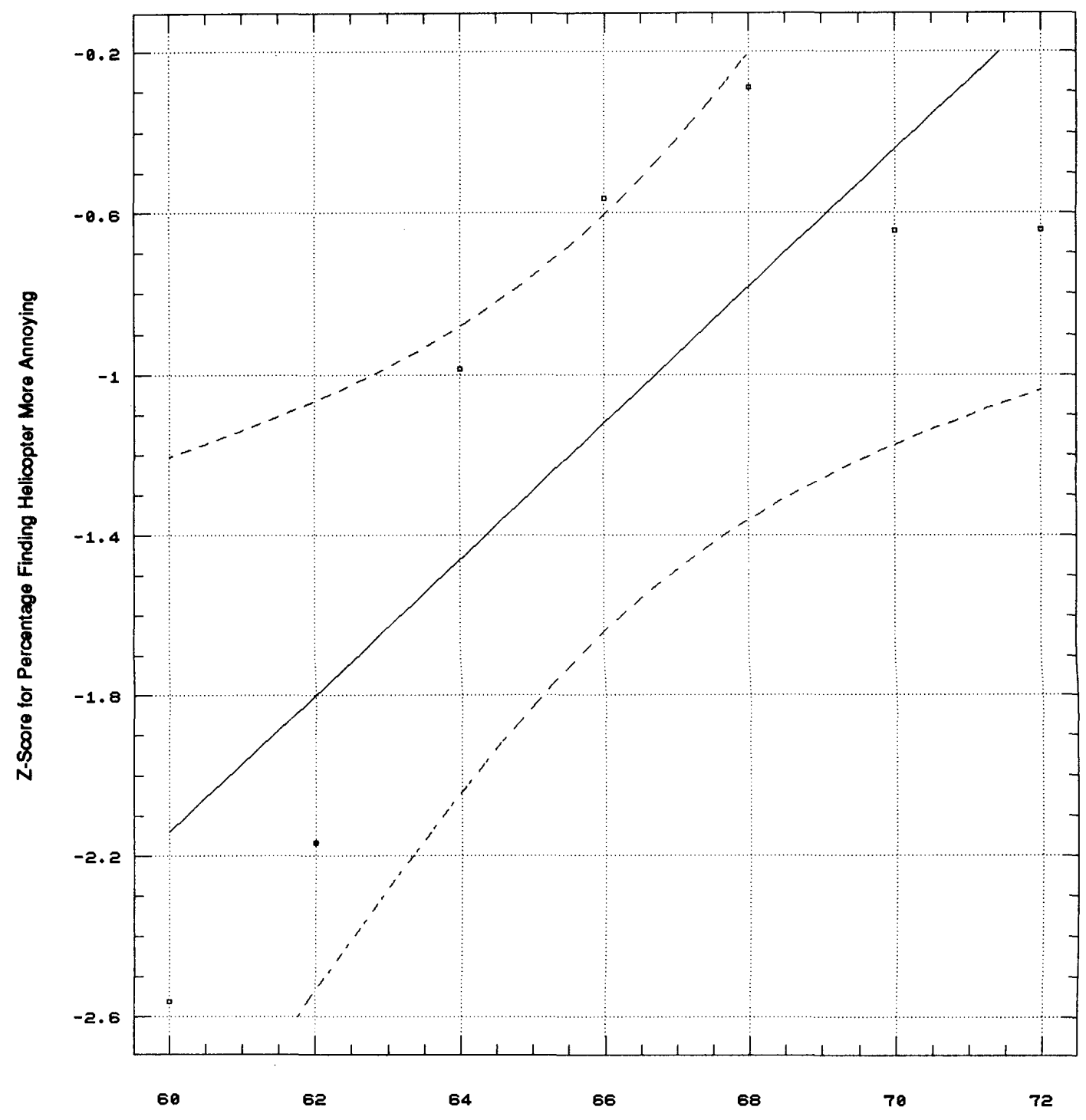

Helicopter ASEL (dB) 


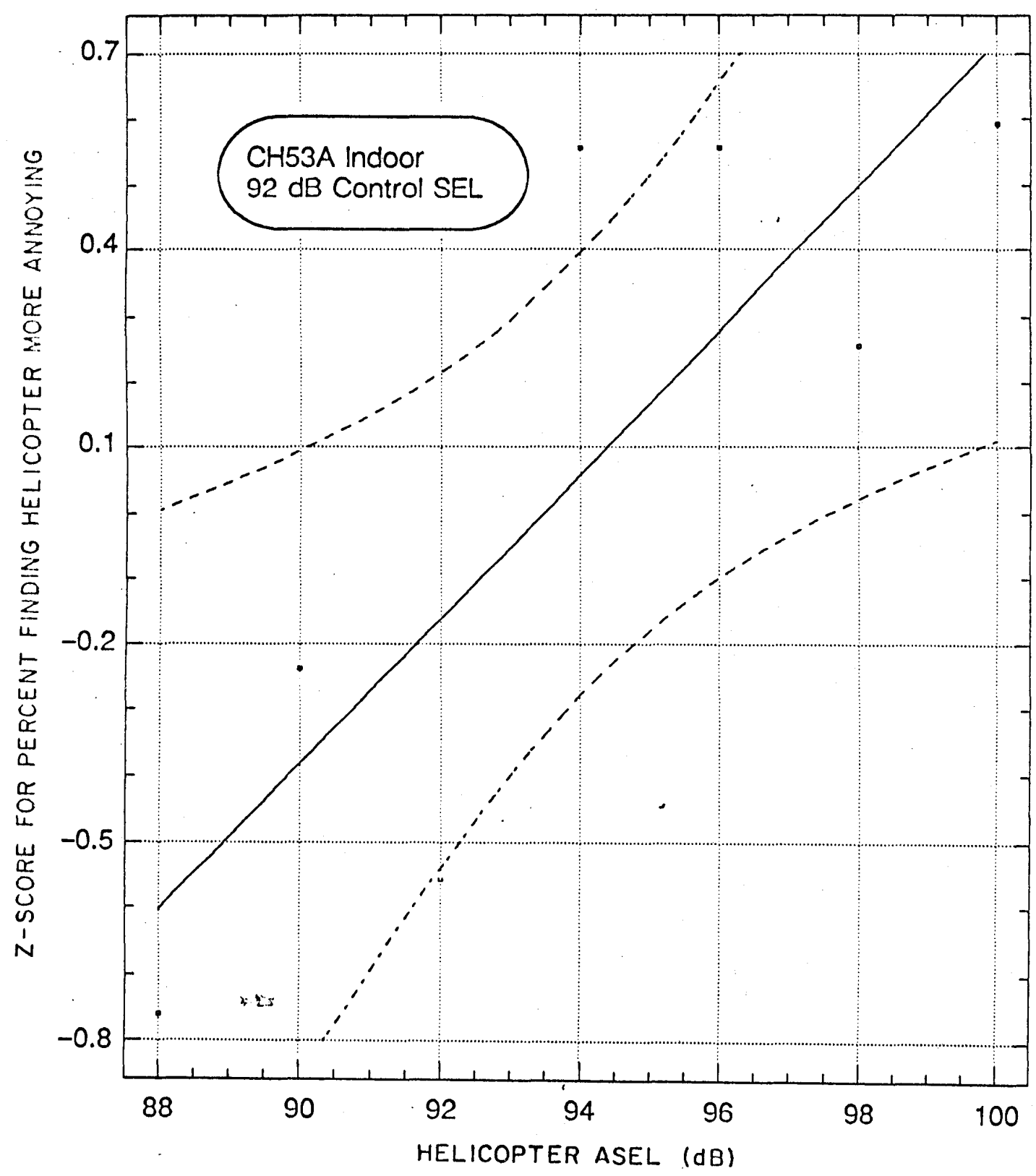

72 


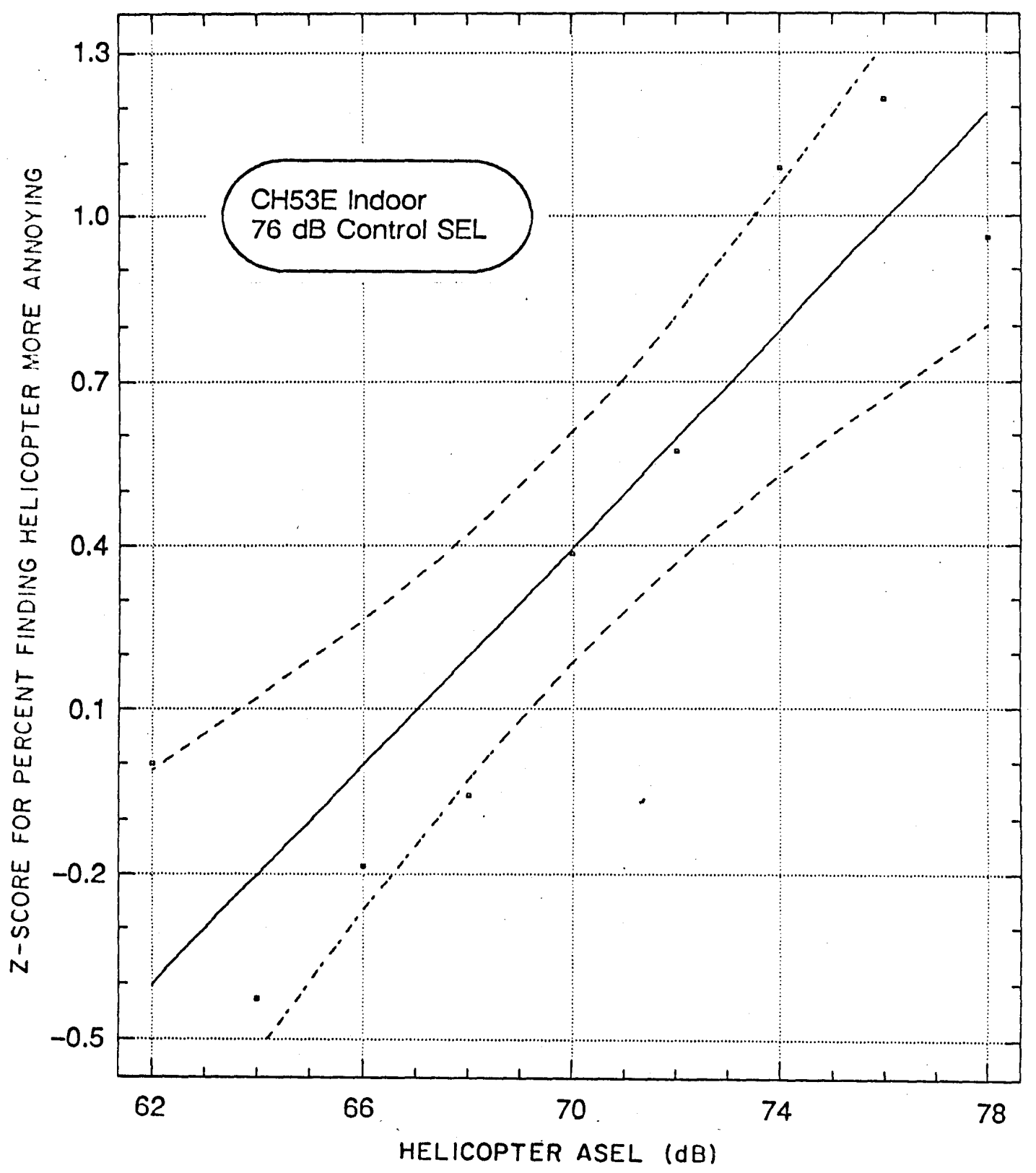




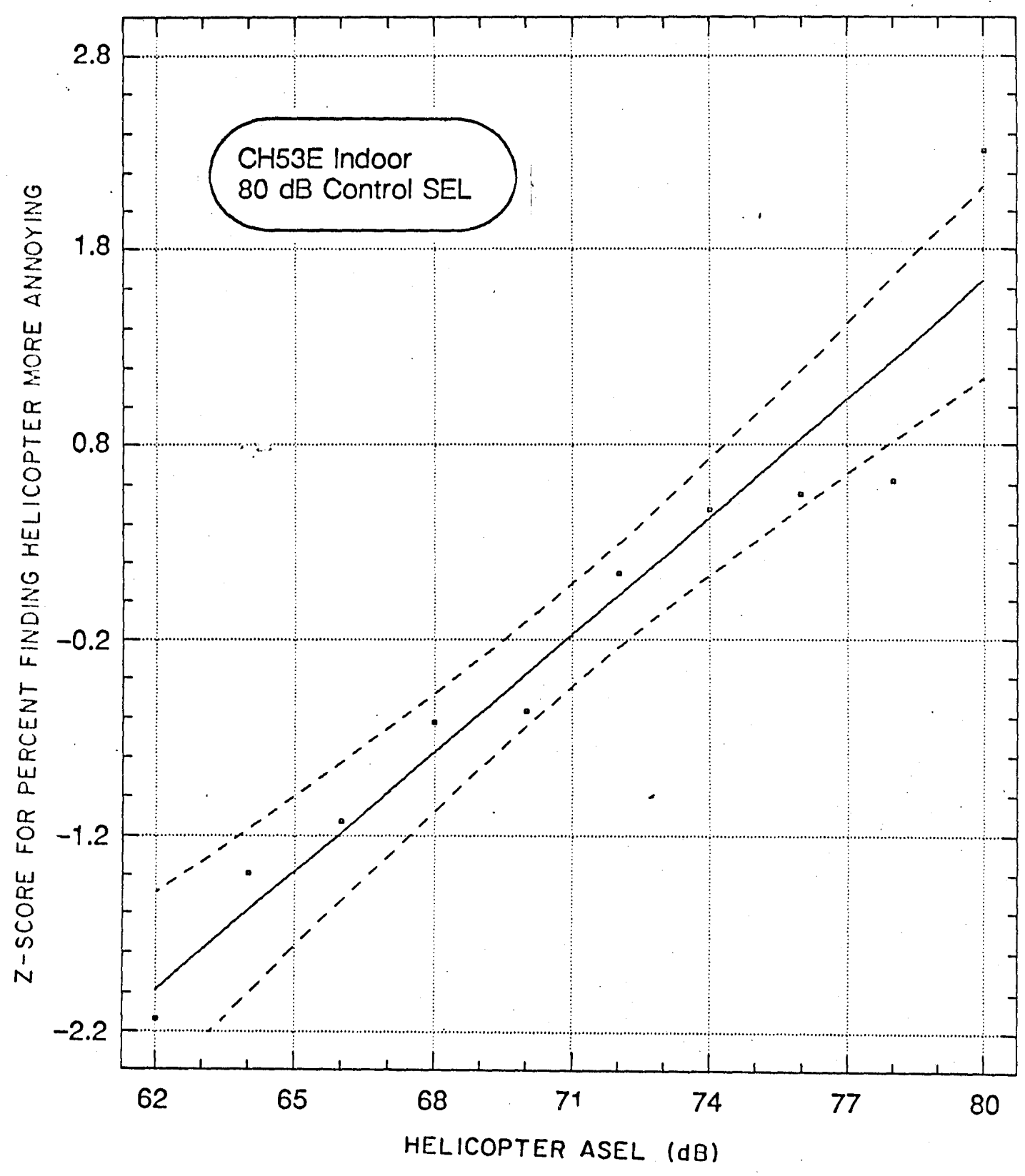

74 


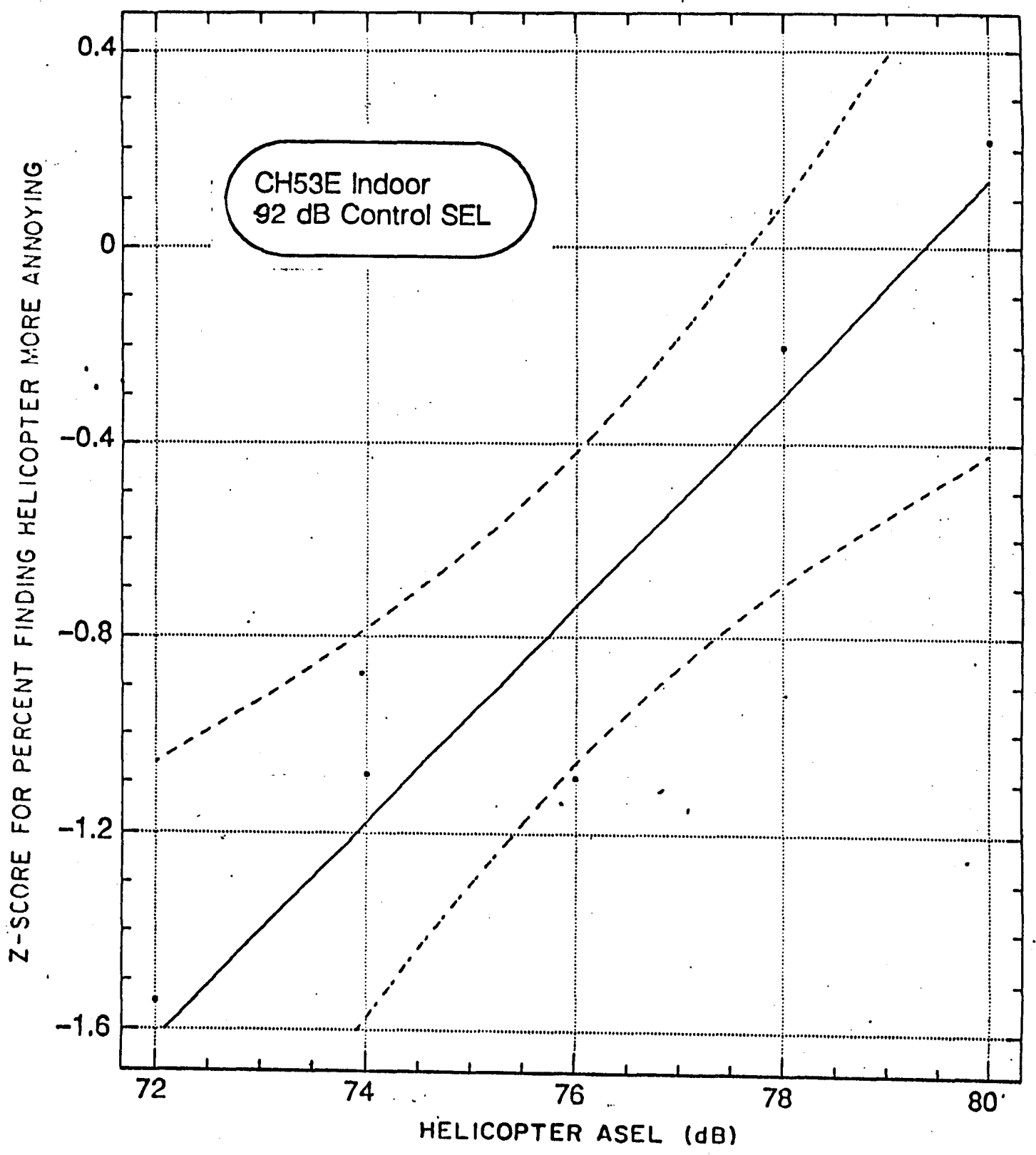

75 


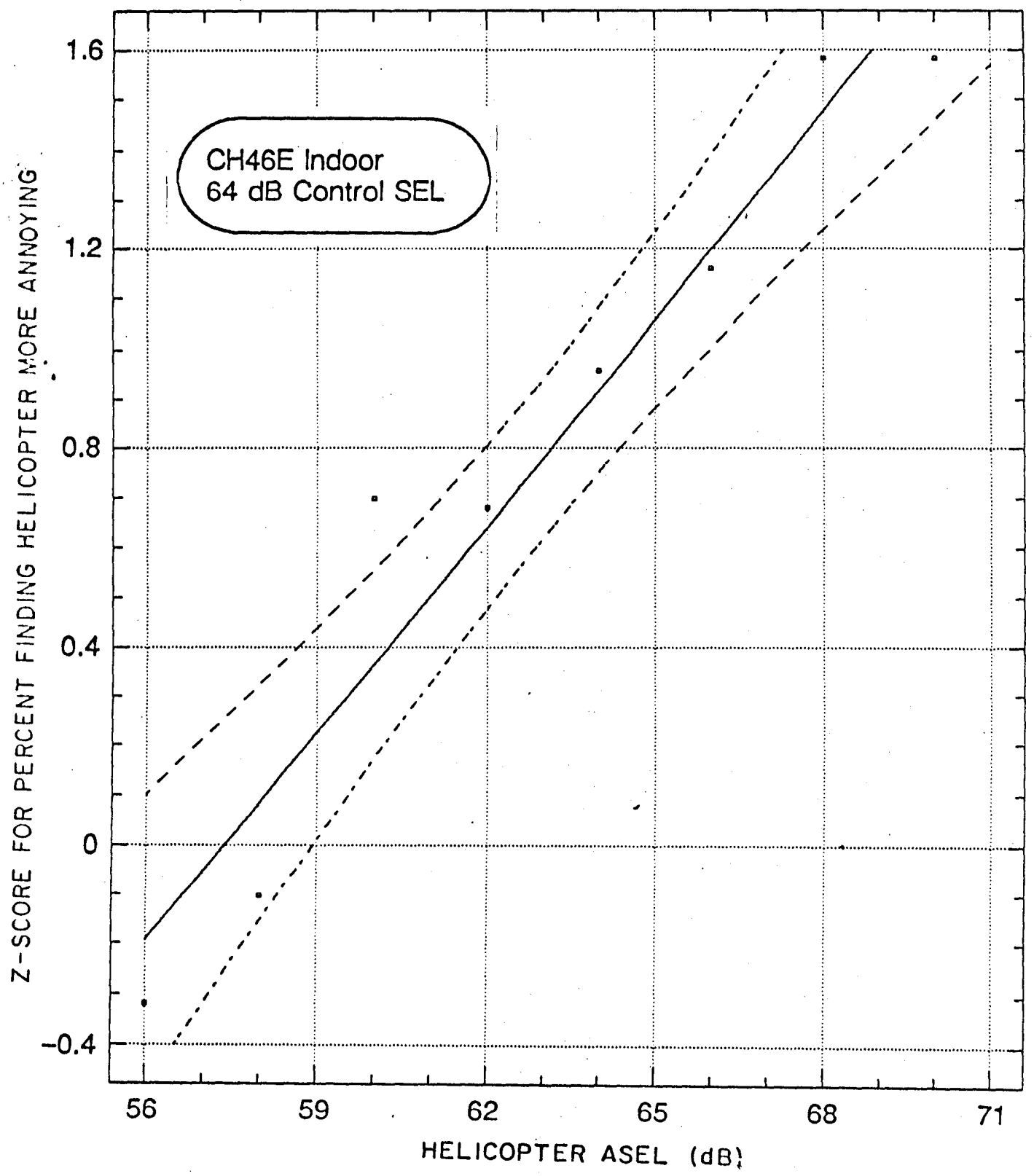

76 


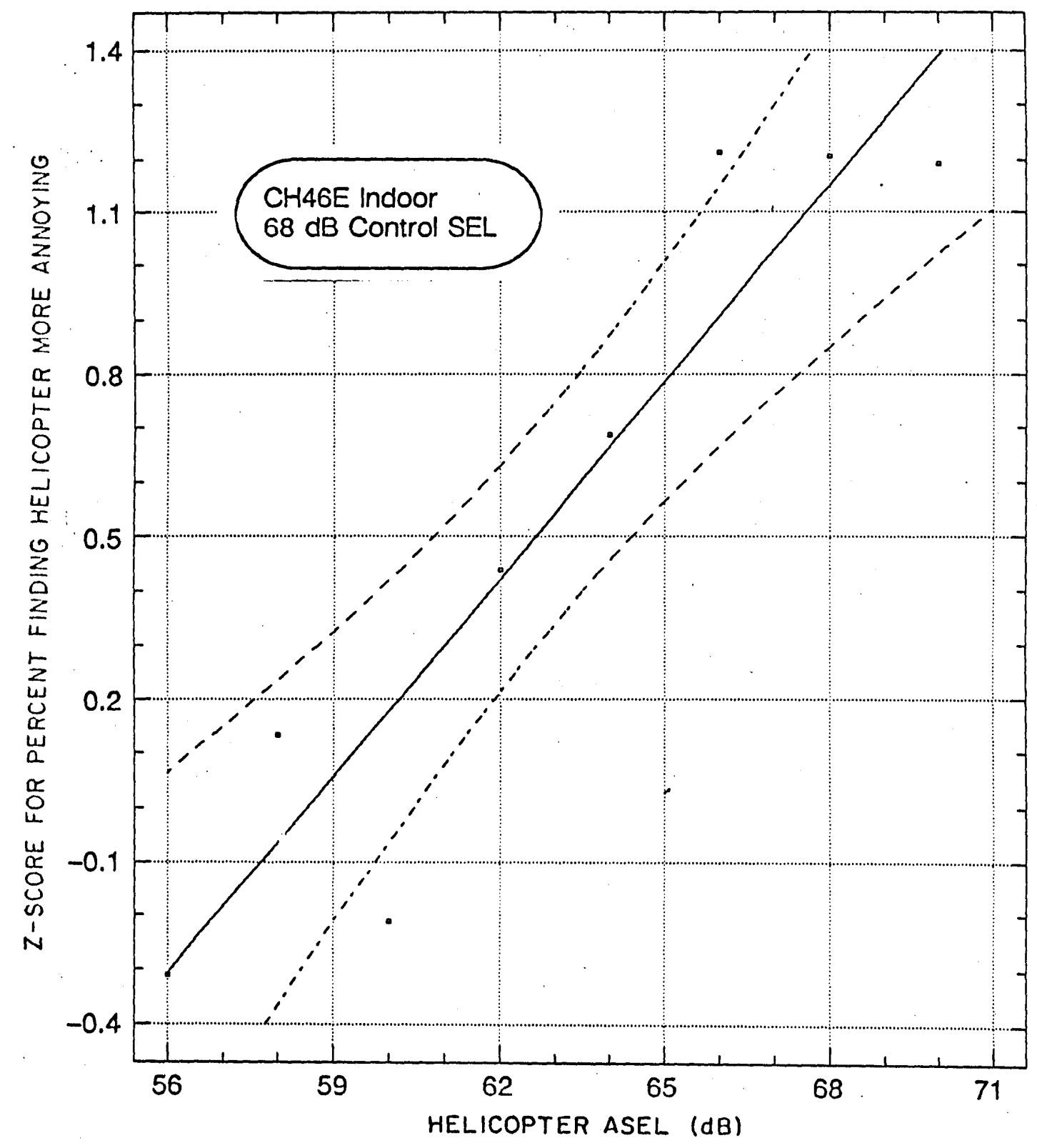




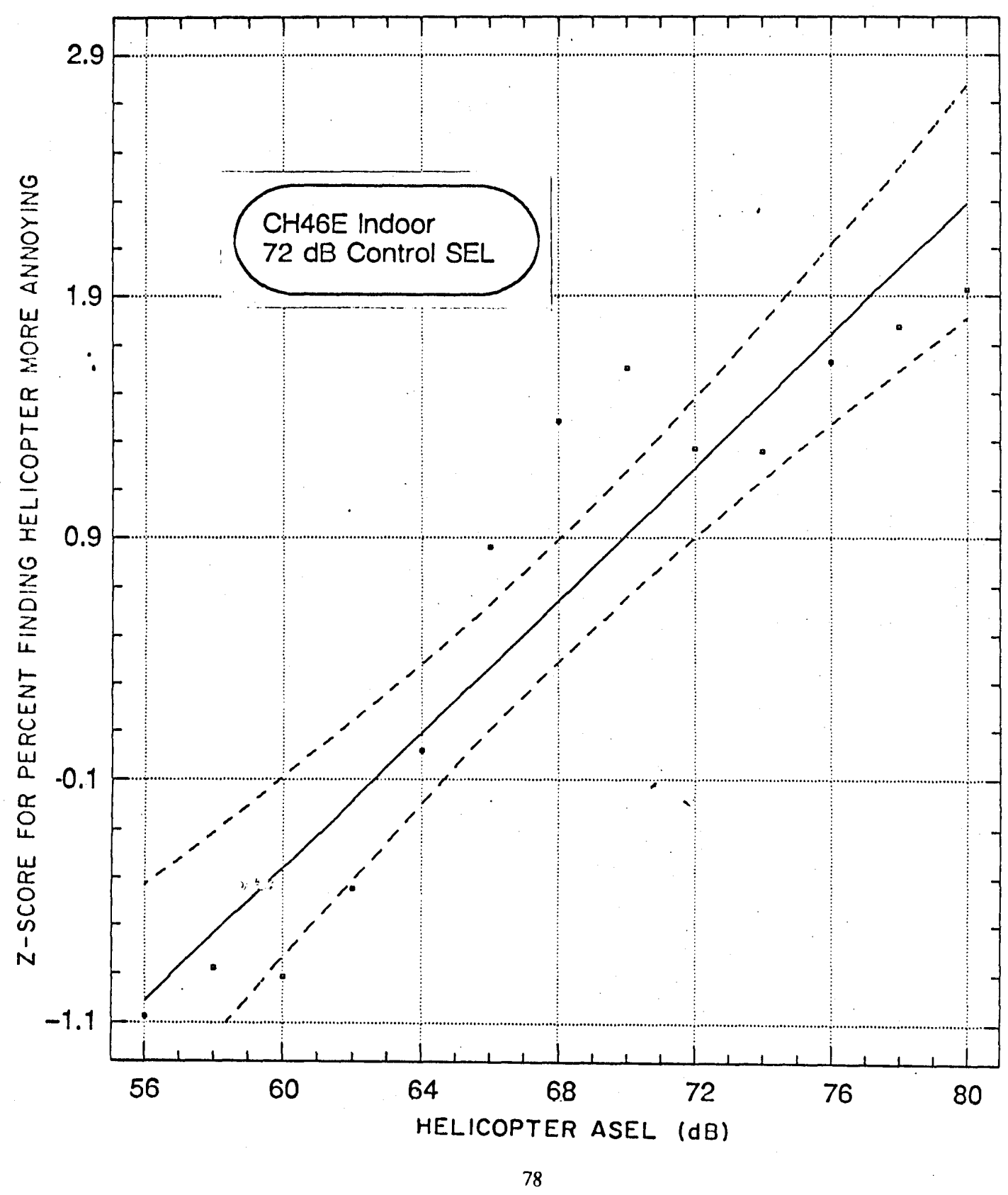




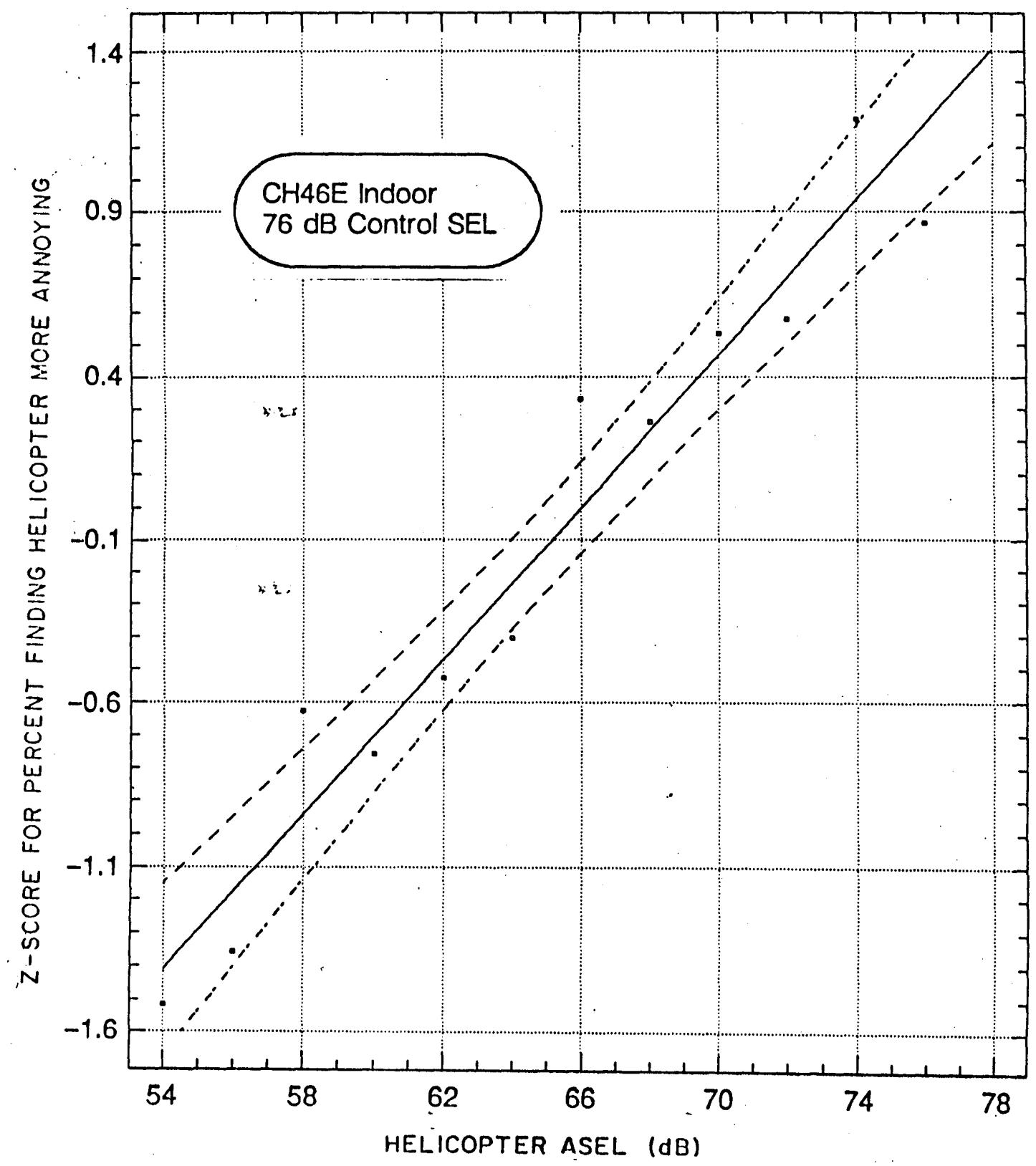




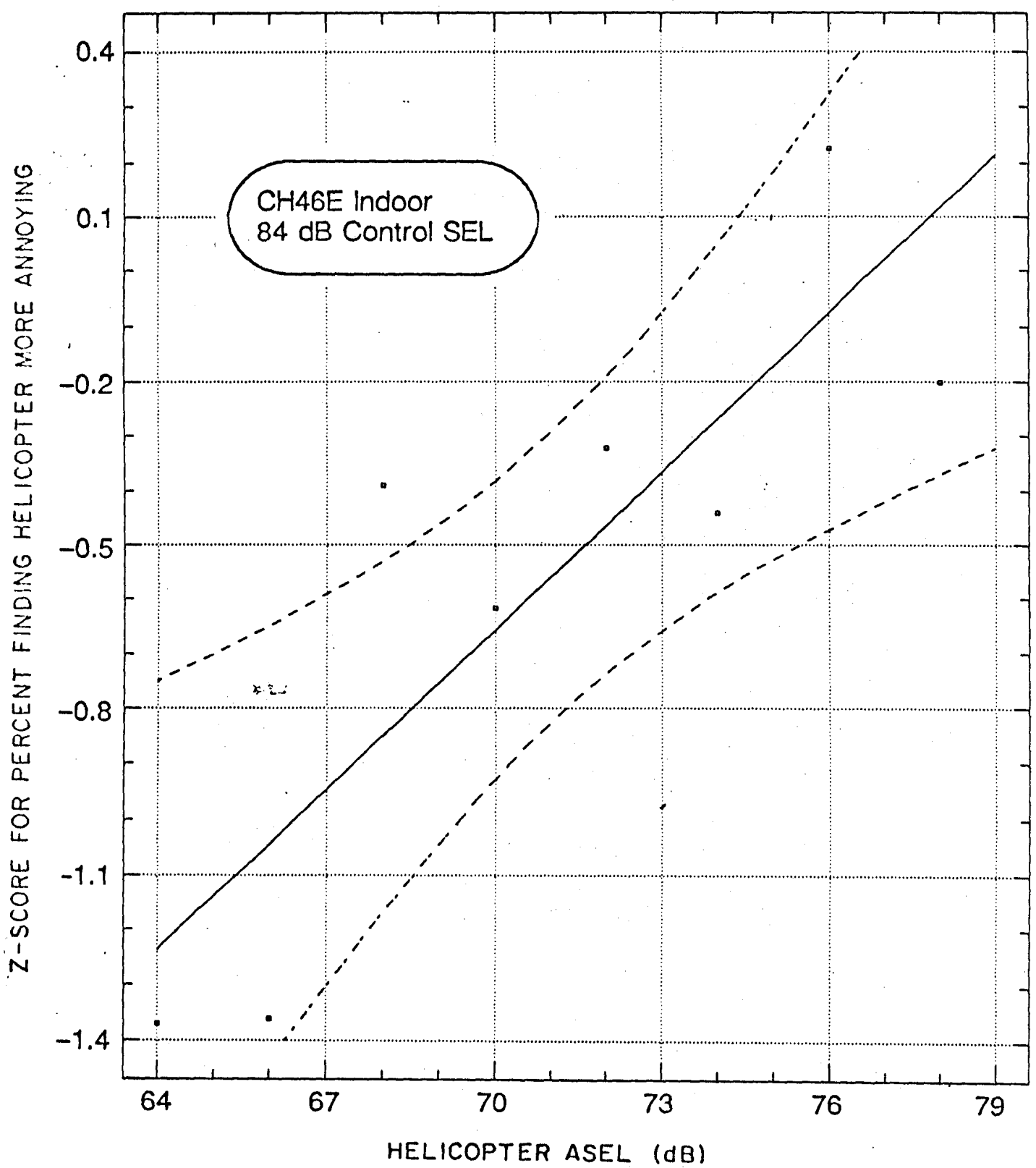

80 
APPENDIX C

PLOTS OF MCAS TUSTIN OUTDOOR TEST DATA

Regression of AW1WO84.ANNOY on AH1WO84.SEL

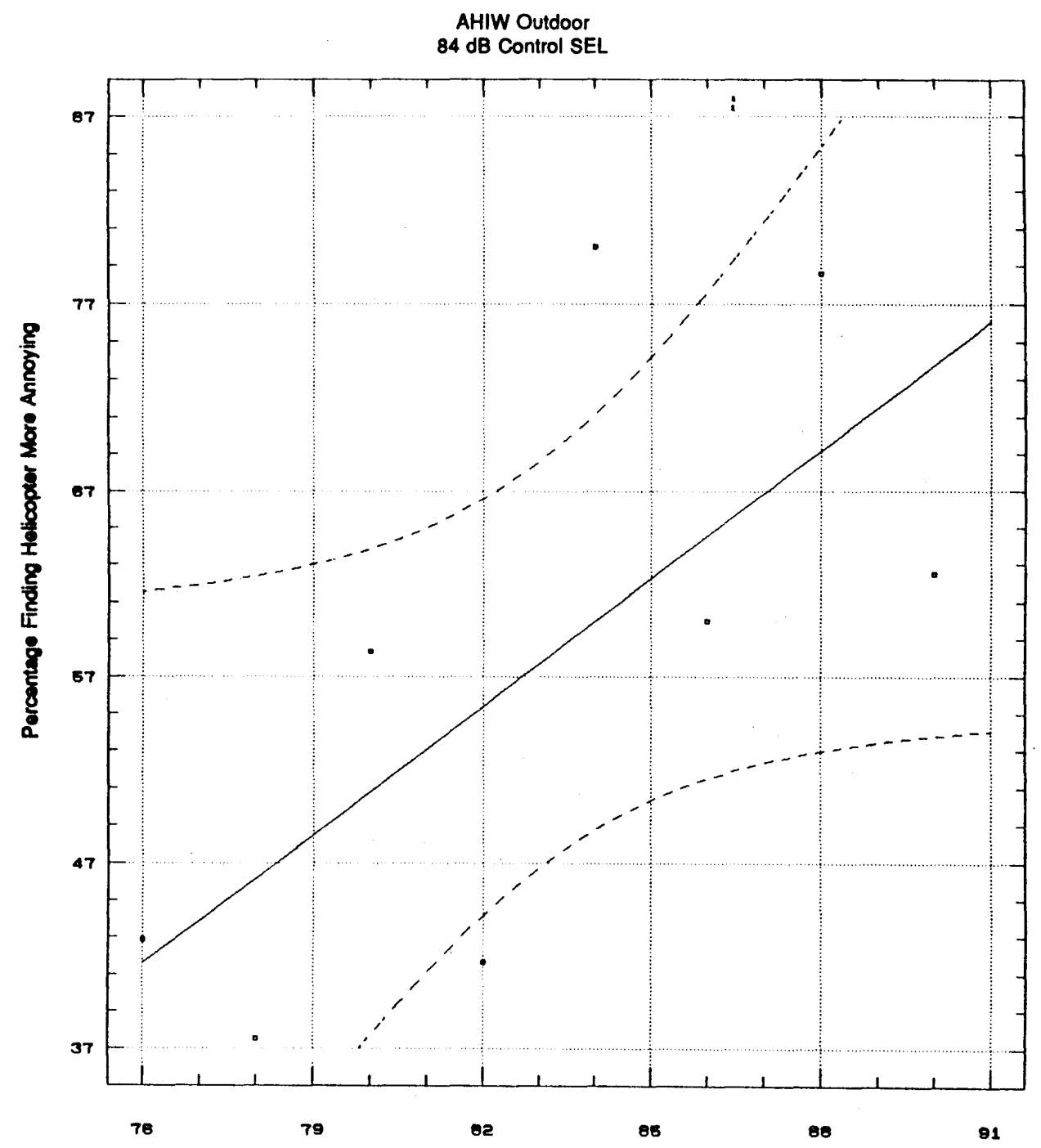

Hollooptor ASEL (dB) 
Regression of AW1WO88.ANNOY on AH1WO88.SEL

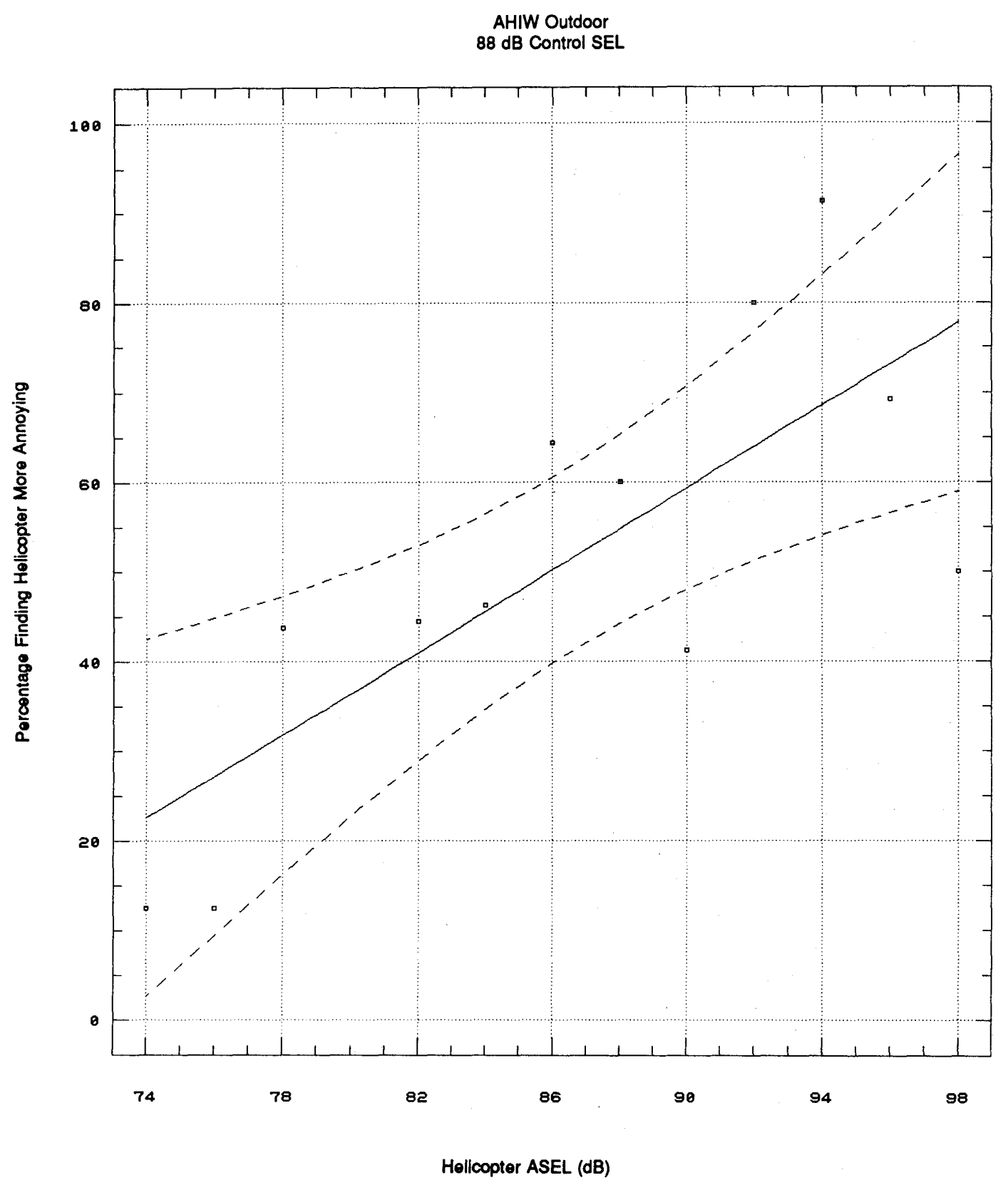


Regression of AW1WO92.ANNOY on AH1WO92.SEL

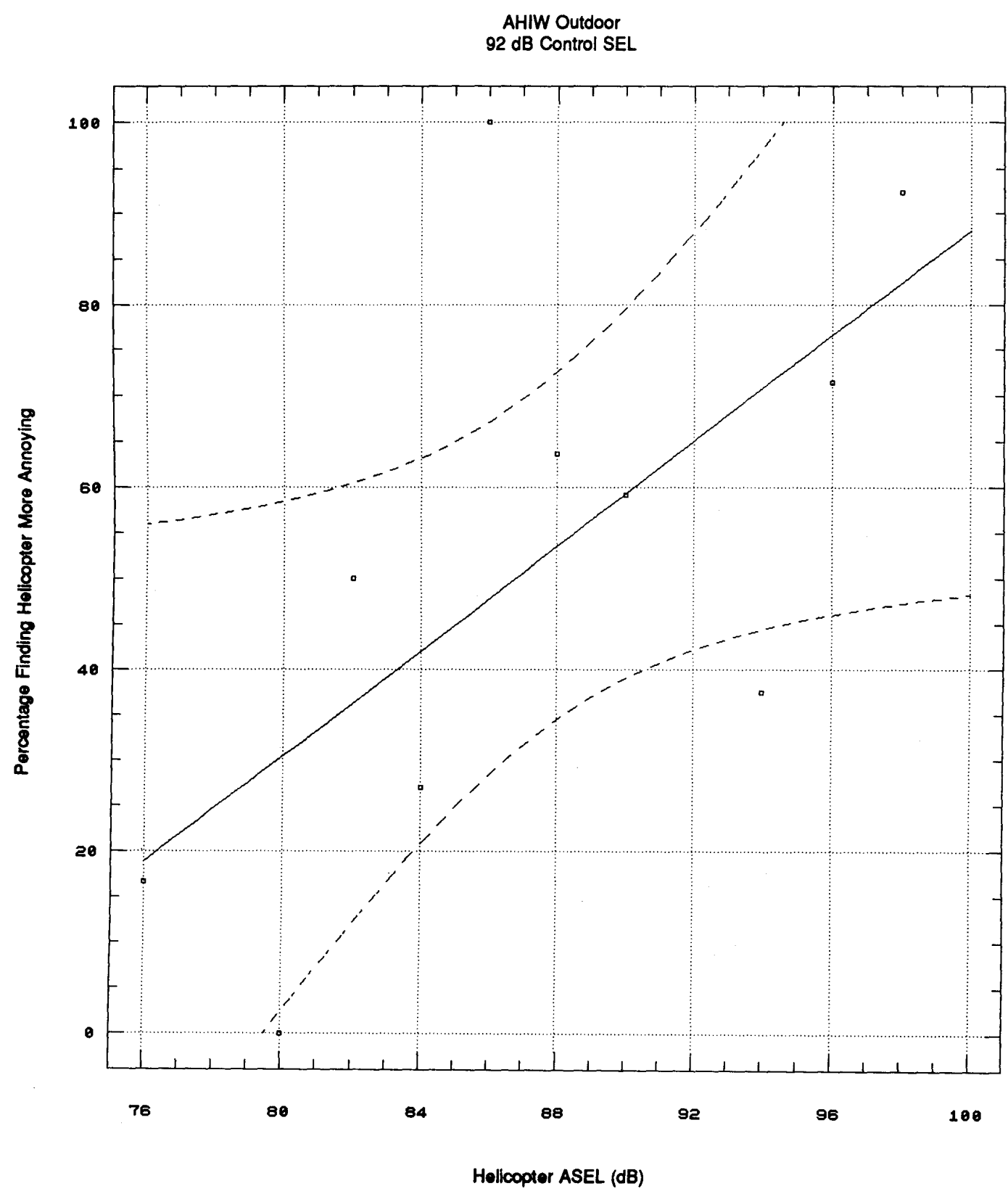

83 
Regression of AW1WO100.ANNOY on AH1WO100.SEL

AHIW Outdoor $100 \mathrm{~dB}$ Control SEL

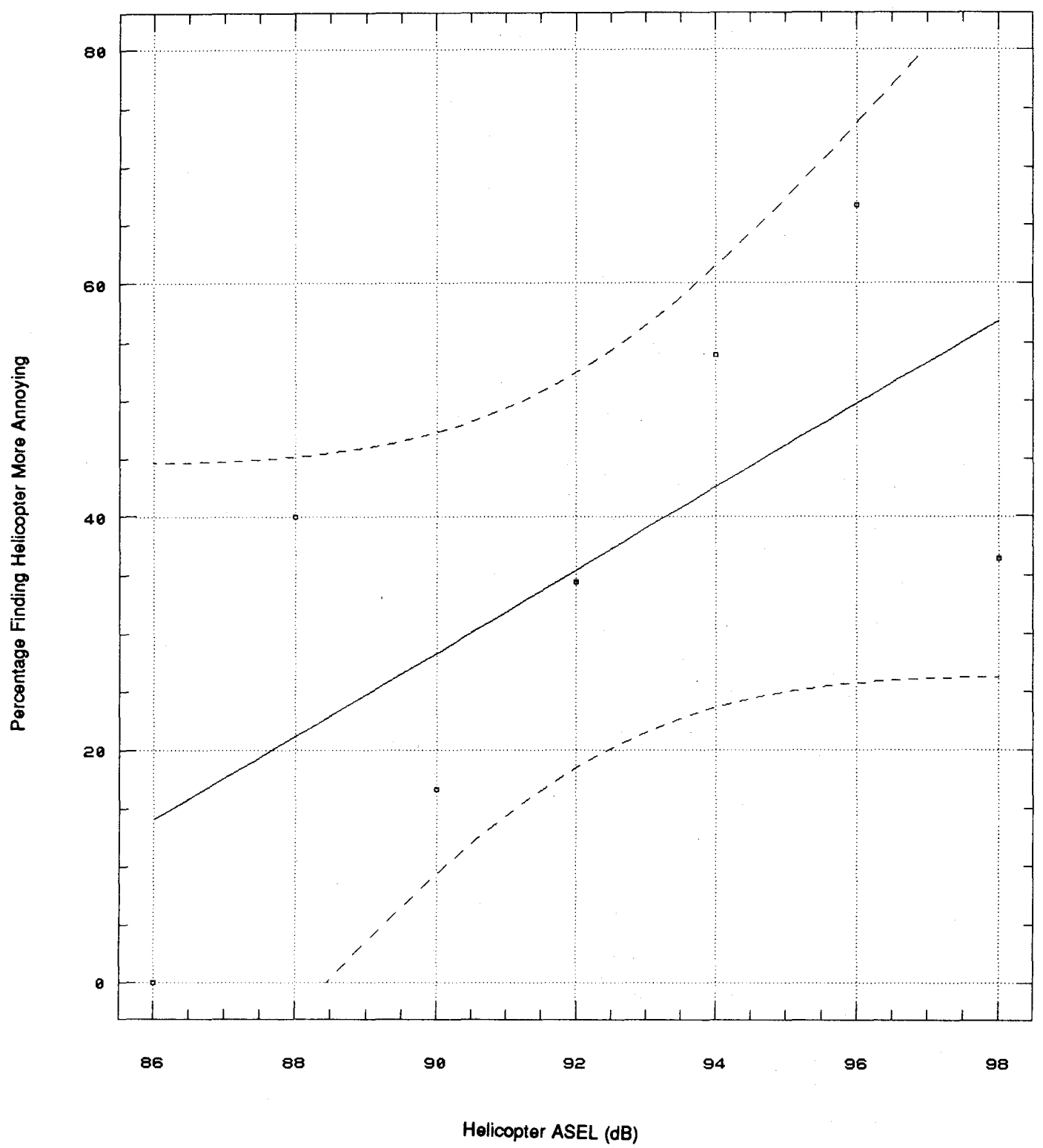

84 
Regression of OUTCH88.ANNOY on OUTCH88.SEL

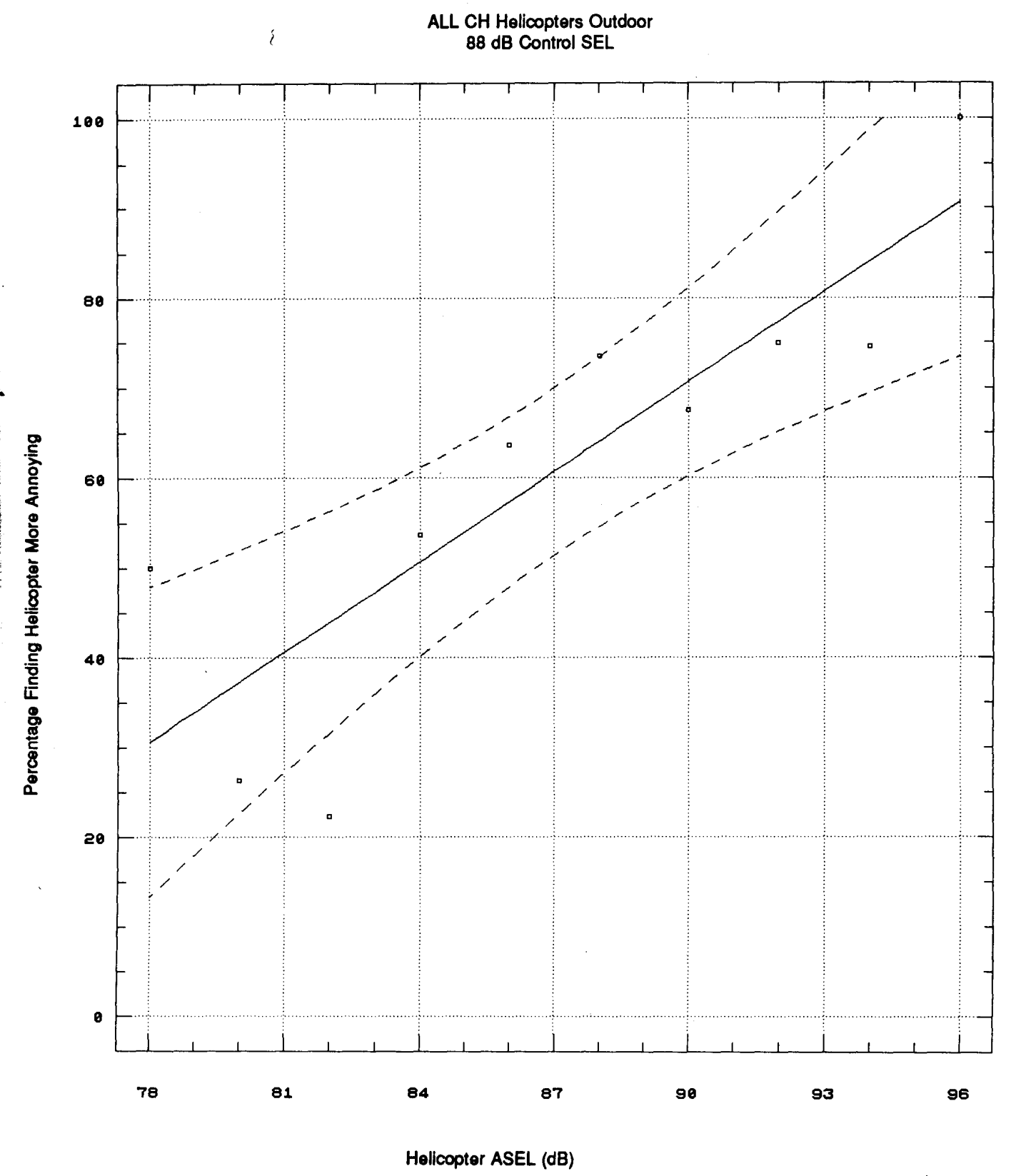


Regression of OUTCH92.ANNOY ON OUTCH92.SEL ALL CH Helicopters Outdoor $92 \mathrm{~dB}$ Control SEL

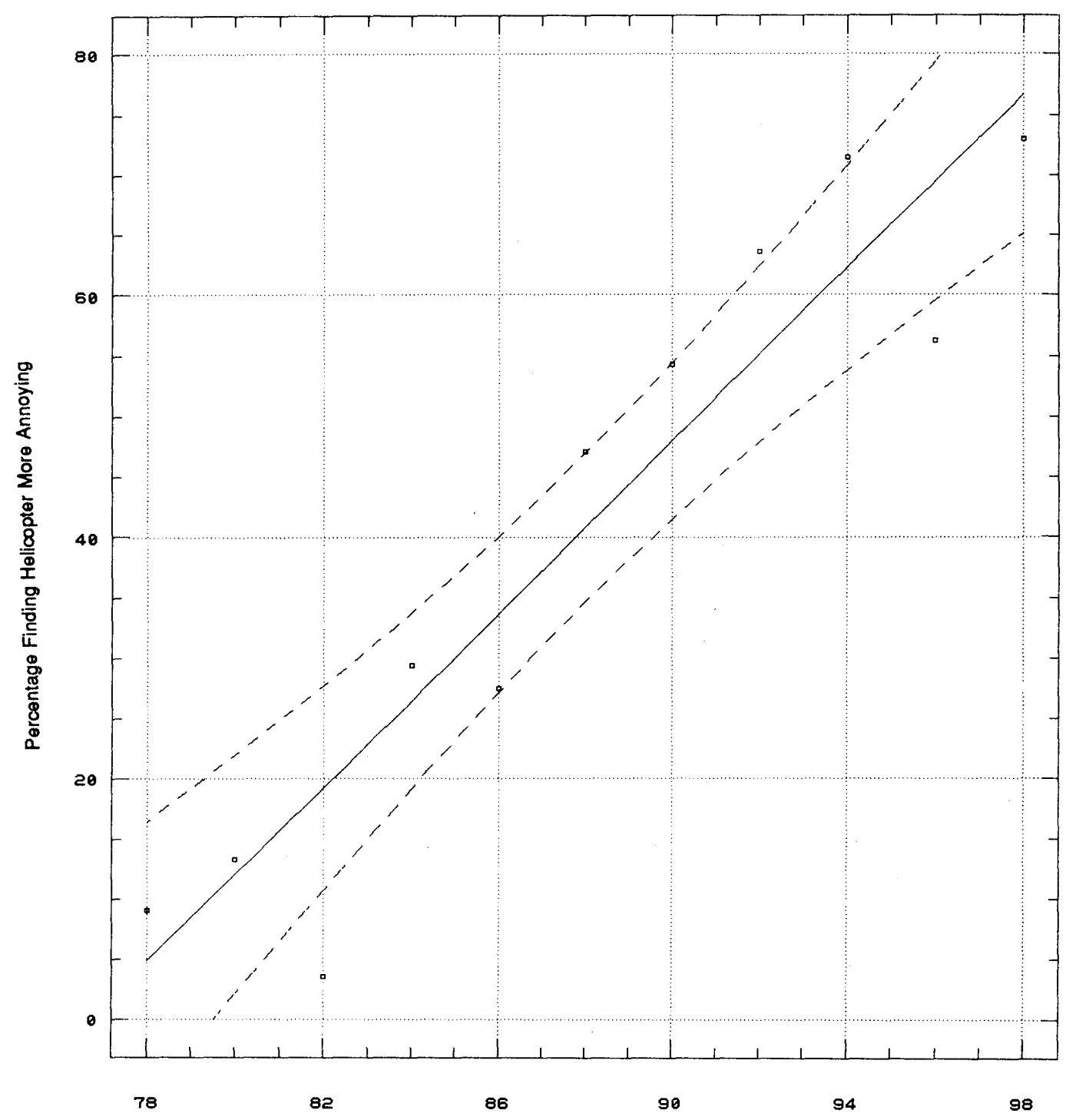

Helicopter ASEL (dB)

86 


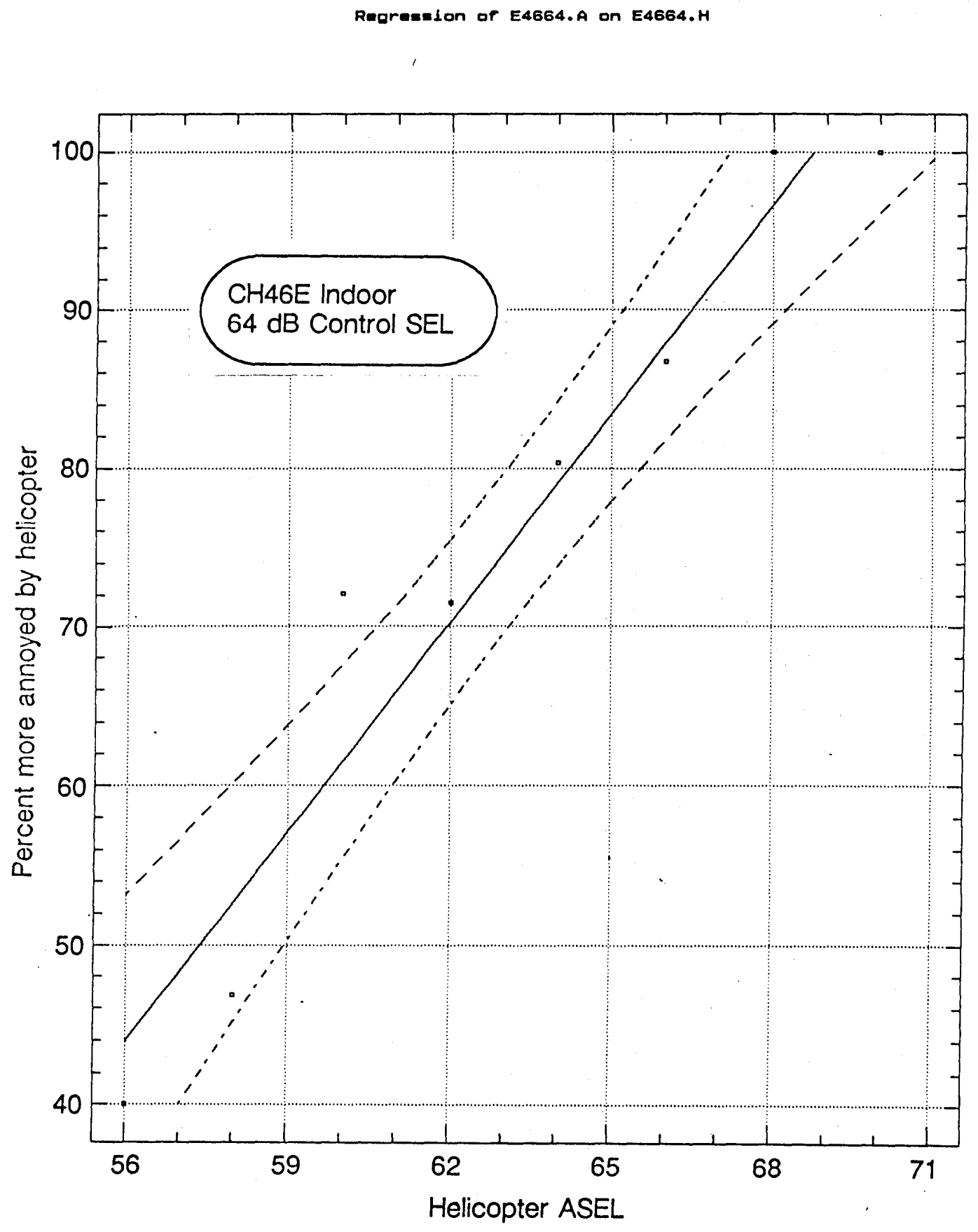

52 